\title{
EL PROCESO DE URBANIZACIÓN EN MÉXICO
}

\author{
Distribución y crecimiento de la población urbana \\ LUIS UNIKEL * \\ El Colegio de México
}

\section{INTRODUCCIÓN}

El proceso de urbanización y el acelerado crecimiento de la población total constituyen, sin duda alguna, dos de los fenómenos a escala mundial de mayor importancia en el desarrollo de la sociedad humana y del medio en que ésta se desenvuelve.

La urbanización es un proceso complejo que se manifiesta a través de dos grandes fenómenos: el primero y más patente de ellos corresponde a la creciente concentración de la población urbana, que opera a través del crecimiento de las localidades urbanas existentes y del surgimiento de nuevas localidades urbanas.2. El segundo, más difícil de definir, consite en la evolución de la forma de vida de la población, de un tipo tradicional-rural a otro moderno-urbano. ${ }^{3}$

* El autor agradece la estrecha colaboración que prestaron en la elaboración de este estudio Julio Boltvinik, Andrés Necochea, Agustín Porras, Federico Torres y Edmundo Victoria, y las sugerencias de Raúl Benítez, Gustavo Cabrera, Susana Lerner y Eliseo Mendoza, quienes revisaron el texto original.

1 El presente estudio corresponde al proyecto 1 de los 8 que forman el programa de investigación sobre el proceso de urbanización en México, que viene llevando a cabo el Centro de Estudios Económicos y Demográficos de El Colegio de México. El programa tiene por objeto conocer los factores que han intervenido en la actual distribución de la población y de las actividades socioeconómicas entre zonas urbanas y rurales, determinar los efectos más significativos del fenó meno de la urbanización en el país, así como sentar las bases para la estimación de la probable estructura urbana de México hasta 1980. En una etapa posterior, con base en los resultados obtenidos, se podrá realizar el estudio normativo del proceso de urbanización, en el cual se deriven estrategias para el desarrollo urbano del país. Para mayores detalles véase El proceso de urbanización en México: anteproyecto de investigación, Centro de Estudios Económicos y Demográficos, E1 Colegio de México, abril de 1967, mimeografiado.

Este trabajo constituye una versión aumentada de la que ha publicado el Centro Editor de América Latina, de Buenos Aires, en el libro La urbanización como campo de investigación en ciencias sociales. Contiene información adicional y un análisis regional más amplio, principalmente en la parte III. El ajuste de algunos cálculos y las modificaciones introducidas aumentan la claridad del estudio y la exactitud estadística del mismo; sin embargo, no alteran las conclusiones originales.

2 Hope T. Eldridge, "The Process of Urbanization", en Joseph Spengler y Otis Duncan (comps.), Demographic Analysis, Nueva York, The Free Press of Glencoe, 1963, pp. 338-343; Jaime Dorselaer y Afonso Gregory, La urbanización en América Latina, Tomo I, Bogotá, Feres, p. 11; P. Hatt y H. Reiss, en Cities and Society, P. Hatt y A. Reiss (comps.), Nueva York, Free Press of Glencoe, 1957, p. 79; y otros autores.

3 J. Dorselaer y A. Gregory, op. cit., p. 12; Philip Hauser, "Urbanization: An 
Los aspectos del proceso de urbanización que se estudian en este trabajo corresponden a las manifestaciones del primer fenómeno mencionado, de naturaleza exclusivamente demográfico-espacial. ${ }^{4}$ De acuerdo con lo anterior, el trabajo tiene por objeto describir el proceso de urbanización en México en el período 1940-1960 en función del nivel y la rapidez alcanzados por el fenómeno y de ciertas características de la estructura de las localidades.

El estudio se compone de tres partes: en la primera se trata de ubicar la posición de México en el contexto del proceso mundial de urbanización, en lo que respecta al nivel y ritmo de urbanización, y se pretende identificar la estructura de las ciudades de México, según su tamaño, y compararla con la de países que se consideran representativos de sistemas "tipo". ${ }^{5}$ En la segunda parte, se estudian con mayor detalle los tres aspectos mencionados del "proceso" en México: nivel y ritmo, así como la estructura de localidades. Finalmente, en la tercera parte, se analizan estas manifestaciones del proceso de urbanización a escala nacional.

\section{MÉxico EN El CONTEXTo DEL PROCESO MUNDIAL DE URBANIZACión}

Como puede observarse en el cuadro $1{ }^{6}$ México tenía en 1940 un nivel de urbanización semejante al mundial, y en 1960 superaba amplia-

Overview", en P. Hauser y L. Schnore (comps.), The Study of Urbanization, Nueva York, John Wiley \& Sons, 1965, pp. 8-9.

4 La definición demográfico-ecológica es limitada, pues no cabe duda que el fenómeno no consiste, exclusivamente, en un proceso de concentración de población en determinados puntos geográficos. Sin embargo, en vista de la innegable interdependencia que tiene la urbanización con otros procesos de cambio, como la modernización, la secularización y el desarrollo económico - todos los cuales, según Germani, tienden a ser considerados como procesos globales y por lo tanto de difícil definición y medición-, se ha considerado que la única formulación concreta del fenómeno susceptible de ser traducida operacionalmente es la de índole demográfico-ecológica. Asimismo, ésta permite analizar con mayor claridad la asociación del proceso de urbanización con los otros procesos mencionados.

El tomar en cuenta la limitación del enfoque demográfico hizo necesario definir lo urbano con base en un análisis de la variable población y su relación con otras variables de índole social y económica (véase Luis Unikel, "Ensayo sobre una nueva clasificación de población rural y urbana en México", DEMOGRAF́́A y Economfa, Vol. II, Núm. 4, México, 1968). Finalmente, es importante señalar que esta descripción de naturaleza demográfico-espacial, si bien se considera fundamental, constituye un punto de partida que será complementado con el análisis de variables no demográficas en los subsiguientes proyectos del programa de investigación. Para mayores detalles sobre lo primeramente expresado, véase Gino Germani, "Urbanización, secularización y desarrollo económico", Revista Mexicana de Sociología, Vol. XXV, Núm. 2, México, pp. 625-646 y H. T. Eldridge, "Urban Theory and Concepts in Relation to the Definition of Urban Agglomerations", Proceedings of the World Population Conference, Reunión 9, Roma, 1954, pp. 581586.

5 En general, se consideran dos sistemas "tipo" de ciudades, el preeminente y el rango-tamaño, los cuales se representan en la gráfica (p. 143). Para ilustrar el primer sistema se empleó el caso de Guatemala y para el segundo el de los Estados Unidos.

6 El cuadro 1 (p. 142) presenta el nivel y el ritmo de urbanización en 16 países en 1940 y 1960. La selección -aun cuando restringida por la disponibilidad de datos ofrece un panorama general de la urbanización de países en diversos estados de desarrollo, en diferentes regiones del mundo. 
mente dicho promedio. De los países que aparecen en el cuadro, sólo Venezuela y Perú acusaron un ritmo de urbanización superior al de México. Otro hecho que destaca es que, de manera regular, las tasas de urbanización de los países subdesarrollados son mayores que las de los países industrializados, algunos de los cuales han alcanzado niveles de urbanización tan altos que su grado de urbanización no puede aumentar sino lentamente. Tal es el caso de Inglaterra y Gales.

Según el estudio elaborado por Breese, ${ }^{7}$ se puede afirmar que el nivel de urbanización ${ }^{8}$ de México $(18.4 \%$ ) era ya en 1940 mayor que el de los países subdesarrollados en su conjunto. En dicho trabajo el autor clasifica a México en el grupo de países con nivel de urbanización "medio alto". Por otro lado, el nivel de urbanización de México fue en 1950 y 1960 , de $26.4 \%$ y $34.7 \%$ respectivamente, mientras que el promedio estimado por Breese para los países desarrollados del mundo fue en tales fechas de $38.0 \%$ y $41.0 \%$, lo cual indica que México se está acercando rápidamente al nivel de urbanización alcanzado por los países desarrollados en su conjunto. De continuar las tendencias de este período hasta 1970, es de suponer que el nivel de urbanización de México alcanzará el "nivel" promedio de los países desarrollados.

Asimismo, según elaboraciones de H. Browning, ${ }^{9}$ México y Venezuela han duplicado su población urbana en localidades de 20000 y más habitantes en la mitad del tiempo que requirieron Inglaterra y los Estados Unidos en el siglo pasado, partiendo de niveles iguales de ur. banización; y en menos de esa mitad de tiempo, por lo que se refiere a localidades de más de 100000 habitantes.

Del análisis comparativo de los cuadros 1 y 2 se corrobora claramente que los países de urbanización más rápida son aquellos que han iniciado este proceso más recientemente, ${ }^{10}$ entre los cuales México ocupa uno de los primeros lugares.

En lo que concierne a la estructura urbana, ${ }^{11}$ México puede clasificarse dentro del grupo de países con sistema de ciudad "preeminente", según el cual una o varias grandes ciudades predominan sobre las restantes, no sólo en población sino en todos o casi todos los aspectos de la vida socioeconómica, cultural y política del país.]

En la gráfica 1 se representa la estructura de las ciudades princi-

7 Gerald Breese, Urbanization in Newly Developing Countries, Nueva York, Prentice-Hall, 1966, cuadros 6 y 7.

8 Tradicionalmente, el nivel de urbanización de una unidad territorial se mide a través del "grado de urbanización". Este se define como la proporción de población urbana respecto a la total. Comúnmente, para efectos de comparación internacional, se considera urbana la población en localidades de 20000 y más habitantes, como en el caso citado. En el análisis interno de México, partes II y III de este trabajo, se aplica como límite urbano-no urbano el de 15000 habitantes. Esta división es resultado de un estudio específico sobre el tema. Véase L. Unikel, loc. cit.

9 Harley Browning, Urbanization in Mexico, tesis doctoral inédita, Universidad de California, Berkeley, 1962. Este trabajo es uno de los pocos realizados sobre el tema y sin duda uno de los más destacados.

10 Kingsley Davis e Hilda Hertz Golden, "Urbanization and the Development of Pre-Industrial Areas", en Hatt y Reiss, op. cit., p. 126.

11 Se entiende por estructura urbana la jerarquía que manifiestan las localidades urbanas de un país según su tamaño de población. 


\section{Cuadro 1}

MÉxico Y otros países: Posición RELATIVA DEL NIVEL Y EL RITMO DE LA URBaNización, 1940-1960

\begin{tabular}{|c|c|c|c|c|c|c|c|c|}
\hline \multicolumn{6}{|c|}{ Paises en orden decreciente del grado de urbanización } & \multicolumn{3}{|c|}{$\begin{array}{c}\text { Paises en orden decreciente de la tasa } \\
\text { de urbanización }\end{array}$} \\
\hline \multicolumn{3}{|c|}{1940} & \multicolumn{3}{|c|}{1960} & \multicolumn{3}{|c|}{$1940-1960$} \\
\hline$\overline{R a n g o}$ & Paises & "Grado" & Rango & Paises & “Grado" & Rango & Países & Tasa * \\
\hline 1 & Inglaterra y Gales & $67.9 a$ & 1 & Inglaterra y Gales & 70.4 & 1 & Venezuela & 4.46 \\
\hline 2 & Estados Unidos & $42.5^{b}$ & 2 & Chile & 54.7 & 2 & Perú & 3.41 \\
\hline 3 & Chile & 36.4 & 3 & Venezuela & 47.2 & 3 & México & 3.07 \\
\hline 4 & España & 35.9 & 4 & Estados Unidos & 46.9 & 4 & Brasil & 2.95 \\
\hline 5 & Hungría & 35.4 & 5 & España & 45.4 & 5 & India & 2.48 \\
\hline 6 & Canadá & 34.2 & 6 & Canadá & 39.4 & 6 & Egipto & 2.36 \\
\hline 7 & U.R.S.S. & 23.7 & 7 & Hungría & 37.5 & 7 & Turquía & 2.28 \\
\hline 8 & Egipto & 22.5 & 8 & Egipto & 36.4 & 8 & Chile & 2.01 \\
\hline 9 & Finlandia & 20.9 & 9 & México & 34.7 & 9 & Finlandia & 1.77 \\
\hline 10 & México & 18.4 & 10 & Finlandia & 29.9 & 10 & España & 1.16 \\
\hline 11 & Venezuela $\mathbf{c}$ & 18.1 & 11 & Perú e & 28.9 & 11 & U.R.S.S. & 0.92 \\
\hline 12 & Brasil & 15.3 & 12 & U.R.S.S. & 28.5 & 12 & Canadá & 0.71 \\
\hline 13 & Perú & 14.2 & 13 & Brasil & 28.1 & 13 & Estados Unidos & 0.49 \\
\hline 14 & Turquía & 13.7 & 14 & Turquía & 21.8 & 14 & Hungría & 0.28 \\
\hline \multirow[t]{2}{*}{15} & Indiad & 8.2 & 15 & India & 13.6 & 15 & Inglaterra y Gales & 0.18 \\
\hline & Promedio mundial & $18.2^{1}$ & & Promedio mundial & 24.0 & & Promedio mundial & 1.37 \\
\hline
\end{tabular}

Fuentes: John Durand y César Peláez, "Características de la urbanización en América Latina", en Clyde Kyser (comp.), Componentes de tos cambios demográficos en América Latina. Nueva York, Fundación Milbank Memorial, Vol. 43, 4, Parte II, 1965; Naciones Unidas, La urbanización y los cambios económicos y sociales, Seminario sobre urbanización celebrado en la Universidad de Pittsburgh, 1966; Naciones Unidas, Demographic Yearbook, 1960, 1962 y 1963; y Breese, op. cit., cuadros 2,6 y 7.

a Interpolación lineal de los datos de 1931 y 1951.

b Cálculo aproximado basado en el estudio de Durand y Peláez, op. cit.

c 1941. d Incluye a Paquistán. e 1961.

f Ante la falta de datos se hizo este cálculo suponiendo que el porcentaje de población urbana creció al mismo ritmo entre 1940 y 1950 que entre 1950 y 1960 . Véase Breese, op. cit.

* La tasa de urbanización es igual al incremento medio anual del grado de urbanización. Su expresión numérica es la siguiente: $2\left(G_{1}-G_{0}\right) /\left(G_{1}+G_{0}\right) \cdot 1 / n$. $k$; en que $G_{1}$ y $G_{0}$, son las proporciones respecto a la población total, de la población que habita en localidades de 20000 y más habitantes; $n$ es el número de años; $k$ es igual a 100 . 
UNIKEL: URBANIZACION EN MÉXICO

Cuadro 2

MÉxico y oTros países: RAPIDEZ DEL PROCESO DE URBANIZACIÓN

\begin{tabular}{|c|c|c|c|c|c|c|}
\hline \multirow[t]{2}{*}{ Paises } & \multicolumn{3}{|c|}{$\begin{array}{l}\text { Localidades de } 20000 \\
y \text { más habitantes }\end{array}$} & \multicolumn{3}{|c|}{$\begin{array}{l}\text { Localidades de } 100000 \\
\text { y más habitantes }\end{array}$} \\
\hline & $A \tilde{n} o$ & $A$ & $B$ & Año & $A$ & $B$ \\
\hline Inglaterra y Gales & 1802 & 17 & 46 & 1802 & 10 & 42 \\
\hline Estados Unidos & 1873 & 16 & 38 & 1866 & 10 & 36 \\
\hline Japón & 1898 & 16 & 24 & 1907 & 10 & 26 \\
\hline Argentina & 1874 & 16 & 37 & 1875 & 10 & 22 \\
\hline México & 1933 & 16 & 26 & 1936 & 10 & 16 \\
\hline Venezuela & 1934 & 16 & 19 & 1931 & 10 & 14 \\
\hline
\end{tabular}

Fuente: Browning, op. cit., cuadro II-5, p. 40.

A: $\%$ de la población total.

B: Años necesarios para duplicar A.

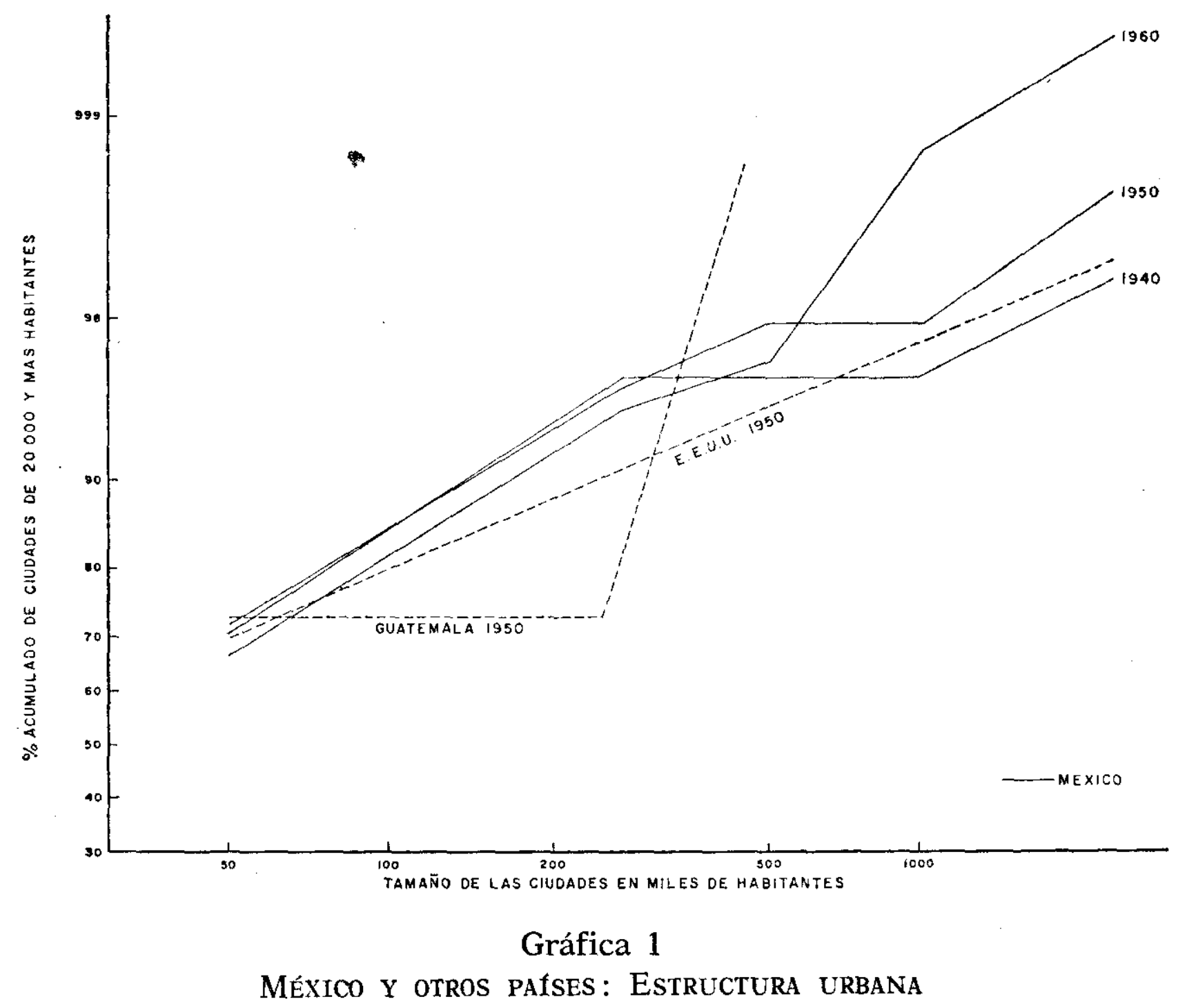

Fuente: Las distribuciones de ciudades de los Estados Unidos y Guatemala se obtuvieron de Brian Berry, op. cit., pp. 140 y 142; las correspondientes a México se graficaron con base en datos calculados en este estudio. 
pales de México y su evolución de 1940 a 1960,12 así como la estructura urbana correspondiente a dos países que se consideraron en un momento dado (1950) representativos de los dos sistemas de ciudades prototipo: Estados Unidos respecto al sistema conocido por "rangotamaño" (rank-size rule) ${ }^{13}$ y Guatemala con relación al sistema preeminente (primate city).

El sistema de ciudades de México puede estudiarse también a través del "índice de primacía" 14 (cuadro 3) según el cual México ocupaba en 1950 una posición media en América Latina y un poco superior a la del promedio mundial.

\section{Cuadro 3}

MÉXICO Y OTROS PAfSES Y REGTONES : INDICE DE PRIMACf́a DE 4 CIUDADES, 1950 a

\begin{tabular}{lcllll}
\hline \multicolumn{1}{c}{ Regiones } & Indice & $\begin{array}{l}\text { Paises de } \\
\text { América } \\
\text { Latina }\end{array}$ & Indice & $\begin{array}{l}\text { Otros } \\
\text { paises }\end{array}$ & Indice \\
\hline Mundial & 2.01 & Uruguay & 5.67 & Francia & 3.25 \\
América Latina & 2.94 & Guatemala & 5.27 & Dinamarca & 3.21 \\
Norteamérica y & & Perú & 4.60 & Reino Unido & 1.48 \\
Oceanía & 0.75 & Argentina & 3.88 & U.R.S.S. & 1.28 \\
Europa, incluida & 1.84 & México & 2.87 & Japón & 1.16 \\
la U.R.S.S. & 1.84 . & Vhile & 2.38 & E.U.A. & 0.95 \\
Asia Menor y Afri- & & Venezuela & 1.64 & India & 0.76 \\
$\quad$ ca del Norte & 1.50 & Brasil & 0.85 & Canadá & 0.60 \\
Africa Central y & & & & & \\
$\quad$ Sudáfrica & 1.26 & & & & \\
Asia, sin incluir & & & & & \\
$\quad$ Asia Menor & 2.35 & & & & \\
\hline
\end{tabular}

Fuente: Kingsley Davis, "Las causas y efectos del fenómeno de primacía urbana con referencia especial a América Latina", en Instituto de Investigaciones Sociales, Estudios sociológicos del Congreso de Sociología del Desarrollo, Vol. I, México, UNAM, 1962, cuadro 3, p. 376.

a $I_{p}(4)=\frac{P_{1}}{P_{2}+P_{3}+P_{4}}$ en que $P_{1}, P_{2}, P_{3}$ y $P_{4}$ son las poblaciones de las ciudades que en esa fecha ocupaban los rangos 1, 2, 3 y 4 .

12 Se considera que la representación de la estructura urbana en papel lognormal expresa con mayor claridad los casos prototipo "rango tamaño" y "preeminente" que las gráficas en papel semilogarítmico o logarítmico. Para mayo res detalles véase Brian Berry, "City Size Distributions and Economic Development", en John Friedmann y William Alonso (comps.), Regional Development and Planning, Cambridge, Mass., MIT Press, 1965, pp. 138-152.

13 Según este sistema, las ciudades se ordenan según una distribución en que la población de la ciudad mayor es el doble que la segunda, el triple que la tercera y tiene una población $n$ veces mayor que la ciudad de rango $n$. Para mayores detalles véase Charles Stewart, Jr. "The Size and Spacing of Cities", en H. Mayer and C. Kohn (comps.), Readings in Urban Geography, University of Chicago Press, 1960 , pp. $240-256$.

14 El índice de primacía expresa el grado en que la ciudad principal predomina en población sobre las $n$ siguientes. Su expresión numérica es: 
De acuerdo con la gráfica y con el comportamiento del índice de primacía, México tiene una estructura urbana básicamente preeminente pero que tiende hacia un tipo intermedio. ${ }^{15}$

En el contexto de la urbanización mundial, México tiene un nivel bastante elevado que se acerca con rapidez al de los países altamente urbanizados en virtud de haber experimentado un proceso muy rápido, superado apenas por contados países. Todo esto ha venido acompañado de cambios en la estructura de sus ciudades que se manifiestan a través de una disminución en el índice de primacía del sistema y que son indicativos de la formación de centros urbanos de importancia regional.

Con base en lo anterior, puede adelantarse la hipótesis de que la estructura urbana del país está "madurando" —según términos de Friedmann-, o sea que están surgiendo centros urbanos que pueden satisfacer regionalmente las necesidades de su creciente población y de importantes zonas periféricas, mejorar su situación socioeconómica, cultural y política y manifestar economías externas y de escala. Esto les permite competir con la ciudad preeminente en cuanto a población y actividades económicas. ${ }^{16}$

\section{El proceso de urbanizactón en MÉxico a escala nacional}

\section{Nivel y ritmo de la urbanización}

LPara expresar el nivel de urbanización alcanzado por un país o región se utiliza generalmente el grado de urbanización. Sin embargo, si se parte de la premisa de que una ciudad es tanto más urbana cuanto mayor sea su población, ${ }^{17}$ se considera que el "grado" no es suficientemente representativo del nivel de urbanización, debido a que no distingue las distintas estructuras urbanas que puede contener implícitamente. De acuerdo con este razonamiento, de dos regiones que tengan igual proporción de población urbana, será más urbanizada aquella cuya población urbana resida en ciudades de mayor tamaño. Así, el nivel de urbanización del país se midió mediante una expresión numérica que se denominó índice de urbanización.18

$I_{p}(\mathrm{n})=\frac{P_{1}}{P_{2}+P_{3}+P_{4}+\ldots+P_{n}}$ en que $I_{p}(\mathrm{n})$ es el índice de primacía de $n$ ciudades, y $P_{1}, P_{2}, P_{3}, P_{4} \ldots P_{n}$ son poblaciones de las ciudades correspondientes a los rangos $1,2,3, \ldots n$.

15 Berry, op. cit., p. 143. Este autor distingue tres tipos de estructura urbana: preeminente, intermedia y rango-tamaño.

16 La literatura sobre la interpretación económica de la primacía urbana es muy amplia. En esta ocasión se considera indicado citar a: J. Friedmann, "The Concept of a Planning Region", Land Economics, Vol. XXXII, No. 1, Feb. de 1956; Berry, op. cit., G. Neutze, Economic Policy and the Size of Cities, Canberra, The Australian National University, 1965; y Browning, op. cit., capítulo VI.

17 Davis y Golden, op. cit., p. 121.

18 La expresión numérica del índice de urbanización es la siguiente:

$$
\begin{aligned}
& I_{u}=\frac{1}{4}\left(\frac{U_{1}}{P}+\frac{U_{2}}{P}+\frac{U_{3}}{P}+\frac{U_{4}}{P}\right)=G\left(0.25 p_{1}+0.50 p_{2}+0.75 p_{3}+p_{4}\right) \\
&=(G) \cdot(\text { factor } E) . \\
&\text { (sigue la nota en la } p .146)
\end{aligned}
$$


El nivel de urbanización de México en el período 1940-1960 casi se duplicó, como puede observarse en el cuadro 4.

La urbanización rápida del país en el período estudiado -medida a través de los cambios en el "nivel" - se debió principalmente al im-

Cuadro 4

MÉxico: Nivel DE URBanización, 1940-1960

\begin{tabular}{|c|c|c|c|}
\hline Indicadores a & 1940 & 1950 & 1960 \\
\hline Indice de urbanización $(\%)$ & 16.16 & 23.59 & 31.69 \\
\hline Grado de urbanización $(\%)$ & 19.99 & 27.92 & 36.50 \\
\hline Factor $E$ & 0.81 & 0.84 & 0.87 \\
\hline
\end{tabular}

a Para mayores detalles véase la nota 18 .

\section{Cuadro 5}

México: Población y participación EN EL grado de URbanización, DE LAS 17 CIUDADES MAYORES DEL PAfS, 1940-1960

\begin{tabular}{cccc}
\hline $\begin{array}{c}\text { Población } y \text { participación } \\
\text { porcentual en el "grado" }\end{array}$ & 1940 & 1950 & 1960 \\
\hline $\begin{array}{l}\text { Población urbana a (habitantes) } \\
\text { Población de las 17 áreas urbanas } \\
\text { de } 100 \text { 000 y más habitantes en } \\
\quad 1960 \text { b (habitantes) }\end{array}$ & 3927694 & 7209528 & 12746685 \\
$\begin{array}{l}\text { Población del área urbana de la } \\
\text { ciudad de México b (habitan- }\end{array}$ & 3005214 & 5256804 & 8968591 \\
$\begin{array}{l}\text { tes) } \\
\text { Participación en el "grado", de } \\
\text { las 17 áreas urbanas c }\end{array}$ & 1559782 & 2872334 & 4909961 \\
$\begin{array}{l}\text { Participación en el "grado", del } \\
\text { área urbana de la ciudad de } \\
\text { México c }\end{array}$ & $76.51 \%$ & $72.91 \%$ & $70.36 \%$ \\
\hline
\end{tabular}

a Véase el cuadro 13.

b Censos generales de población y cálculos realizados para la delimitación de las áreas urbanas de las principales ciudades del país. Para mayores detalles véase la nota 20 de este trabajo.

c La participación en el "grado" equivale a la relación porcentual entre la población urbana correspondiente y la total del país.

En que $U_{1}, U_{2}, U_{3}, U_{4}$ son la población en lacalidades de 15000 y más, 20000 y más, 50000 y más, y 100000 y más habitantes, respectivamente. $P$ es la población total del país o de la unidad territorial estudiada; $G$ es el grado de urbanización $\left(U_{1} / P\right) ; p_{1}, p_{2}, p_{3}$ y $p_{4}$, son las participaciones respecto a la población urbana, de la población de los intervalos de 15-20000, 20-50000, 50-100000 y 100000 y más habitantes, respectivamente. Estas participaciones ponderadas, como se indica en la expresión, constituyen lo que se ha denominado factor $E$, que es un indicador de la estructura urbana. Se hace constar que el número de intervalos que forman el índice es arbitrario; sin embargo, se consideró este número más conveniente para el análisis que 2 y 6 intervalos ensayados previamente. Asimismo es importante señalar que con la aplicación del "índice" sólo se pretende cuan. tificar los diferentes niveles de urbanización de una o varias unidades territoriales en los años estudiados. 
portante incremento experimentado por el "grado".19 Al mismo tiempo debe destacarse que durante el decenio 1950-1960 ambos indicadores del "nivel" aumentaron con rapidez decreciente, lo que puede señalar el inicio de un cambio importante en la tendencia futura del proceso de urbanización en México, supuesto que se refuerza con los resultados obtenidos posteriormente en este trabajo.

El nivel de urbanización alcanzado por el país en ambos decenios se explica, como se observa en el cuadro 5, por la elevada participación en el "grado" de las grandes ciudades del país - las 17 áreas urbanas de 100000 y más habitantes en 1960- y muy especialmente el área urbana de la ciudad de México.20

La desaceleración ocurrida en el nivel de urbanización durante 1950-1960 se explica también en gran parte por el crecimiento más lento de estas ciudades y en particular de la ciudad de México. Sin embargo, esta última mantuvo su predominio nacional.]

A efecto de conocer más a fondo los factores que influyen en el nivel de urbanización, se analizan a continuación el "grado" y el factor $E$; el primero de éstos se estudia a través del crecimiento de la población total y por clases de localidades, ${ }^{\not 1}$ y el segundo como una parte del análisis de la estructura urbana.

Crecimiento de la población total y por clases de localidades. EI ritmo de crecimiento de la población total del país ha venido eleván-

19 El cambio en el "grado" explicó el $86 \%$ y el $90 \%$ de la variación del índice de urbanización en el primer y segundo decenios, respectivamente. Por otro lado, el peso del factor $E$ se redujo del $10 \%$ al $8 \%$ y el peso combinado de ambos disminuyó también del $4 \%$ al $2 \%$. Estas cifras se calcularon mediante la expresión siguiente: $I=G \cdot \Delta E+E \cdot \Delta G+\Delta E \cdot \Delta G$. Véase la definición de los términos en la nota 18. El escaso dinamismo del factor $E$ se debe, entre otras cosas, a que las ciudades mayores de 100000 habitantes han venido perdiendo importancia relativa con respecto a centros urbanos de menor tamaño.

20 Mucho puede decirse sobre las definiciones, aplicaciones y métodos para delimitar áreas urbanas (véanse diversos estudios de J. Gibbs, M. Maçura, G. Goudswaard, O. Boustedt, así como del General Registry Office, y del U. S. Bureau of the Census, en Jack Gibbs, comp., Urban Research Methods, New Jersey, Van Nostrand, 1961, pp. 14-73); sin embargo, la carencia en México de datos a nivel de localidad sobre ocupación, densidad de población y edificación, y en general de características de índole urbana, dificulta en extremo utilizar métodos relativamente complejos para el efecto. Considerándose necesario contar con la población, aún aproximada, de las principales áreas urbanas del país, se decidió - de acuerdo con la información disponible, o sea estadísticas censales así como material cartográfico y aerofotogramétrico- aplicar como criterio básico para determinar las localidades que integran, junto con la ciudad central, las áreas urbanas, el criterio de contiguiidad y de accesibilidad. Estos dos criterios llevan implícitos la dependencia ocupacional de la población periférica respecto a la ciudad central, así como el movimiento continuo $\rightarrow$ la mayor posibilidad de que se realice- de personas y bienes hacia y desde la ciudad central. Este procedimiento ha sido recomendado por Naciones Unidas, Data on Urban and Rurat Population in Recent Censuses, Population Studies, Núm. 8, Nueva York, 1950, p. $4, y$ por Juan Elizaga, Distribución espacial de las poblaciones (Apuntes resumidos mimeografiados del curso dictado por el autor), Santiago, Chile, CELADE, 1961, p. 11 La mayor disponibilidad de información permitió obtener la población de áreas urbanas en forma más detallada y confiable para 1960, particularmente en el caso de la ciudad de México.

21 Para la elaboración de este estudio, las localidades se han dividido en cuatro clases: rurales (menores de 5000 habitantes), mixtas rurales (de 5000 a 10000 
dose en forma constante, de $2.7 \%$ anual en $1940-1950$ a $3.1 \%$ en 1950 1960 y, según estimaciones recientes, al $3.5 \%$ durante el período 1962-1967.22 Sin embargo, las localidades urbanas, mixtas y rurales, que forman el total de la población, registraron tasas de crecimiento muy distintas (cuadro 6); destaca lo elevado de las urbanas, que fueron más del triple de las rurales.

Las tasas de crecimiento anual mencionadas provocaron un aumento en la participación de la población urbana respecto a la total del $20.0 \%$ al $36.5 \%$ entre 1940 y 1960 -que no es sino el incremento

\section{Cuadro 6}

México: INCREMENTO abSOLUTO Y RELATIVO DE LA POBLACIÓN TOTAL URBANA Y NO URBANA, $1940-1960$

\begin{tabular}{|c|c|c|c|c|}
\hline \multirow{2}{*}{$\begin{array}{l}\text { Incremento de } \\
\text { la poblaoion }\end{array}$} & \multicolumn{2}{|c|}{$1940-1950$} & \multicolumn{2}{|c|}{$1950-1960$} \\
\hline & Absoluto & $\begin{array}{c}\text { Inoremento } \\
\text { medio anual. } \\
\text { \& } a /\end{array}$ & Absoluto & $\begin{array}{c}\text { Inoremento } \\
\text { medio anual } \\
\text { \& a }\end{array}$ \\
\hline Total & $\begin{array}{lll}6 & 130 & 092\end{array}$ & 2.70 & 9143875 & 3.01 \\
\hline $\begin{array}{l}\text { Urbana } b / \\
\text { Mixta } \\
\text { Rural }\end{array}$ & $\begin{array}{lll}3 & 281 & 834 \\
& 521 & 444 \\
2 & 326 & 814\end{array}$ & $\begin{array}{l}5.89 \\
2.97 \\
1.51\end{array}$ & $\begin{array}{lll}5 & 537 & 157 \\
743 & 201 \\
2 & 863 & 517\end{array}$ & $\begin{array}{l}5.54 \\
3.12 \\
1.59\end{array}$ \\
\hline Urbans b & 3281834 & 5.89 & 5537157 & 5.54 \\
\hline $\begin{array}{l}\text { Al inioio del } \\
\text { decenio } \\
\text { LocalidadeB } \\
\text { reclasificadas }\end{array}$ & $\begin{array}{r}2654016 \\
627818\end{array}$ & $\begin{array}{l}5.05 \\
6.13\end{array}$ & $\begin{array}{r}4773374 \\
763783\end{array}$ & $\begin{array}{l}4.97 \\
5.01\end{array}$ \\
\hline Urbana & 2997419 & 4.90 & 4883146 & 4.78 \\
\hline $\begin{array}{l}\text { Natural } \\
\text { Social }\end{array}$ & $\begin{array}{lll}1 & 262 & 649 \\
1 & 724 & 770\end{array}$ & $\begin{array}{l}2.06 \\
2.84\end{array}$ & $\begin{array}{lll}3 & 122 & 203 \\
1 & 760 & 943\end{array}$ & $\begin{array}{l}3.06 \\
1.72\end{array}$ \\
\hline
\end{tabular}

a El incremento medio anual se calculó mediante la expresión:

$$
2\left(P_{1}-P_{0}\right) /\left(P_{1}+P_{0}\right) \cdot \frac{1}{n} \cdot 100
$$

$P_{1}$ y $P_{0}$ son la población al final y al principio del periodo, respectivamente, $\mathrm{y} n$ el número de años.

b Incremento bruto de la población urbana, que se obtiene por diferencia entre la población urbana al final y al principio del período (las cifras proceden del cuadro 13).

c Incremento de población 1940-1950 y 1950-1960, de las localidades urbanas en 1960. En cuanto a las ciudades con "áreas urbanas", se consideró la población de 1940 y 1950 de todas las localidades que integraban tales "áreas urbanas" en 1950; para el siguiente decenio, se consideró la población de 1950 de todas las localidades que integraban las "áreas urbanas" en 1960.

habitantes), mixtas urbanas (de 10000 a 15000 habitantes) y urbanas de (15000 y más habitantes). Véase Unikel, loc. cit.

${ }_{22}$ Secretaría de Industria y Comercio, Dirección General de Estadística, Cátculos de la población de los Estados Unidos Mexicanos, at 30 de jumio de cada año, México, 1965. 
en el grado de urbanización a que se hizo referencia previamentey un descenso en la participación de la población rural de $72.4 \%$ a $55.6 \%$. El grupo de localidades mixtas, a pesar de observar un comportamiento errático durante el período 1940-1960, mantiene su participación (véase el cuadro 13) con respecto a la población total. La tasa de crecimiento de las localidades urbanas sufrió un descenso entre los decenios 1940-1950 y 1950-1960 mientras que se elevó en las localidades no urbanas.

Para profundizar e⿳亠丷厂 la dinámica de los cambios en el nivel de la urbanización, se estudia a continuación el crecimiento total de la población urbana en las tres formas siguientes: en primer lugar, a través del crecimiento de las localidades urbanas ya existentes, así como de la reclasificación de localidades del grupo no urbano al urbano. En segundo lugar, desde el punto de vista del crecimiento de la población por expansión física de las ciudades. Por último, en función de su crecimiento natural y social.

Crecimiento de la población urbana; ciudades existentes y reclasificadas. El crecimiento de la población urbana se compone del aumento en el número de habitantes de las ciudades existentes al inicio del período de estudio (1940), y de aquellas localidades que, no siendo urbanas en 1940, pasaron a serlo entre 1940 × 1960, tomando el nombre de localidades reclasificadas en urbanas. En el caso de México, el crecimiento de la población urbana, tal como se muestra en el cuadro 6, se debió básicamente al incremento demográfico experimentado por las ciudades existentes en 1940: 80.8\% en el primer decenio y $86.2 \%$ en el segundo. Sin embargo, no deja de ser significativo que el $19.2 \%$ y el $13.8 \%$ del incremento bruto de la población urbana, en 1940-1950 y 1950-1960 respectivamente, se haya debido a la incorporación de nuevos núcleos urbanos. En el primer decenio estudiado, se reclasificaron 30 localidades no urbanas, cuyo incremento medio anual fue de $6.1 \%$. En los siguientes diez años se convirtieron en urbanos 40 centros de población, cuyo incremento medio anual fue de $5.0 \%$.

- Crecimiento de la población urbana por integración física. EI crecimiento de la población urbana por la expansión física experimentada en las ciudades ha sido un fenómeno reciente en México. Este proceso en el cual localidades cercanas a la ciudad son integradas al área urbana, se produce por la descentralización de población del centro hacia la periferia en las grandes ciudades del país y por el propio crecimiento de ciertas localidades periféricas. Los casos de la ciudad de México, Monterrey, Cuernavaca y otros ilustran claramente dicho fenómeno.

El aumento de la población urbana por efecto de la integración física de localidades no urbanas a las ciudades del país se estimó, en 1940-1950, en 214 localidades con una población total de 418074 habitantes. De 1950 a 1960, las localidades integradas fueron 249, con una población total de 457588 habitantes. ${ }^{23}$

23 La medición de este fenómeno es sumamente laboriosa y difícil de llevar a cabo con exactitud debido a la escasez de información adecuada en las fechas 
La participación de dicho incremento demográfico en el crecimiento total de la población urbana representó el $12.7 \%$ durante el decenio $1940-1950$ y el $8.3 \%$ en el período siguiente. Solamente el área urbana de la ciudad de México aportó el $10.2 \%$ y el $5.2 \%$ respectivamente de tal crecimiento; el pequeño-porcentaje restante correspondió a otras áreas urbanas tales como Guadalajara, Monterrey y Puebla. Sin embargo, es significativo notar que este proceso se acentúa en términos relativos de 1950 a 1960 en estas últimas ciudades así como en otras de menor importancia. Es probable, por lo tanto, que este fenómeno, característico de países desarrollados y altamente urbanizados, empiece a adquirir importancia en México y aumente en magnitud a medida que se multipliquen los centros regionales.

En síntesis, el crecimiento de la población urbana por reclasificación y por integración física, considerados ambos como "nueva población urbana", constituyeron el $31.0 \%$ de 1940 a 1950 y el $22.1 \%$ de 1950 a 1960. En consecuencia, se ha visto que la rapidez del proceso de incorporación de nueva población urbana en México de 1940 a 1960 perdió importancia relativa dentro del crecimiento urbano, del primero al segundo decenio, lo cuial ha influido en la desaceleración de dicho crecimiento. Es probable que la reclasificación de localidades no urbanas y la integración por expansión física alcancen mayores niveles absolutos en el futuro. Sin embargo, su importancia relativa en el crecimiento urbano seguirá disminuyendo, por lo que el crecimiento de las ciudades existentes será el predominante]

Crecimiento natural $y$ social de la población urbana. ${ }^{24}$ Entre 1940 y 1950 la población urbana aumentó 2987419 habitantes (cuadro 6), de los cuales el $57.7 \%$ fue crecimiento social. En el decenio siguiente el incremento de la población urbana alcanzó la cifra de 4883146 habitantes (cuadro 6); es decir, aumentó $63.4 \%$ respecto al decenio anterior; sin embargo, sólo el $36.1 \%$ fue debido a migración. Este pronunciado cambio en la importancia de los componentes del crecimiento -el natural y el social- de un decenio al otro, se

censales. Se considera que las cifras obtenidas constituyen una aproximación aceptable a la población urbana real. De los 418074 habitantes anexados en 1940-1950, 29371 corresponden a 4 localidades que se reclasificaron en urbanas; el resto se incorporó a ciudades existentes. De 1950 a 1960 toda la integración se realizó en ciudades existentes.

24 Esta población corresponde a las localidades urbanas en 1960, excepto las dos de Oaxaca para las cuales no hubo datos disponibles. En el cálculo de los crecimientos natural y social se partió de las estadísticas vitales de los municipios con localidades urbanas en 1960. Para obtener el crecimiento natural al nivel de localidad se supuso que ésta participaba del crecimiento natural del municipio en la misma proporción en que participaba de la población total de dicho municipio. El crecimiento social se calculó por el método de las estadísticas vitales, a partir de la ecuación compensadora $P_{1}=P_{o}+(B-D)+(I-E)$ en donde $P_{1}$ y $P_{o}$ son la población en los años final e inicial del período en cada localidad, $(B-D)$ el crecimiento natural e $(I-E)$ el crecimiento social. $(I-E)$ se obtuvo por diferencia. A pesar de las limitaciones que implica el uso de este método, las pruebas realizadas con las estadísticas vitales mostraron que éstas aseguran la confiabilidad de los resultados obtenidos. Sin embargo, en contados casos, el incremento medio anual natural se considera muy por encima o por debajo de Io que es razonable esperar y por lo tanto el crecimiento social debe tomarse con las reservas del caso. 
debió tanto a la disminución de las tasas de crecimiento social en la - mayoría de las localidades urbanas (cuadros 9 y 20 , pp. 153 y 172), como al aumento considerable de las tasas de crecimiento natural.25 Estos movimientos en las tasas originaron que el crecimiento social urbano en 1950-1960 apenas fuera ligeramente superior en números absolutos al del período anterior y que el crecimiento natural de la población del conjunto de las localidades urbanas casi se triplicara (cuadros 7 y 8 ).

Es probable que este cambio se haya mantenido o acentuado de 1960 a la fecha, ya que los volúmenes de migrantes - aunque hayan aumentado en números absolutos- tendrán menor importancia relativa frente a los grandes volúmenes de crecimiento natural urbano.26

\section{Cuadro 7}

México: Crectmiento total, Natural y soctal de la poblactón uRbana Y DE LAS PRINCIPALES CIUDADES DE ATRAOCTóN, 1940-1950 a

\begin{tabular}{|c|c|c|c|c|c|c|}
\hline \multirow{2}{*}{ Ciudades b/ } & \multicolumn{2}{|c|}{ Crecimiento totel. } & \multicolumn{2}{|c|}{$\begin{array}{c}\text { Crecimiento natu } \\
\text { ral }\end{array}$} & \multicolumn{2}{|c|}{ Creoimiento social } \\
\hline & AbBoluto & 6 & Absoluto & $\%$ & Absoluto & $\$$ \\
\hline Total uxbano & $2987 \cdot 419$ & 100.00 & 1262649 & 100.00 & 1724770 & 100.00 \\
\hline $\begin{array}{l}\text { Ciudad de Mexico } \\
\text { Guadalajara, Jal. } \\
\text { Monterrey, N. L. } \\
\text { Puebla, Pue. } \\
\text { Ciudad Juarez, Chih. } \\
\text { Mexicali, B. C. } \\
\text { Tijuana, B. C. } \\
\text { Torreon, Coah. } \\
\text { San Lui Potosi, S.L.P. } \\
\text { Merida, Yuc. }\end{array}$ & $\begin{array}{rl}1228 & 610 \\
158 & 602 \\
161 & 853 \\
82 & 723 \\
73 & 685 \\
46 & 739 \\
43 & 466 \\
77 & 500 \\
51 & 790 \\
46 & 006\end{array}$ & $\begin{array}{r}41.13 \\
5.31 \\
5.42 \\
2.77 \\
2.47 \\
1.56 \\
1.45 \\
2.59 \\
1.73 \\
1.54\end{array}$ & $\begin{array}{rl}381 & 413 \\
60 & 956 \\
64 & 812 \\
16 & 278 \\
16 & 136 \\
11 & 653 \\
8 & 894 \\
46 & 393 \\
23 & 840 \\
22 & 911\end{array}$ & $\begin{array}{l}30.21 \\
4.83 \\
5.13 \\
1.29 \\
1.28 \\
0.92 \\
0.70 \\
3.67 \\
1.89 \\
1.82\end{array}$ & $\begin{array}{rl}847 & 197 \\
97 & 646 \\
97 & 041 \\
66 & 445 \\
57 & 549 \\
35 & 086 \\
34 & 572 \\
31 & 107 \\
27 & 950 \\
23 & 095\end{array}$ & $\begin{array}{r}49.12 \\
5.66 \\
5.63 \\
3.85 \\
3.34 \\
2.03 \\
2.00 \\
1.80 \\
1.63 \\
1.34\end{array}$ \\
\hline Suma & 1970974 & 65.97 & 653286 & 51.74 & 1317688 & $7 6 \longdiv { 4 0 }$ \\
\hline $\begin{array}{l}\text { Otras looalidades } \\
\text { urbanas }\end{array}$ & 1016445 & 34.03 & 609363 & 48.26 & 407.082 & 23.60 \\
\hline $\begin{array}{l}\text { Leon, Gto. } \\
\text { Veracruz, Ver. } \\
\text { Hermosilio, Son. } \\
\text { Chihuahua, Chih. }\end{array}$ & $\begin{array}{ll}48 & 571 \\
29 & 516 \\
24 & 918 \\
30 & 195\end{array}$ & $\begin{array}{l}1.63 \\
0.99 \\
0.83 \\
1.01\end{array}$ & $\begin{array}{rl}29 & 050 \\
10 & 050 \\
9 & 227 \\
15 & 965\end{array}$ & $\begin{array}{l}2.30 \\
0.80 \\
0.73 \\
1.26\end{array}$ & $\begin{array}{ll}19 & 521 \\
19 & 466 \\
15 & 691 \\
14 & 230\end{array}$ & $\begin{array}{l}1.13 \\
1.13 \\
0.91 \\
0.83\end{array}$ \\
\hline
\end{tabular}

Fuentes: Dirección General de Estadística, Oficina de Estadísticas Demográficas, y Censos generales de población.

a Se consideran localidades de atracción aquellas cuyo saldo neto migratorio es positivo. El análisis se elaboró con respecto a las 10 principales ciudades de atracción, así como a las cuatro - que aparecen al final del cuadro- que figuran entre las 10 principales en el siguiente decenio.

b Corresponde a las localidades que eran urbanas en 1960. En cuanto a las ciudades con "área urbana", se consideró la población de 1940 y 1950 de todas las localidades que integraban tales "áreas urbanas" en 1950.

25 Este aumento puede explicarse con base en la hipótesis de que las fuertes corrientes migratorias de la década 1940-1950 alteraron la composición por edades de la población urbana y por lo tanto las tasas de crecimiento natural de dicha población. Además se manifestó un descenso marcado del nivel de mortalidad en $1950-1960$.

26 El fundamento del supuesto, en lo concerniente al crecimiento natural, se basa en el aumento significativo en la tasa de crecimiento natural de la pobla- 
Cuadro 8

México: Crecimiento total, Natural Y Social de la poblactón URbana Y DE LAS PRINCIPALES CIUDADES DE ATRACCIÓN, 1950-1960 a

\begin{tabular}{|c|c|c|c|c|c|c|}
\hline \multirow[t]{2}{*}{ Ciudades b/ } & \multicolumn{2}{|c|}{ Crecimiento total } & \multicolumn{2}{|c|}{$\begin{array}{c}\text { Crecimiento netu } \\
\text { ral }\end{array}$} & \multicolumn{2}{|c|}{ Creoimiento sootal } \\
\hline & Absoluto & $\$$ & Absoluto & $-\%$ & Absoluto & $\%$ \\
\hline Total urbano & 4883146 & 100.00 & 3122203 & 100.00 & 1760943 & 100.00 \\
\hline $\begin{array}{l}\text { Cludad de Moxioo } \\
\text { Guadalejara, Jal. } \\
\text { Monterrey, N. L. } \\
\text { Ciudad Juarez, Chih. } \\
\text { Mexicali, B. C. } \\
\text { Tijuana, B. C. } \\
\text { Leon, Gto. } \\
\text { Chihuahua, Chih. } \\
\text { Veracruz, Ver. } \\
\text { Hermosillo, Son. }\end{array}$ & 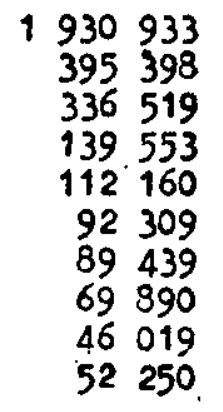 & $\begin{array}{r}39.54 \\
8.10 \\
6.89 \\
2.86 \\
2.30 \\
1.89 \\
1.83 \\
1.43 \\
0.94 \\
1.07\end{array}$ & $\begin{array}{rl}1191 & 830 \\
167 & 492 \\
164 & 226 \\
54 & 398 \\
51 & 381 \\
41 & 649 \\
52 & 117 \\
35 & 524 \\
19 & 462 \\
26 & 842\end{array}$ & $\begin{array}{l}38.18 \\
5.36 \\
5.26 \\
1.74 \\
1.65 \\
1.33 \\
1.67 \\
1.14 \\
0.62 \\
0.86\end{array}$ & $\begin{array}{ll}739 & 053 \\
227 & 906 . \\
172 & 293 \\
85 & 155 \\
60 & 779 \\
50 & 660 \\
37 & 322 \\
34 & 366 \\
26 & 557 \\
25 & 408\end{array}$ & $\begin{array}{r}41.97 \\
12.94 \\
9.78 \\
4.84 \\
3.45 \\
2.88 \\
2.12 \\
1.95 \\
1.51 \\
1.44\end{array}$ \\
\hline Suma & $326440^{\circ}$ & 66.85 & $180497^{\prime} 1$ & 57.81 & 1459499 & 82.88 \\
\hline $\begin{array}{l}\text { tras localj da } \\
\text { uxbanas }\end{array}$ & 1618676 & 33.15 & $1317 \cdot 232$ & 42.19 & 301444 & $17 \cdot 12$ \\
\hline $\begin{array}{l}\text { Puebla, Pue. } \\
\text { Torreón, Couh. } \\
\text { Kérida, Yuo. } \\
\text { San Iuis Potos1, SLP }\end{array}$ & $\begin{array}{ll}69 & 954 \\
72 & 152 \\
28 & 091 \\
36 & .208\end{array}$ & $\begin{array}{l}1.43 \\
1.48 \\
0.58 \\
0.74\end{array}$ & $\begin{array}{rl}.49 & 209 \\
79 & 246 \\
38 & 666 \\
49 & 851\end{array}$ & $\begin{array}{l}1.58 \\
2.54 \\
1.24 \\
1.60\end{array}$ & $\begin{array}{r}20.745 \\
-7094 \\
-10575 \\
-13643\end{array}$ & $\begin{array}{l}1.18 \\
-0.40 \\
-0.60 \\
-0.77\end{array}$ \\
\hline
\end{tabular}

Fuentes: Dirección General de Estadística, Oficina de Estadísticas Demográficas, y Censos generales de población.

- Ver nota a del cuadro 7 .

b Corresponde a las localidades que eran urbanas en 1960. En cuanto a las ciudades con "área urbana", se consideró la población en 1950 de todas las localidades que integraban tales "áreas urbanas" en 1960.

c Las cuatro ciudades estudiadas adicionalmente figuran entre las 10 principales de atracción del decenio anterior.

Esto hace suponer improbable que el ritmo de urbanización del país, de 1960 a 1970, alcance la tasa experimentada de 1940 a 1950; más bien se pueden plantear dos alternativas: que se mantenga la tasa 19501960 o que decrezca, siguiendo la tendencia 1940-1960.

Al analizar el comportamiento de las tasas de crecimiento natural y social según los distintos tamaños de localidades (cuadro 9), se puede observar que las primeras disminuyen a medida que aumenta el tamaño de la población, en forma más clara en 1940-1950. Asimismo destaca el aumento de las tasas de crecimiento natural de todos los grupos de localidades en el período 1950-1960.

El crecimiento social de la población urbana en ambos decenios se debió, como puede verse en los cuadros 7 y 8, a la atracción que ejercieron unas cuantas ciudades del país. En 1940-1950, diez localidades absorbieron el $76.4 \%$ de la inmigración neta urbana y en el decenio 1950-1960 también diez absorbieron el 82.9\%. Cuando menos la mitad de esas diez localidades en ambos períodos fueron impor-

ción del país de 1960 a 1967 (véase la nota 22) y a la probabilidad -según los estudios de Raúl Benítez- de que la diferencial rural-urbana en fecundidad se haya mantenido hasta la fecha. 
Cuadro 9

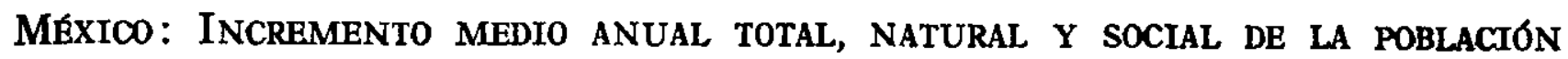
URBANA, POR TAMAÑo DE LOCALIDAD, 1940-1960a

\begin{tabular}{|c|c|c|c|c|c|c|}
\hline \multirow{2}{*}{$\begin{array}{l}\text { Tamaño de 10 } \\
\text { calidade b] }\end{array}$} & \multicolumn{3}{|c|}{$1940-1950$} & \multicolumn{3}{|c|}{$1950-1960$} \\
\hline & $\begin{array}{c}\text { Total } \\
(\phi)\end{array}$ & $\underset{(\phi)}{\text { Naturalof }}$ & $\underset{(\phi)}{\operatorname{soog})^{\prime} d}$ & $\begin{array}{c}\text { Potal } \\
(x)\end{array}$ & $\underset{(x)}{\operatorname{ratura1}}$ & $\underset{(x)^{\circ}}{\text { Sootald }}$ \\
\hline $\begin{array}{rrr}5 & 000 \mathrm{y} \text { monos } \\
5 & 000-10000 \\
10 & 000-15000 \\
15 & 000-20 & 000 \\
20 & 000-50 & 000 \\
50 & 000-100 & 000 \\
100 & 000-200 & 000 \\
200 & 000-500 & 000 \\
500 & 000 & \end{array}$ & $\begin{array}{l}9.6 \\
6.2 \\
3.6 \\
5.8 \\
3.9 \\
3.3 \\
4.8 \\
4.9 \\
5.4\end{array}$ & $\begin{array}{l}2.5 \\
2.7 \\
2.5 \\
2.4 \\
2.3 \\
2.1 \\
2.1 \\
1.9 \\
1.7\end{array}$ & $\begin{array}{l}7.1 \\
3.5 \\
1.1 \\
3.4 \\
1.6 \\
1.2 \\
2.7 \\
3.0 \\
3.7\end{array}$ & $\begin{array}{r}13.7 \\
6.8 \\
3.9 \\
4.2 \\
4.6 \\
4.7 \\
3.8 \\
5.7 \\
4.9\end{array}$ & $\begin{array}{l}4.5 \\
3.2 \\
3.4 \\
3.3 \\
3.4 \\
3.1 \\
2.9 \\
2.7 \\
3.0\end{array}$ & $\begin{array}{l}9.2 \\
3.6 \\
0.5 \\
0.9 \\
1.2 \\
1.6 \\
0.9 \\
3.0 \\
1.9\end{array}$ \\
\hline Total & 4.9 & 2.1 & 2.8 & 4.8 & 3.1 & 1.7 \\
\hline
\end{tabular}

a Las localidades consideradas son las urbanas de 1960 . Se excluyen las 2 localidades urbanas de Oaxaca por no contarse con las estadísticas vitales necesarias.

b Tamaño de la población de las localidades al principio de cada período.

c Este incremento medio anual se calculó mediante la expresión:

$$
2(C N) /\left(P_{0}+P_{1}\right) \cdot \frac{1}{n} \cdot 100,
$$

en donde $C N$ es crecimiento natural en términos absolutos en cada intervalo de población y $P_{0}$ y $P_{1}$ son las poblaciones al principio y al final del período.

d Este incremento medio anual se calculó mediante la expresión:

$$
2(C S) /\left(P_{0}+P_{1}\right) \cdot \frac{1}{n} \cdot 100,
$$

en donde $C S$ es crecimiento social en términos absolutos en cada intervalo de población y $P_{0}$ y $P_{1}$ son las poblaciones al principio y al final del período.

tantes centros urbanos de más de 100000 habitantes al inicio del período correspondiente. Destacaron por su importancia como centros de atracción la ciudad de México, en ambos decenios, y Guadalajara y Monterrey, éstas sobre todo en el segundo decenio. La ciudad de México absorbió el $49.1 \%$ de los inmigrantes netos urbanos en 1940-1950 -aunque su tasa de crecimiento social no fue de las más altas-y el $42.0 \%$ en 1950-1960. Guadalajara y Monterrey aumentaron su participación sustancialmente y se convirtieron en los centros regionales de mayor importancia del país, y uno de los principales factores del cambio operado en la estructura urbana del país.

En los cuadros 7 y 8 puede verse que las diez principales ciudades de atracción aportan también en ambas décadas una parte sustancial del crecimiento total de la población urbana: $66.0 \%$ y $66.9 \%$ en cada período y más de la mitad del crecimiento natural, $51.7 \%$ y $57.8 \%$. Desde luego que estas participaciones son menores que las relativas al crecimiento social. 
Crecimiento natural y social de las localidades urbanas. [Una de las características notables de la urbanización en México en el período estudiado y en particular en el decenio 1940-1950, es el considerable número de localidades urbanas que experimentaron un crecimiento de población sumamente rápido y'elevado, sin precedente en el desarrollo demográfico del país. Tal como se expresó antes, la migración de campo a ciudad y de ciudad a ciudad fue la que tuvo mayor influencia en el mencionado fenómeno durante 1940-1950; mientras que en el decenio siguiente el crecimiento natural de la población fue el que ejerció mayor peso (Véanse los cuadros 6 y 9.)

La disminución relativa experimentada en el crecimiento social de la población urbana se refleja también en los cambios habidos en el número de localidades urbanas agrupadas según el saldo neto migratorio anual. En el cuadro 10 se advierte en primer lugar la disminución, entre el primero y el segundo decenios, del número de localidades de atracción (de 95 a 82) y el aumento del número de centros de rechazo (de 30 a 39); en segundo lugar, la disminución notable del número de localidades de "atracción muy elęvada" e incluso de las localidades de "atracción elevada", todas las cuales se concentran ahora en las categorías de "atracción" y "rechazo moderado". Asimismo, en el cuadro 20 se observa una disminución clara en los saldos netos migratorios anuales positivos de las ciudades de "atracción muy elevada" del segundo con respecto al primer decenio. En general, son menores en 1950-1960 las tasas de crecimiento total y social de las localidades, excepto las que se incorporan a urbanas, que por razones obvias tienden a ser elevadas. Una posible explicación de este fenómeno es que una ciudad, a medida que aumenta su población, en

Cuadro 10

MÉxico: NÚMERO DE LOCALIDAdES URBANAS DE ATRACCIÓN Y DE RECHAZO, 1940-1960

\begin{tabular}{|c|c|c|c|c|c|c|}
\hline \multirow{2}{*}{$\begin{array}{l}\text { Cladifioación segrín la } \\
\text { tasa de grecimiento } \\
\text { social }\end{array}$} & \multicolumn{3}{|c|}{$1940-1950$} & \multicolumn{3}{|c|}{$1950-1960$} \\
\hline & $\begin{array}{l}\text { Abso- } \\
\text { lutos }\end{array}$ & $\%$ & $\%$ & $\begin{array}{l}\text { Abso- } \\
\text { lutos }\end{array}$ & $\%$ & $\%$ \\
\hline Localidades de atracción & 25 & 76.00 & 100.00 & $\underline{82}$ & 67.77 & 100.00 \\
\hline $\begin{array}{l}\text { Atracoión moderada ( } 0 \text { a } 1 \%) \\
\text { Atracción olevada ( } 1 \text { a } 4 \%) \\
\text { Atracción muy elevada (4\% y más) }\end{array}$ & $\begin{array}{l}12 \\
53 \\
30\end{array}$ & $\begin{array}{r}9.60 \\
42.40 \\
24.00\end{array}$ & $\begin{array}{l}12.64 \\
55.78 \\
31.58\end{array}$ & $\begin{array}{l}25 \\
46 \\
11\end{array}$ & $\begin{array}{r}20.66 \\
38.02 \\
9.09\end{array}$ & $\begin{array}{l}30.49 \\
56.10 \\
13.41\end{array}$ \\
\hline Localidades de rechazo & 30 & 24.00 & 100.00 & 32 & 32.23 & 100.00 \\
\hline \multirow{2}{*}{$\begin{array}{c}\text { Rechazo moder } \\
\text { Rechazo eleva } \\
\text { Rechazo muy e } \\
\text { Suma }\end{array}$} & $\begin{array}{r}11 \\
12 \\
7\end{array}$ & $\begin{array}{l}8.80 \\
9.60 \\
5.60\end{array}$ & $\begin{array}{l}36.67 \\
40.00 \\
23.33\end{array}$ & $\begin{array}{r}27 \\
3 \\
9\end{array}$ & $\begin{array}{r}22.31 \\
2.48 \\
7.44\end{array}$ & $\begin{array}{r}69.24 \\
7.69 \\
23.07\end{array}$ \\
\hline & $125^{\mathrm{d} /}$ & 100.00 & - & 121 & 100.00 & - \\
\hline
\end{tabular}

a Los límites establecidos son puntos de referencia arbitrariamente seleccionados con base en el incremento medio anual social de las localidades estudiadas.

b Son aquellas cuyo saldo neto migratorio es positivo.

c Son aquellas cuyo saldo neto migratorio es negativo.

d De estas localidades, 4 se integraron a diferentes áreas urbanas en el siguiente decenio. 
especial cuando alcanza tamaños importantes, difícilmente puede mantener muy elevadas tasas de crecimiento.

No obstante lo anterior, es indiscutible que buen número de las mayores ciudades del país crece a tasas que pueden considerarse bastante elevadas. Los casos de Guadalajara y Monterrey son patentes, así como el de la ciudad de México. ${ }^{27}$

Cabe hacer notar el predominio de las localidades de los estados fronterizos del norte, en el grupo de "atracción", en especial de "atracción muy elevada". ${ }^{28}$ En las localidades de rechazo se nota el predominio, aunque no en forma tan clara, de las localidades del centro de la República y la presencia, en ambos períodos, de la mayoría de las ciudades tradicionalmente mineras del país. Los 10 centros urbanos de "rechazo" más importantes aportan una parte sustancial de las sumas de los saldos netos migratorios negativos de las localidades

\section{Cuadro 11}

MÉXICO: LOCALIDADES URBANAS DE RECHAZO MÁS IMPORTANTES, $1940-1950$

\begin{tabular}{lcc}
\hline \multicolumn{1}{c}{ Ciudades } & \multicolumn{2}{c}{ Saldos netos migratorios } \\
\cline { 2 - 3 } & negativos \\
\hline Total de localidades urbanas & 86600 & $\%$ \\
Aguascalientes, Ags. & 11505 & 100.00 \\
Pachuca, Hgo. & 9518 & 13.29 \\
Matehuala, S.L.P. & 6285 & 10.99 \\
Guanajuato, Gto. & 4922 & 7.26 \\
La Barca, Jal. & 3995 & 5.68 \\
Atlixco, Pue. & 3803 & 4.62 \\
Lagos de Moreno, Jal. & 3646 & 4.39 \\
Zacatecas, Zac. & 3205 & 4.21 \\
San Pedro de las Colonias, Coah. & 3024 & 3.70 \\
Nueva Rosita, Coah. & 3023 & 3.49 \\
\multicolumn{1}{c}{ Suma } & 52926 & 3.49 \\
Otras localidades urbanas & 33674 & 61.12 \\
\hline
\end{tabular}

a Corresponde a las que eran urbanas en 1960. En cuanto a las ciudades con área urbana, el cálculo se hizo considerando las localidades que integraban tales áreas urbanas en 1950.

27 Las tasas aproximadas de crecimiento anual 1930-1960, de las 50 ciudades de América Latina más pobladas, indican lo siguiente: de las 22 ciudades mayores de 500000 habitantes en 1960 (o cerca de 1960), 12 acusaron tasa de crecimiento anual superior a la media de las $50(3.6 \%)$, estando entre ellas las tres de México - ciudad de México, Guadalajara y Monterrey. De las 10 ciudades mayores de 1000000 de habitantes en 1960, solamente Caracas, Lima y Bogotá superaron a la ciudad de México; no obstante lo cual, esta última creció a mayor velocidad que las 3 restantes mayores de dos millones, o sea, más que Río de Janeiro, São Paulo y Buenos Aires. Véase J. P. Cole y B. Twigg, "Notes on the Towns of Latin America", Bulletin of Quantitative Data for Geographers, No. 4, Universidad de Nottingham, junio 1966, cuadro 5.1, p. 38.

28 El $63 \%$ en $1940-1950$ y el $73 \%$ en el decenio siguiente, de las localidades de atracción muy elevada, pertenecía a dichos estados fronterizos del norte, destacando entre ellas Sonora y Tamaulipas, entidades de elevado nivel socioeconómico. 
urbanas de rechazo (véanse los cuadros 11 y 12). Se observa que este tipo de localidades manifiesta cambios de mayor importancia que los 10 centros principales de atracción. Sólo dos ciudades, Pachuca y Nueva Rosita - centros mineros- aparecen en los dos períodos, a diferencia de seis ciudades de atracción: ciudad de México, Guadalajara, Monterrey, Ciudad Juárez, Mexicali y Tijuana, las cuales en conjunto absorbieron el $67.8 \%$ y el $75.9 \%$ del crecimiento social del país en los decenios 1940-1950 y 1950-1960 respectivamente (véanse los cuadros 7 y 8). En consecuencia, estas últimas ciudades -la capital de la República, los dos centros regionales y las tres ciudades fronterizas más importantes-, constituyeron los principales polos de crecimiento demográfico del país en el período estudiad@ JEl mapa anexo presenta las localidades de atracción y de rechazo, por entidades y según distintos tamaños de población en el período 1950-1960. Se capta con claridad lo difundido del fenómeno urbano en México hasta 1960, especialmente si se compara con un mapa similar de las localidades que eran urbanas en 1940.

\section{Cuadro 12}

MÉXIO0: LOCALIDADES URBANAS DE RECHAZO MÁS IMPORTANTES, $1950-1960$

\begin{tabular}{|c|c|c|}
\hline \multirow{2}{*}{ Ciudades $a$} & \multicolumn{2}{|c|}{ Saldos netos migratorios negativos } \\
\hline & Absolutos & $\%$ \\
\hline Total de localidades urbanas & 131482 & 100.00 \\
\hline $\begin{array}{l}\text { Pachuca, Hgo. } \\
\text { San Luis Potosí, S.L.P. } \\
\text { Mérida, Yuc. } \\
\text { Fresnillo, Zac. } \\
\text { Torreón, Coah. } \\
\text { Nueva Rosita, Coah. } \\
\text { Acámbaro, Gto. } \\
\text { Ciudad Mante, Tamps. } \\
\text { Tampico, Tamps. } \\
\text { Parras de la Fuente, Coah. }\end{array}$ & $\begin{array}{r}14068 \\
13643 \\
10575 \\
7310 \\
7094 \\
6224 \\
5668 \\
5173 \\
5068 \\
4946\end{array}$ & $\begin{array}{r}10.70 \\
10.38 \\
8.04 \\
5.56 \\
5.40 \\
4.73 \\
4.31 \\
3.93 \\
3.86 \\
3.76\end{array}$ \\
\hline Suma & 79769 & 60.67 \\
\hline Otras localidades urbanas & 51713 & 39.33 \\
\hline
\end{tabular}

a Corresponde a localidades que eran urbanas en 1960. En cuanto a las ciudades con áreas urbanas, el cálculo se hizo considerando las localidades que integraban tales áreas urbanas en 1960.

\section{Estructura de las localidades urbanas del pais}

La distribución de la población y de las localidades urbanas en México en los años censales estudiados, así como los cambios operados en tal estructura, pueden observarse en el cuadro 13. Lo primero que destaca es el gran aumento del número de localidades urbanas -a más del doble entre 1940 y 1960-, aumento que fue mayor en términos relativos en las ciudades de más población. Esto explica, 
Cuadro 13

Méxioo: Distribución de la población por tamaño de localidades, 1940 a 1960

\begin{tabular}{|c|c|c|c|c|c|c|c|c|c|c|}
\hline \multirow{2}{*}{\multicolumn{2}{|c|}{$\begin{array}{c}\text { Tamaño de las } \\
\text { localidades }\end{array}$}} & \multicolumn{3}{|c|}{$\begin{array}{llll}1 & 9 & 4 & 0\end{array}$} & \multicolumn{3}{|c|}{1950} & \multicolumn{3}{|c|}{$\begin{array}{llll}1 & 9 & 6 & 0\end{array}$} \\
\hline & & $\begin{array}{l}\text { Número } \\
\text { de lo- } \\
\text { cali- } \\
\text { dades }\end{array}$ & Poblacion & $\begin{array}{l}\% \text { de } \\
\text { pobla- } \\
\text { cion } \\
\text { total }\end{array}$ & $\begin{array}{l}\text { Numero } \\
\text { de } 10- \\
\text { cali- } \\
\text { dades }\end{array}$ & Población & $\begin{array}{l}\text { o de } \\
\text { pobla- } \\
\text { cion } \\
\text { total }\end{array}$ & $\begin{array}{l}\text { Numero } \\
\text { de lo- } \\
\text { oall- } \\
\text { dades }\end{array}$ & Poblaoibn & $\begin{array}{l}\text { S de } \\
\text { poblam } \\
\text { olon } \\
\text { total }\end{array}$ \\
\hline \multicolumn{2}{|l|}{ Total del pais } & $105 \cdot 508^{h /}$ & $19649 \quad 162^{4}$ & 100.00 & $28 \quad 325^{\text {h }}$. & $25 \quad 779 \quad 254^{1}$ & 100.00 & 89005 & $34923 \quad 129$ & 100.00 \\
\hline Urbana & & 52 & $3927694^{\mathrm{kJ}}$ & 20.00 & 84 & I 209528 & 27.96 & 123 & $12746 \quad 685^{\mathrm{k}}$ & 36.50 \\
\hline $\begin{array}{ccc}1000 & 000 \text { y } \\
500 & 000-1 & 0 \\
100 & 000- & 5 \\
50 & 000- & 1 \\
15 & 000- & \end{array}$ & 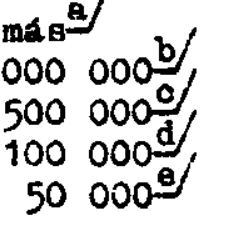 & $\begin{array}{r}1 \\
\overline{5} \\
8 \\
41\end{array}$ & $\begin{array}{rr}1559 & 782 \\
& - \\
731 & 244 \\
539 & 106 \\
997 & 562\end{array}$ & $\begin{array}{l}7.94 \\
- \\
3.98 \\
3.00 \\
5.08\end{array}$ & $\begin{array}{l}1 \\
- \\
10 \\
12 \\
61\end{array}$ & $\begin{array}{rrr}2 & 872 & 334 \\
1 & 926 & 776 \\
1 & 808 & 331 \\
1 & 602 & 037\end{array}$ & $\begin{array}{c}11.14 \\
- \\
7.47 \\
3.14 \\
6.21\end{array}$ & $\begin{array}{r}1 \\
2 \\
14 \\
20 \\
86\end{array}$ & $\begin{array}{llll}4 & 909 & 961 \\
1 & 511 & 092 \\
2 & 547 & 538 \\
1 & 532 & 628 \\
2 & 245 & 466\end{array}$ & $\begin{array}{r}14.06 \\
4.33 \\
7.29 \\
4.39 \\
6.43\end{array}$ \\
\hline \multicolumn{2}{|l|}{ No urbana } & 105.453 & 15721468 & 30.00 & $28 \quad 241$ & $18569726^{\circ}$ & 72.04 & $88 \quad 882$ & $22 \quad 176 \quad 444$ & 63.50 \\
\hline \multicolumn{2}{|l|}{ Mixta } & 195 & 1492170 & 7.59 & 253 & 2013694 & 7.81 & 342 & 2756815 & 7.89 \\
\hline $\begin{array}{r}10000- \\
5000-\end{array}$ & $\begin{array}{l}15000 \frac{1}{8} \\
10000 \mathrm{~g}\end{array}$ & $\begin{array}{r}35 \\
160\end{array}$ & $\begin{array}{l}430738 \\
1061432\end{array}$ & $\begin{array}{l}2.19 \\
5.40\end{array}$ & $\begin{array}{r}57 \\
196\end{array}$ & $\begin{array}{r}676756 \\
1336858\end{array}$ & $\begin{array}{l}2.62 \\
5.19\end{array}$ & $\begin{array}{r}72 \\
270\end{array}$ & $\begin{array}{r}880501 \\
1876 \quad 314\end{array}$ & $\begin{array}{l}2.52 \\
5.37\end{array}$ \\
\hline \multicolumn{2}{|l|}{ Rural } & 105258 & 14229298 & 72.41 & 97988 & 16556112 & 64.23 & 88540 & 19419629 & 55.61 \\
\hline $\begin{array}{l}1000- \\
100- \\
\text { menos de }\end{array}$ & $\begin{array}{r}5000 \\
1000 \\
1 \quad 100\end{array}$ & $\begin{array}{r}2.390 \\
26.546 \\
76 \quad 322\end{array}$ & $\begin{array}{lll}4 & 448 & 811 \\
7 & 775 & 830 \\
2 & 004 & 657\end{array}$ & $\begin{array}{l}22.64 \\
39.57 \\
10.20\end{array}$ & $\begin{array}{rl}3 & 098 \\
29 & 829 \\
65 & 061\end{array}$ & $\begin{array}{lll}5 & 666 & 020 \\
9 & 119 & 066 \\
1 & 771 & 026\end{array}$ & $\begin{array}{r}21.97 \\
35.38 \\
6.87\end{array}$ & $\begin{array}{rr}3 & 950 \\
33 & 083 \\
51 & 507\end{array}$ & $\begin{array}{rrr}7 & 292 & 285 \\
10 & 571 & 237 \\
1 & 556 & 107\end{array}$ & $\begin{array}{r}20.88 \\
30.27 \\
4.46\end{array}$ \\
\hline
\end{tabular}

Fuentes: VI, VII y VIII Censos Generales de Población.

Los diferentes tamaños de ciudades se han denominado, para su mejor identificación, de la siguiente manera:

a Metrópolis; b centros regionales; $\mathbf{c}$ ciudades grandes; d ciudades medianas; o ciudades pequeñas; $\mathbf{f}$ mixtas urbanas; $g$ mixtas rurales.

h No incluye a las localidades censadas con otras, ni a las deshabitadas.

1 Este dato difiere en menos 4390 habitantes de la cifra que proporciona el VI Censo de Población, debido a tres erratas de los volúmenes estatales del mencionado censo: 2000 habitantes en la ciudad de Mérida, 2345 habitantes en el estado de Durango y 45 habitantes en el de Oaxaca.

f Esta población difiere de la proporcionada por el VII Censo de población en 11763 habitantes que el censo clasifica como complementarios y que no pueden atribuirse a ningún tamaño de población, ni a ninguna entidad federativa.

k Esta población difiere de la que se obtiene con la información censal con localidades de 15000 y más habitantes, porque incluye las áreas urbanas principales del país: 6 en 1940, 21 en 1950 y 28 en 1960. 
en parte, los cambios en la estructura urbana manifestados a través del aumento en el factor $E$ y que han influido en el nivel de urbanización. (Véase el cuadro 4.)

En este fenómeno ha jugado un papel importante la formación de centros regionales y ciudades grandes, lo cual ha conducido al gradual acẹrcamiento de la estructura urbana del país a una de naturaleza "intermedia", comparada a la preeminente que tenía en 1940.

Lo que resulta evidente cuando se maneja el número de ciudades, se confirma al analizar los montos de población de las principales ciudades a través del "índice de primacía". En el cuadro 14 se advierte que los cuatro primeros "índices" (desde 2 hasta 8 ciudades) aumentan sistemáticamente de 1900 a 1950 y decrecen de 1950 a 1960, fenómeno este último debido en lo principal al crecimiento acelerado de Guadalajara y Monterrey.

\section{Cuadro 14}


$1900,1940,1950 \mathrm{Y} \cdot 1960$

\begin{tabular}{rllll}
\hline $\begin{array}{c}\text { Indices de } \\
\text { primacia de: } \boldsymbol{~} \boldsymbol{c}\end{array}$ & 1900 & 1940 & 1950 & 1960 \\
\hline 2 ciudades & 4.40 & 6.48 & 7.16 & 6.05 \\
4 ciudades & 1.70 & 2.74 & 2.92 & 2.70 \\
6 ciudades & 1.20 & 1.99 & 2.19 & 2.09 \\
8 ciudades & 0.94 & 1.62 & 1.82 & 1.79 \\
10 ciudades & 0.82 & 1.40 & 1.57 & 1.59 \\
\hline
\end{tabular}

a Para la determinación del "índice", véase la nota a del cuadro 3 .

A pesar de que ambas formas de identificar el fenómeno señalan la misma tendencia, puede verse que el alejamiento del sistema preeminente, medido a través del número de ciudades, se produce en 1940-1950, mientras que el descenso en los índices de primacía no se manifiesta hasta el siguiente decenio, en el cual se acentúa el cambio en la estructura de las ciudades. No es aventurado conjeturar, aun con las reservas que impone un período de estudio de sólo 20 años, que la tendencia se ha mantenido de 1960 a la fecha.

Distribución de las localidades no urbanas. El estudio del proceso de urbanización exige conocer también algunos aspectos sobre las localidades no urbanas. Así, por ejemplo, en el fenómeno migratorio es de capital importancia determinar en qué medida está dispersa la población no urbana del país, pues se considera que la dispersión influye en la magnitud de los movimientos migratorios campo-ciudad. ${ }^{29}$

29 Tal consideración se fundamenta en la hipótesis de que las localidades de muy reducida población, salvo excepciones, tienen un nivel de vida precario, carecen de servicios públicos elementales, con frecuencia se encuentran aisladas geográficamente, y tienen fuentes de ingresos escasas, vulnerables a diversos factores externos. En síntesis, tales localidades manifiestan condiciones de inestabilidad económica y características de vida tales, que hacen que su población sea fuente potencial de migrantes. 
El cuadro 13 muestra con claridad que México es un país con población rural sumamente dispersa. Todavía en 1960 habitaba localidades menores de 1000 habitantes el $34.7 \%$ de la población nacio nal, o sean 12.1 millones de personas. La incorporación de esta población al sistema central de ciudades se dificulta, pues queda al margen de los cambios en la forma de vida que experimenta el resto del país.

La composición de la población rural del país manifiesta cambios cuantitativos en un solo sentido, pero de poca magnitud: el factor $R$ del índice de ruralización ${ }^{30}$ disminuyó con lentitud durante todo el período, lo que indica que la distribución de la población rural se movió hacia los grupos de magnitud superior (véase el cuadro 13). Esta disminución puede implicar menor número de localidades de menos de 100 habitantes o bien un aumento del tamaño medio de las localidades rurales. No puede concluirse nada definitivo al respecto debido a que la disminución en términos relativos y absolutos de las localidades menores de 100 habitantes no pudo cuantificarse exactamente a causa de problemas de comparación de los datos censales. ${ }^{31}$

Si la mayor parte de las localidades "censadas con otras" pertenece al grupo de menos de 100 habitantes, y si, como es de suponer, se agruparon con localidades de tamaños mayores, se tendría que el censo subestima la población en el grupo más pequeño y sobrestima la de los demás. En todo caso, aun cuando se censaran con localidades de la misma clase, esto disminuiría el número de las mismas, aunque no su población. ${ }^{32}$

\section{Tasa de urbanización}

La tasa de urbanización se definió como el incremento medio anual del índice de urbanización. ${ }^{33}$ Por esta razón, se ha dejado su des-

30 A semejanza del "índice de urbanización" previamente explicado, se construyó otro de ruralización, cuya expresión numérica es la siguiente:

$I,=1 / 5\left(R_{1 / P}+R_{2 / P}+R_{3 / P}+R_{1 / P}+R_{5 / P}\right)$ en que $R_{1}, R_{2}, R_{3}, R_{4}$ y $R_{5}$ son la población en localidades menores de $100,500,1000,2500$ y 5000 habitantes, respectivamente. $P$ es la población total de la unidad estudiada. Asimismo el indice de ruralización equivale a $\mathrm{I}_{\mathrm{r}}=R \times$ (grado de ruralización). El factor $R$ expresa el mayor peso que se desea dar a las localidades de menor tamaño de población.

31 Analizados los casos de las localidades "censadas con otras" y las deshabitadas, se llega a considerar dudosa una reducción tan drástica en el número y población que habita en localidades menores de 100 habitantes, y se otorga mayor posibilidad a una disminución solamente en la participación en el total de la población, que sin embargo fue significativa, ya que descendió del $10.2 \%$ al $4.5 \%$, de 1940 a 1960 . (Véase el cuadro 13.) Respecto a las localidades censadas con otras, hay varias indicaciones que sugieren que los censos no son comparables en este aspecto. Si bien no se conocen las razones precisas por las cuales unas localidades son censadas con otras, estas razones parecen en todo caso haber cambiado de un año a otro, como lo indican las grandes variaciones en los datos. En cuanto al número de localidades deshabitadas, éste casi se duplicó entre 1940 y 1960 , lo que implicaría que en ese período se deshabitaron alrededor de 10000 localidades. Éste sí sería un elemento para explicar por qué el número de localidades pequeñas disminuye.

32 El censo de 1950 (que indica con qué localidad se agruparon las localidades censadas con otras) permite ver que en la mayoría de los casos se censaron con localidades mayores.

33 La tasa de urbanización se calculó mediante la siguiente expresión: 
arrollo hasta el final de esta parte a nivel nacional, pues en cierta manera dicho planteamiento es un resumen y un corolario de lo que se ha tratado con relación al nivel y el ritmo de urbanización en los apartados anteriores.

La tasa de urbanización de México es de las más elevadas del mundo.34 Sin embargo, disminuyó sustancialmente entre el decenio 1940-1950 y el siguiente: de $3.7 \%$ anual pasó a $2.9 \%$. Este cambio en la tasa refleja los cambios en los factores que determinan el nivel de urbanización y se pueden resumir de la manera siguiente:

a) El incremento medio anual de la población total fue mayor, entre el primero y el segundo decenios estudiados, que el de la población urbana. Esto trajo como resultado que el grado de urbanización aumentara de 1950 a 1960 en un $30.7 \%$ mientras que en el decenio anterior se había incrementado en $39.6 \%$. En esta disminución relativa influyó la pérdida de importancia de la multiplicación de localidades urbanas por reclasificación, y la disminución de las tasas anuales de los saldos netos migratorios de las localidades urbanas.

b) La modificación de la estructura de localidades también influyó en la tasa de urbanización; la participación de los intervalos superiores de la población urbana siguió aumentando aunque con intensidad menor que en 1940-1950.]

Al margen de estas conclusiones, cabe comentar una hipótesis que se ha planteado para explicar el descenso en la tasa de urbanización. Según esta hipótesis, el hecho de que los índices de urbanización tengan un límite fijo de 100 implica que no puede mantenerse un ritmo elevado de urbanización durante largos períodos. Con base en este razonamiento, Browningas5 sugirió que el período 1940-1950 contiene el punto de inflexión en la curva de la urbanización en México. Esta conclusión ha probado ser válida a la luz de los resultados del presente trabajo. Puede decirse, en términos generales, que todas las manifestaciones de la urbanización estudiadas -índice de urbanización, estructura de ciudades, tasas de crecimiento social y natural, etc.- muestran un cambio de tendencia entre los dos períodos de estudio.

Esta conclusión permite pensar, además, que Tde mantenerse la tendencia del proceso de urbanización del período 1950-1960, la estructura urbana de México cambiaría definitivamente hacia un sistema de ciudades no preeminente, en el que el área urbana de la ciudad de

$T_{u}=2\left(I_{1}-I_{0}\right) /\left(I_{1}+I_{0}\right) \cdot \frac{1}{n} \cdot 100$

Esto equivale a la tasa de incremento medio anual del índice de urbanización, ya que $I_{1}$ e $I_{o}$ son precisamente los índices de urbanización al principio y al final del período. Esta expresión se estableció de acuerdo con la planteada por Naciones Unidas con base en el grado de urbanización. Véase Naciones Unidas, Administrative Problems of Rapid Urban Growth in the Arab States, Nueva York, 1964, p. 40.

34 Esta conclusión se había apuntado en la parte del análisis internacional en la que se calculó la tasa a partir del grado de urbanización. El hecho de que se utilice el "índice" en lugar del "grado" no altera esta conclusión.

35 Browning, op. cit., p. 42. 
México tendría un predominio demográfico y posiblemente socioeconómico inferior al actual, y se formaría paralelamente una red de ciudades de creciente interdependencia. Esto significa que México pasaría de un proceso de urbanización que Sovani denominó "primario" a otro de características "maduras", que se encuentra con mayor frecuencia en los países desarrollados.j6

\section{El PROCESO DE URBANIZACIÓN EN MÉXICO a NIVEL REgIONAL}

\section{Nivel de urbanización}

Para complementar la descripción del proceso de urbanización del país, se estudian en esta parte las manifestaciones del fenómeno en las entidades federativas, con base en la determinación de patrones de comportamiento semejantes de acuerdo con el nivel y el ritmo de la urbanización.

En 1940, el nivel de urbanización del país estaba determinado, como lo indica el cuadro 15, fundamentalmente por el Distrito Federal $(49.1 \%)$ y otras cinco entidades que en total contribuyeron con el $76.3 \%$ del índice de urbanización nacional. En 1960, el $75.4 \%$ del nivel de urbanización del país correspondió al Distrito Federal (42.4 \%) y a siete entidades más. ${ }^{37}$

De lo anterior se infiere que el nivel de urbanización del país sigue dependiendo en gran medida del Distrito Federal -aunque en menor grado en el segundo decenio estudiado- $\mathrm{y}$ de un reducido número de entidades, mientras que el resto sigue mostrando características predominantemente rurales. Asimismo, es importante destacar que si bien todas las entidades del país incrementaron su nivel de urbanización, en el_período se acentuaron las desigualdades regionales de la urbanización. . $^{8}$

36 Véase la declaración presentada por N. V. Sovani como moderador de la reunión A8 de la Conferencia Mundial de Población de Belgrado. Naciones Unidas, World Population Conference, 1965, Vol. I: Summary Report. Nueva York, 1966 , pp. 169-174.

37 En el cuadro 15 puede verse que en 1940 las cinco entidades adicionales al Distrito Federal fueron: Jalisco, Nuevo León, Puebla, Veracruz y Tamaulipas. En 1960, las siete entidades adicionales al Distrito Federal fueron estas mismas, excepto Puebla, y además Chihuahua, Guanajuato y Baja California Norte. Si se amplía el análisis a las 10 entidades de mayor participación en el nivel de urbanización del país, se observa que en 1940 aportaron el $87.5 \%$ y en 1960 el $81.7 \%$. Es importante destacar que de las 10 entidades, 4 son de la frontera norte en 1940, y 5 en 1960. De acuerdo con su participación relativa en el "índice", las entidades de la frontera norte contribuyeron con el $16.0 \%$ y el $20.7 \%$ respectivamente $y$, por lo tanto, su participación conjunta con el Distrito Federal fue de las dos terceras partes del nivel de urbanización del país.

38 La desviación estándar del índice de urbanización aumentó de 17 a 21 en el período 1940-1960. Este movimiento obedeció a que el promedio no ponderado del índice de urbanización se elevó rápidamente en términos absolutos, como resultado de los aumentos en el "índice" de las entidades altamente urbanizadas, que mantuvieron su elevada participación en el mismo. El resto de las entidades, aunque en conjunto acusó tasa de urbanización más acelerada, estaba formado por entidades que se encontraban a niveles tan bajos que los aumentos en términos absolutos fueron menores que los registrados en el promedio nacional. 


\section{Cuadro 15}

MÉXICO: INDICE dE URBaNIZACIón DE LAS ENTIDADES, PARTICIPACIÓN DEL ÍNDICE ESTATAL EN EL TOTAL NACIONAL Y RANGO DE LAS ENTIDADES SEGÚN SU PARTICIPACIÓN, 1940,1950 Y 1960

\begin{tabular}{|c|c|c|c|c|c|c|c|c|c|}
\hline \multirow[b]{2}{*}{ Ent1dades } & \multirow[b]{2}{*}{ Indice } & \multicolumn{2}{|c|}{940} & \multicolumn{3}{|c|}{19} & \multirow[b]{2}{*}{ Indice } & \multicolumn{2}{|l|}{960} \\
\hline & & $\begin{array}{l}\text { Parti- } \\
\text { cipa- } \\
\text { cion } \%\end{array}$ & $\frac{\operatorname{Ran}}{\text { go }}$ & Indice & $\begin{array}{l}\text { Parti- } \\
\text { cipa- } \\
\text { cion } 6\end{array}$ & ${ }_{80}^{\operatorname{Ran}}$ & & $\begin{array}{l}\text { Parti- } \\
\text { cipa- } \\
\text { cion } 6\end{array}$ & $\operatorname{Ran}_{\text {go }}$ \\
\hline Total Nacional & 16.16 & 100.00 & & 23.59 & 100.00 & & 31.69 & 100.00 & \\
\hline $\begin{array}{l}\text { Aguascalientea } \\
\text { Baja California Norte } \\
\text { Baja California Sur } \\
\text { Campeche } \\
\text { Coahuila } \\
\text { Colima } \\
\text { Chiapas } \\
\text { Chihuahua } \\
\text { Distrito Federal } \\
\text { Durango } \\
\text { Guanajuato } \\
\text { Guerrero } \\
\text { Hidalgo } \\
\text { Jalisco } \\
\text { Hexico } \\
\text { Michoacan } \\
\text { Morelog } \\
\text { Nayarit } \\
\text { Nuevo Leon } \\
\text { Oaxaca } \\
\text { Puebla } \\
\text { Queretaro } \\
\text { Quintana Roo } \\
\text { San Luis Potos } \\
\text { Sinaloa } \\
\text { Sonora } \\
\text { Tabasco } \\
\text { Tamaulipas } \\
\text { Tlaxcala } \\
\text { Veracruz } \\
\text { Yucatan } \\
\text { Zacatecas }\end{array}$ & $\begin{array}{r}38.14 \\
11.17 \\
-. \\
12.86 \\
19.26 \\
14.34 \\
1.14 \\
12.68 \\
88.75 \\
6.12 \\
9.50 \\
- \\
5.18 \\
17.76 \\
1.90 \\
3.07 \\
- \\
2.02 \\
35.13 \\
1.23 \\
11.34 \\
6.87 \\
- \\
9.14 \\
5.50 \\
1.28 \\
4.40 \\
29.15 \\
- \\
8.66 \\
17.45 \\
4.11\end{array}$ & $\begin{array}{r}1.94 \\
.28 \\
. \\
3.37 \\
.35 \\
.24 \\
2.50 \\
49.10 \\
.93 \\
3.13 \\
- \\
1.26 \\
7.93 \\
.69 \\
1.14 \\
- \\
.14 \\
5.98 \\
.46 \\
4.62 \\
.53 \\
- \\
1.95 \\
.85 \\
.15 \\
.39 \\
4.22 \\
- \\
4.42 \\
2.29 \\
.73\end{array}$ & $\begin{array}{r}12 \\
24 \\
- \\
22 \\
7 \\
23 \\
25 \\
9 \\
1 \\
15 \\
8 \\
- \\
13 \\
2 \\
18 \\
14 \\
-27 \\
27 \\
3 \\
20 \\
4 \\
19 \\
-11 \\
16 \\
26 \\
21 \\
6 \\
-5 \\
10 \\
17\end{array}$ & $\begin{array}{r}37.23 \\
43.53 \\
-- \\
12.80 \\
31.12 \\
14.52 \\
3.69 \\
24.62 \\
94.29 \\
14.18 \\
15.90 \\
2.08 \\
5.72 \\
24.10 \\
2.88 \\
6.02 \\
12.11 \\
4.24 \\
47.84 \\
1.64 \\
14.90 \\
8.64 \\
- \\
15.39 \\
8.83 \\
12.34 \\
4.88 \\
34.14 \\
- \\
12.31 \\
27.64 \\
4.07\end{array}$ & $\begin{array}{c}1.15 \\
1.62 \\
- \\
.26 \\
3.69 \\
.27 \\
.55 \\
3.42 \\
47.28 \\
1.47 \\
3.47 \\
.31 \\
.80 \\
6.93 \\
.66 \\
1.41 \\
.54 \\
.20 \\
5.82 \\
.38 \\
3.99 \\
.41 \\
- \\
2.17 \\
.92 \\
1.04 \\
.29 \\
4.04 \\
- \\
4.13 \\
2.34 \\
.45\end{array}$ & $\begin{array}{r}15 \\
12 \\
- \\
23 \\
7 \\
27 \\
20 \\
9 \\
1 \\
13 \\
8 \\
25 \\
18 \\
2 \\
19 \\
14 \\
21 \\
29 \\
3 \\
24 \\
6 \\
23 \\
- \\
11 \\
17 \\
16 \\
26 \\
5 \\
- \\
4 \\
10 \\
22\end{array}$ & $\begin{array}{r}52.03 \\
67.92 \\
14.86 \\
19.33 \\
38.66 \\
20.02 \\
4.70 \\
38.30 \\
96.33 \\
17.68 \\
23.53 \\
3.58 \\
6.39 \\
35.76 \\
15.80 \\
10.98 \\
19.52 \\
10.40 \\
64.82 \\
3.55 \\
17.49 \\
14.59 \\
- \\
18.05 \\
17.29 \\
25.82 \\
8.36 \\
41.82 \\
1.13 \\
15.23 \\
28.68 \\
4.57\end{array}$ & $\begin{array}{r}1.15 \\
3.19 \\
.11 \\
.29 \\
3.17 \\
.30 \\
.51 \\
4.24 \\
42.40 \\
1.22 \\
3.70 \\
.38 \\
.57 \\
7.90 \\
2.71 \\
1.84 \\
.68 \\
.37 \\
6.32 \\
.55 \\
3.12 \\
.47 \\
- \\
1.71 \\
1.31 \\
1.83 \\
.37 \\
3.87 \\
.04 \\
3.75 \\
1.59 \\
.34\end{array}$ & $\begin{array}{r}18 \\
8 \\
30 \\
29 \\
9 \\
28 \\
22 \\
4 \\
1 \\
17 \\
7 \\
24 \\
20 \\
2 \\
11 \\
12 \\
19 \\
26 \\
3 \\
21 \\
10 \\
23 \\
- \\
14 \\
16 \\
13 \\
25 \\
5 \\
31 \\
6 \\
15 \\
27\end{array}$ \\
\hline
\end{tabular}

Nota: La participación porcentual del índice estatal en el total nacional se calculó con base en la expresión siguiente:

$$
\text { Participación estatal }=\left(P_{i} / P\right) \times\left(I_{i} / I\right) \times 100 \% \text {, }
$$

en que $\boldsymbol{P}_{i}$ y $\boldsymbol{P}$ son la población de la entidad federativa y la población total del país, respectivamente. $I_{i}$ e $I$ son los índices de urbanización estatal y nacional, respectivamente.

En función del nivel de urbanización de las entidades federativas del país, éstas se clasificaron en cinco categorías, tal como se indica en el cuadro 16.

En el mismo cuadro puede observarse la disminución constante del número de entidades de muy bajo "nivel", que se distribuyen entre los grupos de urbanización alta, media y baja, todo lo cual es reflejo claro de que el proceso de urbanización se está difundiendo en el territorio nacional.

Puede decirse que, en términos generales, las entidades que han 
Cuadro 16

México: Categorfas DE ENTIDADES FEDERATIVAS SEGÛN SU NIVEL DE URBANIZACIÓN Y SU PARTICIPACTÓN EN EL NIVEL. DEL PAfs, 1940,1950 Y 1960



Fuente: cuadro 15

A: Número de entidades.

B: Participación en el índice de urbanización (\%).

permanecido con niveles más bajos de urbanización en 1960 son las entidades de escaso desarrollo socioeconómico. En forma menos clara, las entidades más urbanizadas del país corresponden en general a las de mayor nivel de desarrollo. ${ }^{39}$

\section{Ritmo de urbanización}

A efecto de determinar qué tipo de entidades fueron las que se urbanizaron más rápidamente en el período 1940-1960 se examinaron comparativamente el índice y la tasa de urbanización. En el cuadro 17 puede advertirse claramente que las entidades de mayor nivel de urbanización (cuadro 15) fueron las que se urbanizaron más lentamente, ${ }^{40}$ y que a medida que se desciende en el "nivel" crece el ritmo

39 Esta inferencia se basa en un ensayo preliminar en el que se compararon los rangos ocupados por cada entidad, según su nivel de urbanización y su nivel de desarrollo, tanto en 1940 como en 1960. Las correlaciones de rango, +0.967 en $1940 \mathrm{y}+0.977$ en 1960 , indican un alto grado de correspondencia entre ambas jerarquías y seguramente una elevada asociación entre ambos fenómenos. La información sobre el nivel de desarrollo socioeconómico estatal se obtuvo de Calixto Rangel Contla, El desarrollo diferencial de México (1940-1960), tesis profesional, Escuela Nacional de Ciencias Políticas y Sociales, UNAM, 1965, pp. 133 y 134.

40 Las entidades siguientes: Distrito Federal, Jalisco, Nuevo León, Puebla, Veracruz y Tamaulipas, acusaron tasas anuales de urbanización, en el período 1940-1950, menores que la media nacional y ocupaban, en ese orden, del primero al sexto lugar en el nivel de urbanización de 1940. De 1950 a 1960, se repitió el fenómeno en el Distrito Federal, Puebla, Veracruz, Tamaulipas, Coahuila y Durango, las cuales ocupaban en 1950, respectivamente, el primero y del cuarto al 
Cuadro 17

MÉxico: ENTIDADES FEDERATIVAS SEGÚN SU RITMO DE URBANIZACIóN, 1940-1960

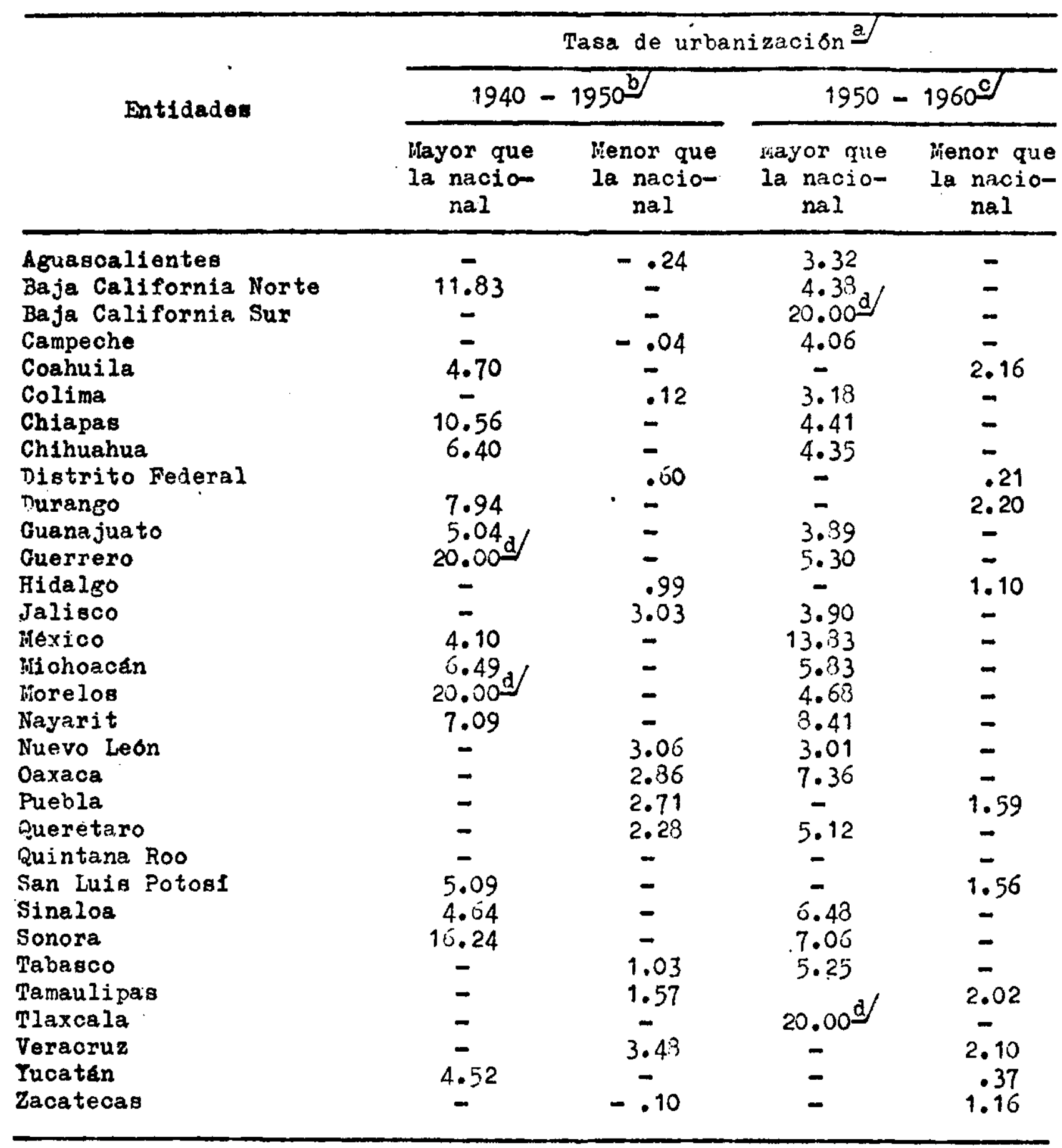

a La tasa de urbanización se calculó mediante la expresión:

$$
2 \frac{\left(I_{1}-I_{0}\right)}{\left(I_{1}+I_{0}\right)} \cdot \frac{1}{n} \cdot 100
$$

en que $I_{1}$ y $I_{0}$ son los índices de urbanización al final y al principio del periodo, $n$ es el número de años.

b La tasa de urbanización del país en el decenio 1940-1950 fue de 3.73\%.

c La tasa de urbanización del país en el decenio 1950-1960 fue de $2.93 \%$.

d Éste es el valor máximo de la tasa de urbanización cuando $I_{0}$ vale cero.

octavo lugares en el nivel de urbanización del país. Jalisco y Nuevo León fueron las dos excepciones principales, pues habiendo sido la segunda y tercera en el "nivel", se urbanizaron más rápidamente que la media nacional. A ello contribuyó el acelerado crecimiento de Guadalajara y Monterrey. 
de urbanización: De 1950 a 1960, se acentuó este último fenómeno. Estos resultados son congruentes con la hipótesis planteada previamente a nivel nacional, de que a medida que se asciende en el nivel de urbanización, la rapidez del "proceso" tiende a disminuir. Asimismo, a nivel regional se manifiesta también un punto de inflexión en la urbanización de las entidades de mayor peso en el "nivel" del país, entre ambos decenios.

El ritmo de urbanización de las entidades del país en el período estudiado se debió tanto al crecimiento de las ciudades que había al principio de cada decenio, como también a las nuevas localidades urbanas que se reclasificaron. Este último proceso tuvo en algunas entidades, tal como se observa en el cuadro 18, mayor importancia relativa que el primer fenómeno, habiéndose dado casos como el de Guerrero y Morelos en 1940-1950, y Baja California Sur y Tlaxcala en el decenio siguiente, en que el incremento bruto de la población urbana se debió exclusivamente a la reclasificación de localidades no urbanas. Por otro lado, varias entidades no experimentaron reclasificación alguna de 1940 a 1960 , como Nayarit, Nuevo León y otras cinco, lo cual es indicativo de escasa población mixta o de muy lento crecimiento de estas localidades.

El análisis de la reclasificación de localidades no urbanas indica que no existe un patrón de comportamiento regional.41 Sin embargo, el número de entidades en que la reclasificación participó en el crecimiento urbano aumentó de 15 a 21 entre 1940-1950 y 1950-1960. Asimismo, la multiplicación de pequeñas ciudades señala la formación de elementos actuales o en potencia de sistemas regionales de ciudades, lo cual se supone que tiene implicaciones socioeconómicas significativas en el desarrollo del mercado interno regional y nacional, en la distribución del ingreso y, en general, en un mayor flujo de bienes naturales y de comunicación así como de una mayor difusión de la forma de vida urbana en el ámbito nacional.

E1 crecimiento por expansión física de las principales ciudades del país contribuyó también a la urbanización regional. Este fenómeno tuvo lugar en forma más dispersa, geográficamente hablando, de 1950 a 1960 que en el decenio anterior, puesto que el número de entidades -y por lo tanto de ciudades- aumentó de 15 a 20. Por una parte, el área Distrito Federal-Estado de México,2 a pesar de mantener su elevado predominio en el total de la población integrada del país durante todo el período - debido a la significativa expansión física de la ciudad de México- perdió importancia relativa, del $79.7 \%$ al $63.5 \%$, del primero al segundo decenios. A la vez, otras entidades aumentaron su importancia relativa, destacando en ambos periodos: Morelos (Cuernavaca y Cuautla), Coahuila-Durango (Torreón-Gómez

41 La correlación de rangos en 1940-1950 y 1950-1960 entre el incremento de la población urbana por reclasificación y el porcentaje de población mixta al final de ambos decenios, resultó de $+0.03 \mathrm{y}+0.12$, respectivamente. Asimismo, no se observa asociación significativa entre la primera variable y el nivel de urbanización al final de los períodos, ni tampoco con el saldo neto migratorio por entidad.

42 En el caso del área urbana de la ciudad de México, como la de Torreón, se optó por hacer los cálculos con las dos entidades federativas contiguas que contienen partes de tales unidades urbanas. 
Palacio-Lerdo), Puebla (Puebla), Nuevo León (Montêrrey) y Jalisco (Guadalajara), las cuales alcanzaron en conjunto el $15.6 \%$ del total de población integrado, en el primer decenio, contra $26.4 \%$ en el segundo.]

\section{Cuadro 18}

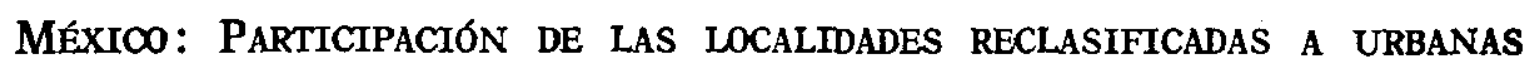
EN EL INCREMENTO BRUTO DE LA POBLACTÓN URBANA, 1940-1960

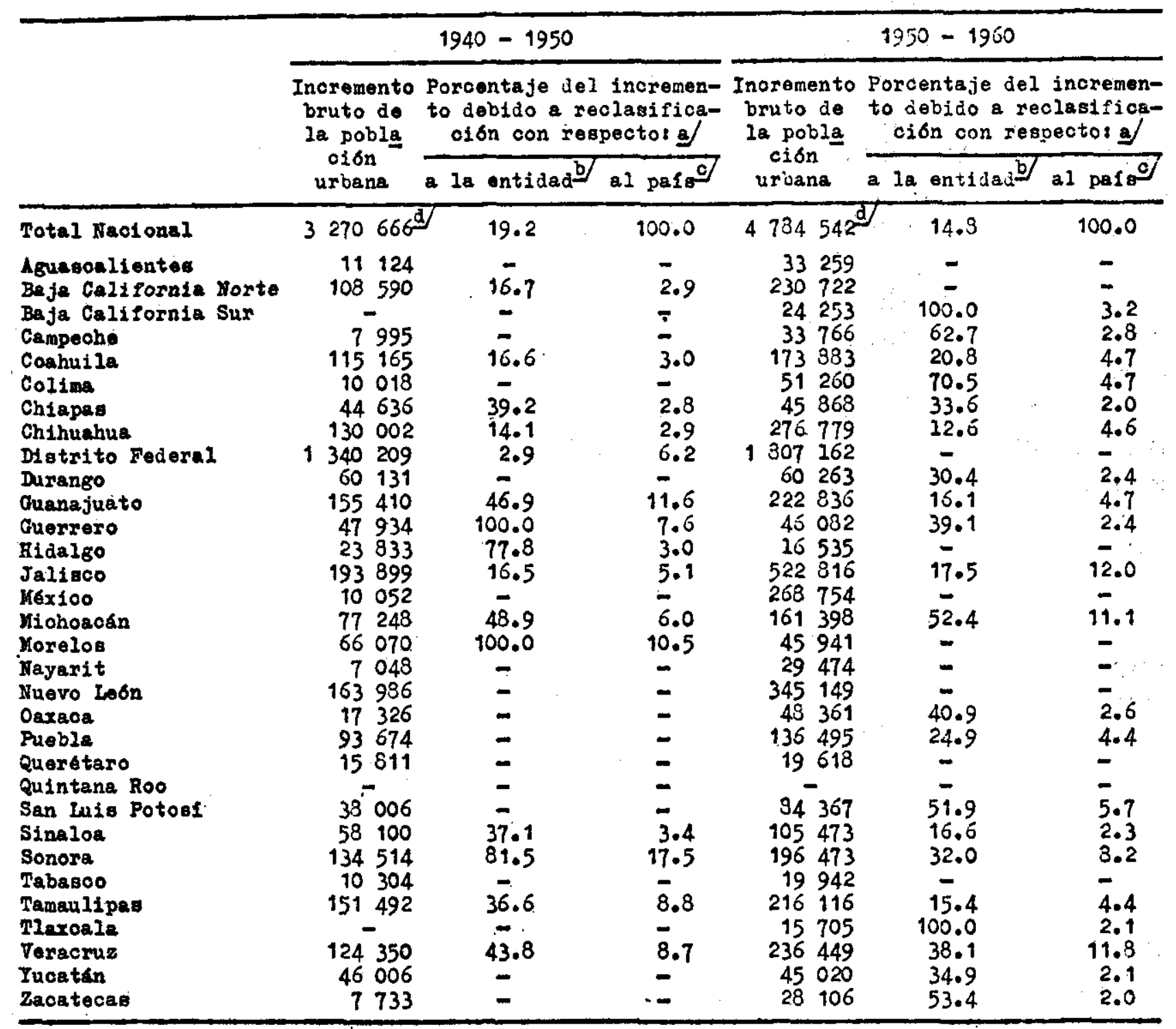

a El incremento bruto de población urbana se consideró compuesto de dos elementos: el crecimiento de las localidades urbanas existentes al principio de cada período, y la población de las localidades que se reclasificaron durante el período, de mixtas a urbanas. En este caso se ha considerado solamente el segundo tipo de incremento mencionado.

b Este porcentaje expresa la importancia del fenómeno de reclasificación dentro de cada entidad. La diferencia con respecto al $100 \%$ expresa la participación relativa de las ciudades existentes en el incremento bruto de población urbana en cada entidad.

c En este caso, el porcentaje expresa la importancia relativa de la reclasificación de cada entidad con respecto al incremento nacional urbano debido a la reclasificación de localidades urbanas.

d Presenta una diferencia de 11168 habitantes con respecto al cálculo hecho con las cifras nacionales. Esto se debió a la decisión de considerar estadísticamente, en 1950, como mixta urbana -entre 10 y 15000 habitantes- una localidad del estado de México, integrada ese año al área urbana de la ciudad de México. 
Asimismo, la expansión física de algunas ciudades importantes del pais contribuyó al incremento bruto de la población urbana de sus respectivas entidades, destacando las anteriormente mencionadas, así como Chihuahua (Chihuahua), Guanajuato (León) y San Luis Potosí (San Luis Potosí). En este aspecto, es digno de mención que el área Distrito Federal-Estado de México experimentó del primero al segundo decenios una disminución del $24.5 \%$ al $14.5 \%$. Por otra parte, Nuevo León y Jalisco acusaron aumentos considerables (4.6 \% a $13.9 \%$ y $1.8 \%$ al $6.0 \%$, respectivamente) debido a la acelerada expansión física de las periferias de Monterrey y Guadalajara. Esto señala la manifestación en ambas ciudades de una dinámica ecológica centro-periferia, característica de las metrópolis, tal como se empezó a presenciar en forma patente en la ciudad de México después de 1940.7

\section{Estructura de localidades}

La estructura de localidades a nivel estatal se estudió a través de la distribución del número de localidades por tamaño de población, y la participación porcentual en la población de cada estado, de los grupos rural, mixto y urbano (véanse los cuadros 21 al 23). En 1940, la distribución de localidades por tamaños de población se caracterizaba por un elevado porciento de población en ciudades pequeñas. En cerca de la mitad de las entidades, la población urbana en ciudades pequeñas representaba el $100 \%$ de la población urbana estatal. Asimismo, es importante destacar que la mayoría de los estados carecía de ciudades de tamaño mediano y grande. Por otra parte, el número de localidades urbanas dentro de los estados era muy reducido; sólo siete entidades en ese año tenían 3 o más localidades urbanas. De 1940 a 1960 se observa un aumento del número de centros urbanos en la mayoría de los estados, y al mismo tiempo una disminución de la importancia relativa de las ciudades pequeñas como consecuencia de la expansión de centros urbanos de tamaños superiores.

Al formarse un sistema más amplio de ciudades y una probable disminución en la dispersión de la población, se ha experimentado un aumento de la concentración demográfica del país. En un estudio reciente sobre el tema se determina que la concentración de la población de México ha venido aumentando de 1930 a 1960 , siendo más patente el fenómeno en 1940-1950.43 Estos resultados, sumados a los antes expuestos sobre la estructura de las ciudades, muestran una creciente concentración territorial de la población mexicana, explicados principalmente por una acelerada concentración intrarregional -a pesar de que las diferencias interregionales sigan siendo mayores- lo cual refleja la formación de polos de crecimiento demográfico adicionales al de la ciudad de México.

* Los cuadros 21 a 23 aparecen al final de este trabajo (pp. 172-182).

$43 \mathrm{El}$ autor de ese trabajo aplica medidas de concentración no paramétricas basadas en conceptos de la teoría de la información, que permiten determinar la concentración demográfica intra e interregional. Véase Pedro Uribe Jr., "Concentración demográfica y estructura urbana: un enfoque vía teoría de la información", DEMOGRAFfa y ECONOMfa, Vol. I, Núm. 2, 1967, pp. 151-180. 


\section{Crecimiento social de la población total y urbana}

Así como al nivel nacional el crecimiento de la población urbana se explica por la transferencia de población- de los grupos rural y mixto hacia el urbano, al nivel estatal se debe a los flujos migratorios intra e interestatales, tanto del campo a las ciudades, como entre ciudades. Esto da lugar a dos tipos de entidades: de atracción y de rechazo.44 Con base en estas categorías y en el signo de los saldos netos migratorios de la población urbana del estado, se forman los siguientes grupos de entidades:

Grupo I: Entidades de atracción con población urbana de atracción (A-A)

Grupo II: Entidades de rechazo con población urbana de atracción (R-A)

Grupo III : Entidades de rechazo con población urbana de rechazo $(R-R)$

Siguiendo esta tipología, las entidades del país se clasifican como se muestra en el cuadro 19.

La agrupación de entidades y los cambios de grupo presentan características interesantes. Se observa, en primer lugar, que las entidades que predominan en el grupo I (A-A) son de elevado nivel de urbanización y -según diversos estudios sobre desarrollo regional de México-45 también de avanzado desarrollo socioeconómico. Tal es el caso de las entidades de la frontera norte, excepto Coahuila, y del Distrito Federal. En el extremo contrario, las entidades del grupo III manifiestan ser de bajo nivel de desarrollo y, en general, con excepción de Aguascalientes, de escasa urbanización. De lo anterior puede deducirse que las entidades que ascienden de grupo probablemente hayan registrado mejoría en su nivel de desarrollo. Jalisco y México -entidades que ascienden al grupo I- son dos casos que parecen confirmar lo anterior. Lo contrario no puede decirse con igual claridad respecto a las entidades que descienden de grupo.

Otro tipo de análisis comparativo de esta agrupación de entidades, con relación a otros factores demográficos previamente estudiados a nivel nacional, presenta algunos resultados interesantes. Con base en los cuadros 19, 21, 22 y 23 , las entidades que tienen mayor proporción de población rural son en su mayoría de rechazo, es decir, corresponden al grupo III (R-R).

44 Las dos categorías mencionadas resultan del signo del saldo neto migratorio. Aunque en esta etapa no fue posible estimar su monto a nivel estatal, por las limitaciones que se presentaron al tratar de aplicar el método de estadísticas vitales -que se utilizó en el caso de las localidades- los cálculos se consideraron confiables solamente para definir el signo del saldo neto migratorio. Para mayores detalles sobre migración interestatal en México, véase Gustavo Cabrera, "La migración interna en México, 1950-1960: aspectos metodológicos y cuantitativos", Demograffa Y Economfa, Vol. I, Núm. 3, pp. 312-367, 1967.

45 Los estudios que se han consultado sobre el particular son: Rangel Contla, op. cit.; P. L. Yates, Desarrolto regional de México, México, Banco de México, $1960 ;$ y M. Huerta Maldonado, "El nivel de vida en México", Revista Mexicana de Sociología, Vol. XXII, Núm. 2, mayo-agosto de 1960, pp. 463-527. 
UNIKEL: URBANIZACIÓN EN MEXICO

Cuadro 19

MÉXICO: ENTIDADES CLASIFICADAS SEGÚN EL SALDO NETO MIGRATORIO DE SU POBLACTON TOTAL Y URBANA, 1940-1960

\begin{tabular}{|c|c|c|c|c|c|}
\hline \multirow[t]{2}{*}{ Entidades } & \multicolumn{2}{|c|}{$\begin{array}{l}\text { Saldo neto migr ato- } \\
\text { rio entidad-urb ano }\end{array}$} & \multirow[t]{2}{*}{ Entidades } & \multicolumn{2}{|c|}{$\begin{array}{l}\text { Saldo neto migrato } \\
\text { rio entidad-urbano }\end{array}$} \\
\hline & $1940-50$ & $1950-60$ & & $1940-50$ & $1950-60$ \\
\hline $\begin{array}{l}\text { Aguascalientes } \\
\text { Baja California Norte } \\
\text { Baja California Sur } \\
\text { Campeche } \\
\text { Colima } \\
\text { Coahuila } \\
\text { Chiapas } \\
\text { Chihuahua } \\
\text { Distrito Federal } \\
\text { Durango } \\
\text { Guanajuato } \\
\text { Guerrero } \\
\text { Hidalgo } \\
\text { Jalisco } \\
\text { México } \\
\text { Michoacán }\end{array}$ & $\begin{array}{l}\text { R-R } \\
\text { A-A } \\
\text { R-R } \\
\text { A-A } \\
\text { A-A } \\
\text { R-A } \\
\text { A-A } \\
\text { A-A } \\
\text { A-A } \\
\text { R-A } \\
\text { R-A } \\
\text { R-A } \\
\text { R-R } \\
\text { R-A } \\
\text { R-A } \\
\text { R-A }\end{array}$ & $\begin{array}{l}\text { R-R } \\
\text { A-A } \\
\text { R-A } \\
\text { R-A } \\
\text { A-A } \\
\text { R-A } \\
\text { A-A } \\
\text { A-A } \\
\text { A-A } \\
\text { R-A } \\
\text { R-A } \\
\text { R-A } \\
\text { R-R } \\
\text { A-A } \\
\text { A-A } \\
\text { R-A }\end{array}$ & $\begin{array}{l}\text { Morelos } \\
\text { Nayarit } \\
\text { Nuevo León } \\
\text { Oaxaca a } \\
\text { Puebla } \\
\text { Querétaro } \\
\text { Quintana Roo b } \\
\text { San Luis Potosí } \\
\text { Sinaloa } \\
\text { Sonora } \\
\text { Tabasco } \\
\text { Tamaulipas } \\
\text { Tlaxcala } \\
\text { Veracruz } \\
\text { Yucatán } \\
\text { Zacatecas }\end{array}$ & $\begin{array}{l}\text { A-A } \\
\text { A-A } \\
\text { A-A } \\
- \\
\text { A-A } \\
\text { R-A } \\
- \\
\text { R-A } \\
\text { R-A } \\
\text { A-A } \\
\text { R-A } \\
\text { A-A } \\
\text { R-A } \\
\text { A-A } \\
\text { R-A } \\
\text { R-R }\end{array}$ & $\begin{array}{l}\text { A-A } \\
\text { R-A } \\
\mathbf{A}-\mathbf{A} \\
- \\
\text { R-A } \\
\text { R-A } \\
- \\
\text { R-R } \\
\text { R-A } \\
\text { A-A } \\
\text { R-A } \\
\text { A-A } \\
\text { R-R } \\
\text { A-A } \\
\text { R-R } \\
\text { R-R }\end{array}$ \\
\hline
\end{tabular}

a No se dispuso de datos de estadísticas vitales a nivel municipal.

b No contaba con población urbana.

Por otra parte, las variaciones en la proporción de población mixta muestran patrones bastante definidos. A nivel nacional esta proporción de población no varió en forma significativa (véanse los cuadros 21 y 23 ); en cambio, en las entidades $R-R$ hubo variaciones claramente identificables. En 1940, Ia proporción de población mixta en estas entidades estaba muy abajo del promedio nacional, mientras que en 1960, su valor relativo aumentó sustancialmente, sobrepasando en casi todas las entidades el promedio nacional. Asimismo, las variaciones en el número de localidades mixtas en cada entidad confirman aún más esta situación, puesto que las entidades $R-R$ experimentaron un aumento tres veces mayor que el incremento nacional ( $246 \%$ y $75.4 \%$, respectivamente). Lo anterior expresa que las entidades R-R, en general de estructura urbana escasa e "inmadura" (de alto índice de primacía), manifiestan la posibilidad de reforzar su sistema urbano mediante ciudades pequeñas. Este fenómeno no se produce con la misma regularidad en las entidades R-A y A-A, pues al comparar sus valores con el promedio nacional se observan variaciones sustanciales en uno y otro sentido.

Se ha observado también cierta relación entre la mencionada agrupación de entidades y el monto de la población. Las entidades A-A (1940-1960) abarcan el $43 \%$ de las 12 entidades que en 1960 sobrepasaban el millón de habitantes (véanse los cuadros 19 y 23). Esta proporción desciende al $21.4 \%$ y al $7.1 \%$ en los grupos R-A y R-R, respectivamente. De aquí se plantea, aunque débilmente, que las entida- 
des más pobladas son las de mayor atracción tanto a nivel estatal como urbano.

Del análisis realizado se desprende que el comportamiento de las entidades A-A y R-R - los dos extremos de la escala- es más estable que el mostrado por las clasificadas como R-A o que el de aquellas que cambian de grupo. Sin embargo, no se manifiestan patrones de comportamiento regionales claramente definidos, excepto en lo concerniente a la relación demográfica y el desarrollo económico.

Los resultados de este trabajo serán complementados y analizados correlativamente en los proyectos de las próximas etapas del programa de investigación. Asimismo, los supuestos e hipótesis planteados se podrán probar o fundamentar de manera más categórica a medida que los estudios programados en adición a este análisis demográfico-espacial aporten elementos de juicio, en mayor número y detalle, sobre este complejo proceso de cambio social.

\section{CONCLUSIONES GENERALES}

1. El nivel de urbanización de México en 1960 se acerca al observado en los países desarrollados en su conjunto.

2. La tasa de crecimiento de la población total y la tasa de urbanización de México están situadas entre las más elevadas del mundo, lo cual explica que se haya alcanzado este "nivel" en un periodo de tiempo menor que el requerido por los países hoy desarrollados.

3. El nivel de urbanización del país casi se duplicó de 1940 a 1960 . Ello se debió al elevado crecimiento de la población urbana con respecto a la total, destacando el crecimiento de las 17 áreas urbanas de 100000 y más habitantes en 1960, y en particular el área urbana de la ciudad de México.

4. El elevado incremento de la población urbana del país se ha debido, en el primer decenio estudiado, principalmente a las altas tasas de migración campo-ciudad; en el segundo decenio, fundamentalmente, a las tasas de crecimiento natural.

5. El crecimiento de la población urbana se debió básicamente al incremento experimentado por las ciudades existentes al inicio de los decenios analizados. Sin embargo, no deja de ser una característica significativa del proceso de urbanización en México el que las localidades que adquirieron la categoría de urbanas por reclasificación hayan participado con el $19.2 \%$ y el $13.8 \%$ en el primero y segundo decenios, respectivamente, en el citado incremento bruto de la población urbana.

6. La expansión física de las principales ciudades del país constituye otro rasgo del "proceso" que debe tomarse en cuenta, por cuanto que siendo un fenómeno característico de las metrópolis en países avanzados y altamente urbanizados, empieza a manifestarse y difundirse en el país. Este proceso ecológico ha sido patente en la ciudad de México, el cual participó con el $10.2 \%$ y el $5.2 \%$ en el incremento bruto de la población urbana del país.

7. Una de las manifestaciones más notables del proceso de urbanización en México de 1940 a 1960 ha sido el aumento cercano al doble en el número de localidades urbanas y más del triple en las ciudades 
de 100000 y más habitantes. A pesar de este fenómeno, México mantiene una estructura de localidades rurales sumamente dispersa, en especial en aquellas menores de 1000 habitantes.

8. La estructura urbana de México se clasifica como preeminente, pero ha experimentado en el período estudiado una tendencia hacia un sistema de ciudades de naturaleza "intermedia", resultado de la formación de ciudades de importancia regional.

9. El proceso de urbanización en México experimentó entre ambos decenios cambios importantes en todas las características analizadas: desaceleración de la tasa de urbanización; disminución de la tasa de incremento de la población urbana; cambio en el peso de los componentes del crecimiento urbano; disminución en términos relativos del crecimiento urbano por reclasificación e integración; y se redujo la importancia relativa de la ciudad de México en el crecimiento de la población. Todo esto indica que en este período se observó un punto de inflexión en el proceso de urbanización.

10. El proceso de urbanización se está difundiendo en el ámbito nacional; sin embargo, las desigualdades regionales en el "nivel" se han acentuado.

11. Las entidades que han permanecido en 1960 con más bajo nivel de urbanización son las de escaso desarrollo económico. En forma menos clara, las entidades más urbanizadas corresponden a las de mayor nivel de desarrollo. En el primer grupo se presentan por lo general las entidades de atracción (A-A), y en el segundo las de rechazo (R-R). 
Cuadro 20

México: Población e incrementos medios anUales de las localidades urbanas EN 1960, POR ENTIDAD FEDERATIVA, 1940-1960

\begin{tabular}{|c|c|c|c|c|c|c|c|c|c|c|c|}
\hline \multirow{3}{*}{$\begin{array}{l}\text { Entidades } \\
\text { y oiudades }\end{array}$} & \multirow{2}{*}{\multicolumn{3}{|c|}{ Población }} & \multicolumn{6}{|c|}{ Incremento medio anual b/ } & \multirow{2}{*}{\multicolumn{2}{|c|}{ Clase c/ }} \\
\hline & & & & \multicolumn{3}{|c|}{$1940-1950$} & \multicolumn{3}{|c|}{$1950-1960$} & & \\
\hline & 1940 & 1950 & 1960 & Total & $\begin{array}{l}\text { Natu } \\
\text { rai }\end{array}$ & $\begin{array}{l}\text { So- } \\
\text { cial }\end{array}$ & Total & Natu & $\begin{array}{l}\text { So- } \\
\text { cial }\end{array}$ & $\begin{array}{l}1940 \\
1950\end{array}$ & $\begin{array}{l}1950 \\
1960\end{array}$ \\
\hline Total naojonal d & $4564 \quad 359$ & 7666041 & $12746 \quad 685$ & 4.9 & $\underline{2.1}$ & $\underline{2.8}$ & 4.8 & 3.1 & 1.7 & & \\
\hline$\frac{\text { Aguascalienteg }}{\text { 1. Aguascalíentes }}$ & $\frac{82 \quad 234}{82}$ & $\frac{93 \quad 358}{93358}$ & $\frac{126617}{126617}$ & $\frac{1.3}{1.3}$ & $\frac{2.6}{2.6}$ & $\frac{-1.3}{-1.3}$ & $\frac{3.0}{3.0}$ & $\frac{3.4}{3.4}$ & $\frac{-0.4}{-0.4}$ & $\mathrm{RE}$ & RN \\
\hline $\begin{array}{l}\text { Baja California Norte } \\
\text { 2. Mexicali } \\
\text { 3. Ti juana } \\
\text { 4. Ensenada }\end{array}$ & $\begin{array}{r}39877 \\
18 \\
16775 \\
4616\end{array}$ & $\begin{array}{ll}143 & 851 \\
65 & 749 \\
59 & 952 \\
18 & 150\end{array}$ & 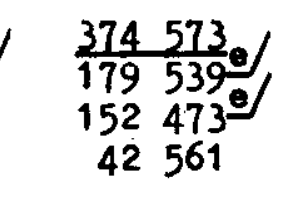 & $\begin{array}{l}\frac{11.3}{11.0} \\
11.4 \\
12.9\end{array}$ & $\begin{array}{l}\frac{2.6}{2.8} \\
2.3 \\
3.3\end{array}$ & $\begin{array}{l}\frac{8.6}{8.3} \\
9.1 \\
8.6\end{array}$ & $\begin{array}{l}8.8 \\
9.1 \\
8.7 \\
8.0\end{array}$ & $\begin{array}{l}\frac{4.0}{4.2} \\
3.9 \\
3.5\end{array}$ & $\begin{array}{l}4.8 \\
4.9 \\
4.8 \\
4.5\end{array}$ & $\begin{array}{l}\text { ANE } \\
\text { ANE } \\
\text { MNE }\end{array}$ & $\begin{array}{l}\text { AME } \\
\text { AME } \\
\text { AME }\end{array}$ \\
\hline$\frac{\text { Baja California Sur }}{5 . \text { La Paz }}$ & $\frac{10401}{10401}$ & $\frac{13071}{13071}$ & $\frac{24253}{24253}$ & $\frac{2.3}{2.3}$ & $\frac{3.2}{3.2}$ & $\frac{-0.9}{-0.9}$ & $\frac{6.0}{6.0}$ & $\frac{3.8}{3.8}$ & $\frac{2.2}{2.2}$ & RM & $\mathbf{A E}$ \\
\hline $\begin{array}{l}\frac{\text { Campeche }}{6 . \text { Campeche }} \\
\text { 7. Ciudad deI Carmen }\end{array}$ & $\begin{array}{rr}30 & 964 \\
23 & 277 \\
7 & 687\end{array}$ & $\begin{array}{l}42875 \\
31272 \\
11603\end{array}$ & $\begin{array}{l}65038 \\
43874 \\
21164\end{array}$ & $\begin{array}{l}\frac{3.2}{2.9} \\
4.1\end{array}$ & $\begin{array}{l}\frac{2.9}{3.0} \\
2.6\end{array}$ & $\begin{array}{r}\frac{0.3}{-0.1} \\
1.5\end{array}$ & $\begin{array}{l}\frac{4.1}{3.4} \\
5.8\end{array}$ & $\begin{array}{l}\frac{3.7}{3.6} \\
3.9\end{array}$ & $\begin{array}{r}\frac{0.5}{-0.2} \\
1.9\end{array}$ & $\begin{array}{l}\mathrm{RM} \\
\mathrm{AS}\end{array}$ & $\begin{array}{l}\mathrm{RU} \\
\boldsymbol{N}\end{array}$ \\
\hline \multirow[t]{2}{*}{$\begin{array}{l}\text { Coahuilag/ } \\
\text { 8. Torreonf/ } \\
\text { 9. Saltillo } \\
\text { 10. Piedras Negras } \\
\text { 11. Monclova } \\
\text { 12. Nueva Rosita } \\
\text { 13. San Pedro de las } \\
\text { Colonias }\end{array}$} & $\begin{array}{rr}217 & 321 \\
101 & 354 \\
49 & 430 \\
15 & 663 \\
7 & 181 \\
25 & 551\end{array}$ & $\begin{array}{rr}335 & 494 \\
188 & 203 \\
69 & 842 \\
27 & 581 \\
19 & 049 \\
29 & 625\end{array}$ & $\begin{array}{rr}486 & 756 \\
263 & 564 \\
98 & 839 \\
44 & 992 \\
43 & 077 \\
34 & 302\end{array}$ & $\begin{array}{l}4.3 \\
5.2 \\
3.4 \\
5.5 \\
9.0 \\
1.5\end{array}$ & $\begin{array}{l}\frac{3.2}{3.1} \\
3.7 \\
2.7 \\
3.2 \\
2.6\end{array}$ & $\begin{array}{r}\frac{1.1}{2.1} \\
-0.3 \\
2.8 \\
5.8 \\
-1.1\end{array}$ & $\begin{array}{l}\frac{3.6}{3.2} \\
3.4 \\
4.8 \\
7.7 \\
1.5\end{array}$ & $\begin{array}{l}3.4 \\
3.5 \\
3.3 \\
3.1 \\
3.6 \\
3.4\end{array}$ & $\begin{array}{r}0.2 \\
-0.3 \\
0.1 \\
1.7 \\
4.1 \\
-1.9\end{array}$ & $\begin{array}{l}\mathbf{A E} \\
\mathrm{RM} \\
\mathbf{A R} \\
\mathbf{A M E} \\
\mathrm{RE}\end{array}$ & $\begin{array}{c}\mathrm{RM} \\
\mathbf{A N} \\
\mathbf{A E} \\
\mathbf{A M E} \\
\mathbf{R E}\end{array}$ \\
\hline & 15713 & 19258 & 26018 & 2.0 & 3.8 & -1.7 & 3.0 & 3.6 & -0.6 & $\begin{array}{l}\mathrm{RE} \\
\text { (cor }\end{array}$ & $\begin{array}{c}\text { RM } \\
\text { tinúa) }\end{array}$ \\
\hline
\end{tabular}


Cuadro 20 (continuación)

\begin{tabular}{|c|c|c|c|c|c|c|c|c|c|c|c|}
\hline \multirow{3}{*}{$\begin{array}{l}\text { Entidades } \\
\text { y ciudades }\end{array}$} & \multirow{2}{*}{\multicolumn{3}{|c|}{ Población a/ }} & \multicolumn{6}{|c|}{ Incremento medio anual b } & \multirow{2}{*}{\multicolumn{2}{|c|}{ Clase of }} \\
\hline & & & & \multicolumn{3}{|c|}{$1940-1950$} & \multicolumn{3}{|c|}{$1950-1960$} & & \\
\hline & 1940 & 1950 & 1960 & Total & Natu & So- & Total & Natu & $\begin{array}{c}\text { Sot } \\
\text { cial }\end{array}$ & $\begin{array}{l}1940 \\
1950\end{array}$ & $\begin{array}{l}1950 \\
1960\end{array}$ \\
\hline $\begin{array}{l}\text { 14. Villa Aouña } \\
\text { 15. Parras de la Fuente } \\
\text { 16. Sabinas }\end{array}$ & $\begin{array}{rl}5 & 607 \\
15 & 555 \\
6 & 825\end{array}$ & $\begin{array}{ll}11 & 372 \\
18 & 547 \\
11 & 249\end{array}$ & $\begin{array}{ll}20 & 048 \\
19 & 768 \\
16 & 076\end{array}$ & $\begin{array}{l}6.8 \\
1.8 \\
4.9\end{array}$ & $\begin{array}{l}2.8 \\
3.4 \\
3.0\end{array}$ & $\begin{array}{r}4.0 \\
-1.6 \\
1.9\end{array}$ & $\begin{array}{l}5.5 \\
0.6 \\
3.5\end{array}$ & $\begin{array}{l}3.2 \\
3.2 \\
3.4\end{array}$ & $\begin{array}{r}2.3 \\
-2.6 \\
0.1\end{array}$ & $\begin{array}{l}A B \\
R E\end{array}$ & $\begin{array}{l}\text { AN } \\
\text { RME } \\
\text { AM }\end{array}$ \\
\hline $\begin{array}{l}\text { Colima } \\
\text { 17. Colima } \\
\text { 18. Manzanillo } \\
\text { 19. Tecomán }\end{array}$ & $\begin{array}{rr}32 & 727 \\
22 & 601 \\
6 & 831 \\
3 & 295\end{array}$ & $\begin{array}{ll}\frac{52}{2} & 842 \\
32 & 619\end{array}$ & $\begin{array}{ll}83879 \\
47767 \\
19950 \\
16162\end{array}$ & $\begin{array}{l}\frac{4.1}{2.8} \\
6.2 \\
7.5\end{array}$ & $\begin{array}{l}\frac{2.2}{2.4} \\
2.0 \\
1.8\end{array}$ & $\begin{array}{l}1.9 \\
0.4 \\
4.2 \\
5.7\end{array}$ & $\begin{array}{l}\frac{4.6}{3.9} \\
4.2 \\
7.7\end{array}$ & $\begin{array}{l}4.2 \\
5.0 \\
3.2 \\
3.2\end{array}$ & $\begin{array}{r}-\frac{0.4}{-1.1} \\
1.0 \\
4.5\end{array}$ & $\begin{array}{l}A M \\
A M E \\
A B S\end{array}$ & $\begin{array}{l}\text { RE } \\
\text { AN } \\
\text { AMS }\end{array}$ \\
\hline $\begin{array}{l}\text { Chiapas } \\
20 . \text { Tapachula } \\
\text { 21. Tuxtla Gutiorrez } \\
\text { 22. San Cristobal de las }\end{array}$ & $\begin{array}{ll}\frac{51}{15} 521 \\
15 & 187 \\
15883\end{array}$ & $\begin{array}{l}87 \quad 459 \\
29990 \\
28243\end{array}$ & $\begin{array}{l}121574 \\
41578 \\
41244\end{array}$ & $\begin{array}{l}\frac{5.2}{6.6} \\
5.6\end{array}$ & $\begin{array}{l}\frac{1.7}{1.5} \\
2.6\end{array}$ & $\begin{array}{l}\frac{3.4}{5.1} \\
3.0\end{array}$ & $\begin{array}{l}\frac{3.3}{3.2} \\
3.7\end{array}$ & $\begin{array}{l}\frac{2.8}{2.6} \\
3.0\end{array}$ & $\begin{array}{l}0.5 \\
0.6 \\
0.7\end{array}$ & $\underset{\Delta S}{\Delta S}$ & $\underset{N \mathbf{M}}{\mathbf{M H}}$ \\
\hline 23. Camitán de Domfrnguez & $\begin{aligned} 11768 \\
8683\end{aligned}$ & $\begin{array}{ll}17473 \\
11753\end{array}$ & $\begin{array}{ll}23 & 343 \\
15 & 409\end{array}$ & $\begin{array}{l}3.9 \\
3.0\end{array}$ & $\begin{array}{l}0.7 \\
2.1\end{array}$ & $\begin{array}{l}3.2 \\
0.9\end{array}$ & $\begin{array}{l}2.9 \\
2.7\end{array}$ & $\begin{array}{l}2.8 \\
2.8\end{array}$ & $\begin{array}{r}0.1 \\
-0.1\end{array}$ & is & $\underset{\mathrm{RM}}{\mathrm{AM}}$ \\
\hline $\begin{array}{l}\text { Chihuahua } \\
24 . \text { Ciudad Juarez } \\
25 . \text { Chihuahua } \\
26 \text {. Hidalgo del Parral } \\
\text { 27. Delicias } \\
\text { 28. Ciudad Camargo } \\
\text { 29. Santa Bárbara }\end{array}$ & $\begin{array}{rl}157 & 544 \\
48881 \\
56805 \\
24231 \\
6020 \\
7705 \\
13902\end{array}$ & $\begin{array}{rl}286 & 672 \\
122 & 566 \\
87 & 000 \\
32 & 063 \\
18 & 290 \\
11 & 945 \\
14 & 808\end{array}$ & $\begin{array}{l}536698 \\
262119 \\
158.389 \\
41474 \\
39919 \\
18951 \\
15846\end{array}$ & $\begin{array}{r}5.8 \\
8.6 \\
4.2 \\
2.8 \\
10.1 \\
4.3 \\
0.6\end{array}$ & $\begin{array}{l}2.2 \\
1.9 \\
2.2 \\
2.2 \\
3.3 \\
3.1 \\
2.4\end{array}$ & $\begin{array}{r}\frac{3.6}{6.7} \\
2.0 \\
0.6 \\
6.8 \\
1.2 \\
-1.8\end{array}$ & $\begin{array}{l}6.0 \\
7.3 \\
5.7 \\
2.6 \\
7.4 \\
4.5 \\
0.7\end{array}$ & $\begin{array}{l}\frac{3.0}{2.8} \\
2.9 \\
3.5 \\
3.1 \\
3.4 \\
3.5\end{array}$ & $\begin{array}{r}3.0 \\
4.4 \\
2.8 \\
-0.9 \\
4.3 \\
1.1 \\
-2.8\end{array}$ & 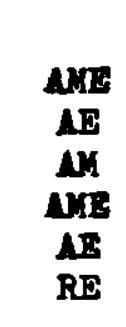 & $\begin{array}{l}\text { ANE } \\
\text { AEE } \\
\text { RUI } \\
\text { NHE } \\
\text { AE } \\
\text { RME }\end{array}$ \\
\hline $\begin{array}{l}\text { Distrito Federal } \mathbb{E} / \\
30 . \text { Ciuded de México } \\
\text { 31. Xochimilgo } \\
\text { Tlalpanh }\end{array}$ & $\begin{array}{r}1584588 \\
1559782 \\
14370 \\
10436\end{array}$ & 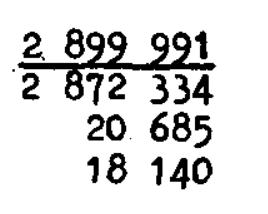 & $\begin{array}{c}4707153 \\
4909961 \\
30031 \\
-\end{array}$ & $\frac{5.4}{5.4}$ & $\begin{array}{l}\frac{1.7}{1.7} \\
0.9 \\
2.2\end{array}$ & $\begin{array}{l}\frac{3.7}{3.7} \\
2.7 \\
3.2\end{array}$ & $\begin{array}{l}\frac{4.6}{4.9} \\
3.7\end{array}$ & $\begin{array}{l}\frac{3.1}{3.0} \\
2.5 \\
-\end{array}$ & $\begin{array}{l}\frac{1.5}{1.9} \\
1.2 \\
-\end{array}$ & As & $\begin{array}{l}A s \\
\Delta S\end{array}$ \\
\hline$\frac{\text { Durangog/ }}{32 . \text { Durango }}$ & $\frac{68 \quad 319}{33412}$ & $\frac{119101}{59869}$ & $\frac{179364}{99436}$ & 2.4 & $\frac{2.8}{2.5}$ & $\frac{2.6}{3.1}$ & $\frac{3.8}{4.7}$ & $\frac{3.4}{3.3}$ & $\frac{0.4}{1.4}$ & 18 & $\mathbf{A B}$ \\
\hline
\end{tabular}


Cuadro 20 (continuación)

\begin{tabular}{|c|c|c|c|c|c|c|c|c|c|c|c|}
\hline \multirow{3}{*}{$\begin{array}{l}\text { Entidades } \\
\text { y ciudades }\end{array}$} & \multirow{2}{*}{\multicolumn{3}{|c|}{ Población a/ }} & \multicolumn{6}{|c|}{ Incremento medio anual b] } & \multirow{2}{*}{\multicolumn{2}{|c|}{ Clase }} \\
\hline & & & & \multicolumn{3}{|c|}{$1940-1950$} & \multicolumn{3}{|c|}{$1950-1960$} & & \\
\hline & 1940 & 1950 & 1960 & Total & Natul & $\begin{array}{l}\text { So- } \\
\text { cial }\end{array}$ & Total & Natu & $\begin{array}{l}\text { So- } \\
\text { cial }\end{array}$ & $\begin{array}{l}1940 \\
1950\end{array}$ & $\begin{array}{l}1950 \\
1960\end{array}$ \\
\hline $\begin{array}{l}\text { Guana juato } \\
\text { 33. Lebn } \\
\text { 34. Irapuato } \\
\text { 35. Celaya } \\
\text { 36. Salamanca } \\
\text { 37. Guanajuato } \\
\text { 38. Acambaro } \\
\text { 39. Silao } \\
\text { 40. Valle de Santiago } \\
\text { 41. San Franoigco del }\end{array}$ & $\begin{array}{ll}240 & 082 \\
74 & 155 \\
32 & 377 \\
22 & 766 \\
11 & 985 \\
23 & 521 \\
17 & 643 \\
13 & 880 \\
12 & 278\end{array}$ & $\begin{array}{rr}351 & 812 \\
122 & 726 \\
49 & 445 \\
34 & 424 \\
20 & 610 \\
23 & 379 \\
23 & 004 \\
18 & 463 \\
15 & 628\end{array}$ & $\begin{array}{ll}548 & 708 \\
216 & 246 \\
83 & 768 \\
58 & 851 \\
32 & 663 \\
28 & 212 \\
26 & 187 \\
24 & 229 \\
21 & 795\end{array}$ & $\begin{array}{r}\frac{3.8}{4.9} \\
4.2 \\
4.1 \\
5.3 \\
-0.1 \\
2.6 \\
.2 .8 \\
2.4\end{array}$ & $\begin{array}{l}\frac{2.4}{2.9} \\
3.0 \\
2.9 \\
2.7 \\
2.0 \\
3.0 \\
2.6 \\
3.0\end{array}$ & $\begin{array}{r}\frac{0.2}{2.0} \\
1.2 \\
1.2 \\
2.6 \\
-2.1 \\
-0.4 \\
0.2 \\
-0.6\end{array}$ & $\begin{array}{l}\frac{4 \cdot 3}{5 \cdot 2} \\
5 \cdot 1 \\
5 \cdot 2 \\
4 \cdot 5 \\
1.9 \\
1.3 \\
2.7 \\
3 \cdot 3\end{array}$ & $\begin{array}{l}\frac{3.1}{3.0} \\
3.4 \\
2.2 \\
3.5 \\
1.9 \\
3.6 \\
3.3 \\
4.1\end{array}$ & $\begin{array}{r}\frac{1.1}{2.2} \\
1.7 \\
3.0 \\
1.0 \\
0.0 \\
-2.3 \\
-0.6 \\
-0.8\end{array}$ & $\begin{array}{l}A E \\
A E \\
A E \\
A E \\
\text { RME } \\
\text { RM } \\
A M \\
\text { RMI }\end{array}$ & $\begin{array}{l}A E \\
A E \\
A E \\
A M \\
R M \\
R M E \\
R M \\
R M\end{array}$ \\
\hline $\begin{array}{l}\text { Rinoon } \\
\text { 42. Norolebn } \\
\text { 43. Cortazar }\end{array}$ & $\begin{array}{rr}12 & 015 \\
10 & 418 \\
9 & 044\end{array}$ & $\begin{array}{ll}18 & 193 \\
13 & 801 \\
12 & 139\end{array}$ & $\begin{array}{ll}20 & 878 \\
17 & 954 \\
17 & 925\end{array}$ & $\begin{array}{l}4.1 \\
2.8 \\
2.9\end{array}$ & $\begin{array}{l}3.0 \\
2.8 \\
3.2\end{array}$ & $\begin{array}{r}1.1 \\
0.0 \\
-0.3\end{array}$ & $\begin{array}{l}1.4 \\
2.6 \\
3.8\end{array}$ & $\begin{array}{l}3 \cdot 7 \\
3 \cdot 2 \\
4 \cdot 2\end{array}$ & $\begin{array}{l}-2.3 \\
-0.6 \\
-0.4\end{array}$ & $\begin{array}{l}\text { AE } \\
\text { AM }\end{array}$ & $\begin{array}{l}\text { RME } \\
\text { RM } \\
R M\end{array}$ \\
\hline $\begin{array}{l}\text { Guerrero } \\
\text { 44. Acapuloo de Juárez } \\
\text { 45. Iguala } \\
\text { 46: Chilpancingo de Brevo }\end{array}$ & $\begin{array}{r}31.583 \\
9993 \\
12756 \\
8834\end{array}$ & $\begin{array}{ll}60 & 607 \\
28 & 512 \\
19 & 422 \\
12 & 673\end{array}$ & 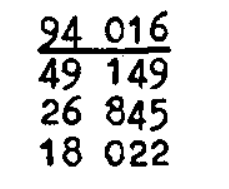 & $\begin{array}{l}\frac{6.3}{9.6} \\
4.1 \\
3.6\end{array}$ & $\begin{array}{l}\frac{2.7}{3.4} \\
2.5 \\
1.7\end{array}$ & $\begin{array}{l}\frac{3.6}{6.2} \\
1.6 \\
1.9\end{array}$ & $\begin{array}{l}\frac{4.3}{5.3} \\
3.2 \\
3.5\end{array}$ & $\begin{array}{l}\frac{4.3}{5.0} \\
3.3 \\
3.9\end{array}$ & $\begin{array}{r}\frac{0.0}{0.3} \\
-0.1 \\
-0.4\end{array}$ & $\begin{array}{l}\mathrm{AME} \\
\mathrm{AE} \\
\mathrm{AE}\end{array}$ & $\begin{array}{l}\text { AM } \\
\mathrm{RM} \\
\mathrm{RM}\end{array}$ \\
\hline $\begin{array}{l}\frac{\text { Hidalso }}{\text { 47. Pachuce }} \\
\text { 48. Tulancingo }\end{array}$ & $\begin{array}{l}65906 \\
\frac{65354}{354} \\
12.552\end{array}$ & $\begin{array}{ll}77 & 187 \\
58 & 658 \\
18 & 529\end{array}$ & $\begin{array}{l}\frac{93}{66} \frac{722}{683} \\
26839\end{array}$ & $\begin{array}{l}\frac{1.6}{1.0} \\
3.8\end{array}$ & $\begin{array}{l}\frac{2.5}{2.7} \\
2.1\end{array}$ & $\begin{array}{r}-0.1 \\
-1.7 \\
1.7\end{array}$ & $\begin{array}{l}\frac{1.7}{1.1} \\
3.7\end{array}$ & $\begin{array}{l}\frac{3.1}{3.3} \\
2.8\end{array}$ & $\begin{array}{r}\frac{-1.4}{-2.2} \\
0.9\end{array}$ & $\begin{array}{l}\mathrm{RE} \\
\mathrm{AE}\end{array}$ & $\mathrm{RMg}$ \\
\hline $\begin{array}{l}\text { Jal1800 } \\
\text { 49. Cradal a jara I } \\
\text { 50. Ciudad Guzmén } \\
\text { 51. Oootlen } \\
\text { 52. Lagos de Moreno } \\
\text { 53. Tepatitlin de Morolos } \\
\text { 54. Aneca } \\
\text { 55. Arandas } \\
\text { 56. Intlan }\end{array}$ & $\begin{array}{rl}343 & 163 \\
240 & 721 \\
22 & 170 \\
14 & 289 \\
12 & 490 \\
8 & 894 \\
13 & 003 \\
7 & 254 \\
10 & 915\end{array}$ & $\begin{array}{rr}518 & 117 \\
401 & 283 \\
23 & 630 \\
16 & 824 \\
13 & 190 \\
15 & 053 \\
13 & 589 \\
9 & 335 \\
11 & 345\end{array}$ & $\begin{array}{rr}979 & 606 \\
811 & 829 \\
30 & 941 \\
25 & 416 \\
23 & 636 \\
19 & 835 \\
17 & 588 \\
17 & 071 \\
17 & 017\end{array}$ & $\begin{array}{l}4.0 \\
4.9 \\
0.6 \\
1.6 \\
0.6 \\
5.1 \\
0.4 \\
2.5 \\
0.4\end{array}$ & $\begin{array}{l}\frac{2.1}{1.9} \\
1.7 \\
3.0 \\
3.4 \\
3.3 \\
2.4 \\
3.6 \\
2.0\end{array}$ & $\begin{array}{r}\frac{1.9}{3.0} \\
-1.1 \\
-1.4 \\
-2.8 \\
1.8 \\
-2.0 \\
-1.1\end{array}$ & $\begin{array}{l}5.9 \\
6.4 \\
2.7 \\
4.1 \\
5.7 \\
2.8 \\
2.6 \\
5.9\end{array}$ & $\begin{array}{l}\frac{2.9}{2.7} \\
2.8 \\
3.6 \\
3.9 \\
3.7 \\
3.2 \\
3.3\end{array}$ & $\begin{array}{r}\frac{3.0}{3.7} \\
-0.1 \\
0.5 \\
1.8 \\
-1.0 \\
-0.6 \\
2.6\end{array}$ & $\begin{array}{c}A E \\
R E \\
R E \\
R M E \\
A E \\
R E \\
R E\end{array}$ & $\begin{array}{l}A D \\
R M \\
A M \\
A M \\
R M \\
R M \\
A D\end{array}$ \\
\hline 57. La Baros & 13427 & 13868 & 16273 & $\begin{array}{l}0.4 \\
0.3\end{array}$ & $\begin{array}{l}2.9 \\
3.2\end{array}$ & $\begin{array}{l}-2.5 \\
-2.9\end{array}$ & $\begin{array}{l}4.0 \\
1.6\end{array}$ & $\begin{array}{l}3.4 \\
3.7\end{array}$ & $\begin{array}{r}0.6 \\
-2.1\end{array}$ & $\begin{array}{l}\text { RME } \\
\text { RME }\end{array}$ & $\underset{\mathrm{RME}}{\Delta M}$ \\
\hline
\end{tabular}

(continúa) 
Cuadro 20 (continuación)




Cuadro 20 (continuación)

\begin{tabular}{|c|c|c|c|c|c|c|c|c|c|c|c|}
\hline \multirow{3}{*}{$\begin{array}{l}\text { Entidades } \\
\text { y ciudades }\end{array}$} & \multirow{2}{*}{\multicolumn{3}{|c|}{ Población }} & \multicolumn{6}{|c|}{ Incremento medio anual b] } & \multirow{2}{*}{\multicolumn{2}{|c|}{ clase of }} \\
\hline & & & & \multicolumn{3}{|c|}{$1940-1950$} & \multicolumn{3}{|c|}{$1950-1960$} & & \\
\hline & 1940 & 1950 & 1960 & Total & $\begin{array}{l}\text { Natu } \\
\text { raI }\end{array}$ & Som & Total & Natu & $\begin{array}{l}\text { Sow } \\
\text { oial. }\end{array}$ & $\begin{array}{l}1940 \\
1950\end{array}$ & $\begin{array}{l}1950 \\
1960\end{array}$ \\
\hline $\begin{array}{l}\text { Puebla } \\
74 . \text { Puebla } \\
75 . \text { Tehuacán } \\
\text { 76. Atlixco } \\
\text { 77. Teziutlán } \\
78 \text {. Izúcar de Matamoros }\end{array}$ & $\begin{array}{rr}187 & 254 \\
138 & 491 \\
16 & 278 \\
17 & 034 \\
8 & 386 \\
7 & 065\end{array}$ & $\begin{aligned} & 289610 \\
& 226646 \text { / } \\
& 23209 \\
& 15622 \\
& 13536 \\
& 10597\end{aligned}$ & $\begin{array}{l}401972 \\
305469 \\
31897 \\
30650 \\
17400 \\
16556\end{array}$ & $\begin{array}{r}4.0 \\
4.5 \\
3.5 \\
-0.9 \\
4.7 \\
4.0\end{array}$ & $\begin{array}{l}1.0 \\
0.9 \\
0.9 \\
1.5 \\
1.6 \\
1.0\end{array}$ & $\begin{array}{r}\frac{3.1}{3.6} \\
2.6 \\
-2.4 \\
3.1 \\
3.0\end{array}$ & $\begin{array}{l}\frac{3.0}{2.6} \\
3.2 \\
6.5 \\
2.5 \\
4.4\end{array}$ & $\begin{array}{l}\frac{2.0}{1.8} \\
2.1 \\
2.7 \\
2.7 \\
2.1\end{array}$ & $\begin{array}{r}1.0 \\
0.8 \\
1.1 \\
3.8 \\
-0.2 \\
2.3\end{array}$ & $\begin{array}{c}\mathbf{N S} \\
\mathbf{A S} \\
\mathbf{R H E} \\
\mathbf{N B}\end{array}$ & $\begin{array}{l}M / \\
A B \\
A B \\
R K \\
A B\end{array}$ \\
\hline$\frac{\text { Querétaro }}{79 . \text { Querétaro }}$ & $\frac{33629}{33629}$ & $\frac{49440}{49440} \mathrm{e}$ & $\frac{69058}{69058} e /$ & $\frac{3.8}{3.8}$ & $\frac{2.1}{2.1}$ & $\frac{1.7}{1.7}$ & $\frac{3.1}{3.1}$ & $\frac{2.7}{2.7}$ & $\frac{0.4}{0.4}$ & $\mathbf{A B}$ & $\Delta$ \\
\hline $\begin{array}{l}\text { San Luis Potosi } \\
80 . \text { San Luis Potosi } \\
81 . \text { Ciudad Valles } \\
\text { 82. Matehuala }\end{array}$ & $\begin{array}{rr}100 & 949 \\
77 & 161 \\
7 & 240 \\
16 & 548\end{array}$ & $\begin{array}{rl}160 & 260 \\
131 & 715 \\
14 & 382 \\
14 & 163\end{array}$ & $\begin{array}{l}\frac{216082}{172332} \mathrm{~J} \\
23823 \\
19927\end{array}$ & $\begin{array}{r}\frac{4.3}{4.9} \\
6.6 \\
-1.6\end{array}$ & $\begin{array}{l}\frac{2.3}{2.3} \\
2.8 \\
2.5\end{array}$ & $\begin{array}{r}\frac{2.0}{2.6} \\
3.8 \\
-4.1\end{array}$ & $\begin{array}{l}\frac{2.7}{2.3} \\
4.9 \\
3.4\end{array}$ & $\begin{array}{l}\frac{3.2}{3.2} \\
3.4 \\
2.5\end{array}$ & $\begin{array}{r}-0.5 \\
-0.9 \\
1.5 \\
0.9\end{array}$ & $\begin{array}{c}\mathbf{A R} \\
\mathbf{A R} \\
\mathrm{RME}\end{array}$ & $\begin{array}{l}\mathbf{B M} \\
\mathbf{A R} \\
\Delta \mathbf{I}\end{array}$ \\
\hline $\begin{array}{l}\frac{\text { Sinaloa }}{83 . \text { Culiacán }} \\
\text { 84. Mazatlán } \\
\text { 85. Los Mochis } \\
\text { 86. Guasave }\end{array}$ & $\begin{array}{rl}67 & 079 \\
22 & 025 \\
32 & 117 \\
12 & 937 \\
4 & 997\end{array}$ & $\begin{array}{rl}120 & 748 \\
48 & 936 \\
41 & 754 \\
21 & 552 \\
8 & 506\end{array}$ & $\begin{array}{l}\frac{217715}{85024} \\
76874^{e} \\
38307 \\
17510\end{array}$ & $\begin{array}{l}5.1 \\
7.6 \\
2.6 \\
5.0 \\
5.2\end{array}$ & $\begin{array}{l}\frac{2.6}{2.6} \\
2.1 \\
3.3 \\
3.6\end{array}$ & $\begin{array}{l}2.5 \\
5.0 \\
0.5 \\
1.7 \\
1.6\end{array}$ & $\begin{array}{l}5.7 \\
5.4 \\
5.8 \\
5.6 \\
6.9\end{array}$ & $\begin{array}{l}3.4 \\
3.9 \\
2.8 \\
3.7 \\
3.3\end{array}$ & $\begin{array}{l}\frac{2.3}{1.5} \\
3.0 \\
1.9 \\
3.6\end{array}$ & $\begin{array}{l}\text { MME } \\
\dot{A M} \\
\mathrm{AE} \\
\mathrm{AE}\end{array}$ & 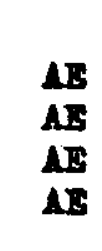 \\
\hline $\begin{array}{l}\text { Sonora } \\
\text { 87. Hermosillo } \\
\text { 88. Ciudad Cbregón } \\
\text { 89. Nogales } \\
\text { 90. Guaymas } \\
\text { 91. Navojoa } \\
\text { 92. San Luis Rio Colorado } \\
\text { 93. Cananea } \\
\text { 94. Erpalme } \\
\text { 95. Ngua Prieta }\end{array}$ & $\begin{array}{rl}85 & 142 \\
18 & 601 \\
12 & 497 \\
13 & 866 \\
8 & 796 \\
11 & 009 \\
& .558 \\
11 & 006 \\
4 & 703 \\
4 & 106\end{array}$ & $\begin{array}{rr}178 & 044 \\
43 & 519 \\
30 & 991 \\
24 & 478 \\
18 & 890 \\
17 & 345 \\
4 & 079 \\
17 & 892 \\
10 & 379 \\
10 & 471\end{array}$ & $\begin{array}{ll}\frac{349}{408} & 58 \text { / } \\
96 & c 19 \\
67 & 956 \\
37 & 657 \\
34 & 865 \\
30 & 560 \\
28 & 545 \\
19683 \\
18964 \\
15339\end{array}$ & $\begin{array}{r}7.1 \\
8.0 \\
8.5 \\
5.5 \\
7.3 \\
4.5 \\
15.2 \\
4.8 \\
7.5 \\
8.7\end{array}$ & $\begin{array}{l}\frac{3.1}{3.0} \\
3.4 \\
2.5 \\
2.8 \\
3.2 \\
1.7 \\
4.1 \\
2.8 \\
2.5\end{array}$ & $\begin{array}{r}\frac{4.0}{5.0} \\
5.1 \\
3.0 \\
4.5 \\
1.3 \\
13.5 \\
0.7 \\
4.7 \\
6.2\end{array}$ & $\begin{array}{l}6.5 \\
7.5 \\
7.5 \\
4.2 \\
5.9 \\
5.5 \\
15.0 \\
1.0 \\
5.8 \\
3.8\end{array}$ & $\begin{array}{l}\frac{3.9}{3.8} \\
4.3 \\
3.4 \\
4.1 \\
3.8 \\
4.8 \\
3.4 \\
4.1 \\
3.5\end{array}$ & $\begin{array}{r}\frac{2.6}{3.7} \\
3.2 \\
0.8 \\
1.8 \\
1.7 \\
10.2 \\
-2.4 \\
1.7 \\
0.3\end{array}$ & $\begin{array}{c}\text { AME } \\
\text { AYE } \\
\text { AH } \\
\text { AYS } \\
\text { AM } \\
\text { AME } \\
\text { AM } \\
\text { AME } \\
\text { AME }\end{array}$ &  \\
\hline
\end{tabular}

(continúa) 
Cuadro 20 (continuación)

\begin{tabular}{|c|c|c|c|c|c|c|c|c|c|c|c|}
\hline \multirow{3}{*}{$\begin{array}{l}\text { Entidades } \\
\text { y ciudades }\end{array}$} & \multirow{2}{*}{\multicolumn{3}{|c|}{ Población a/ }} & \multicolumn{6}{|c|}{ Incremento medio anual b } & \multirow{2}{*}{\multicolumn{2}{|c|}{ Clase }} \\
\hline & & & & \multicolumn{3}{|c|}{$1940-1950$} & \multicolumn{3}{|c|}{$1950-1960$} & & \\
\hline & 1940 & 1950 & 1960 & Total & $\underset{\mathrm{ral}}{\mathrm{Natu}}$ & so- & Total & $\begin{array}{l}\text { Natu- } \\
\text { ral }\end{array}$ & $\begin{array}{l}\text { So- } \\
\text { cial }\end{array}$ & $\begin{array}{l}1940 \\
1950\end{array}$ & $\begin{array}{l}1950 \\
1960\end{array}$ \\
\hline$\frac{\text { Tabasco }}{96 \cdot V i l l a h e r m o s a}$ & $\frac{25114}{25114}$ & $\frac{35418}{35418} \Theta$ & $\frac{55 \quad 360}{55 \quad 360} \mathrm{e} /$ & $\frac{3.2}{3.2}$ & $\frac{1.9}{1.9}$ & $\frac{1 \cdot 3}{1 \cdot 3}$ & $\frac{4 \cdot 4}{4 \cdot 4}$ & $\frac{2.8}{2.8}$ & $\frac{1.6}{1.6}$ & $\mathrm{AE}$ & $\mathrm{As}$ \\
\hline $\begin{array}{l}\text { Tamaulipas } \\
\text { 97. Tampico } \\
\text { 98. Nuevo Laredo } \\
\text { 99. Matamoros } \\
\text { 100. Reynosa } \\
\text { 101. Ciudad Victoria } \\
\text { 102. Ciudad Mante } \\
\text { 103. Rio Bravo } \\
\text { 104. Valle Hermoso }\end{array}$ & $\begin{array}{rr}193 & 685 \\
110 & 550 \\
28 & 872 \\
15 & 699 \\
9 & 412 \\
19 & 513 \\
8 & 616 \\
& 936 \\
& 87\end{array}$ & $\begin{array}{rl}337 & 761 \\
135 & 419 \\
57 & 668 \\
45 & 846 \\
34 & 087 \\
31 & 815 \\
21 & 291 \\
4 & 610 \\
7 & 025\end{array}$ & $\begin{array}{rl}542 & 242 \\
176 & 163 \\
92 & 627 \\
92 & 327 \\
74 & 140 \\
50 & 797 \\
22 & 919 \\
17 & 500 \\
15 & 769\end{array}$ & $\begin{array}{r}5.4 \\
2.0 \\
6.6 \\
9.8 \\
11.3 \\
4.8 \\
8.5 \\
13.2 \\
19.5\end{array}$ & $\begin{array}{l}\frac{2.2}{2.0} \\
2.0 \\
2.4 \\
2.5 \\
2.9 \\
2.8 \\
2.5 \\
2.4\end{array}$ & $\begin{array}{l}3.2 \\
0.0 \\
4.6 \\
7.4 \\
8.8 \\
1.9 \\
5.7 \\
10.7 \\
17.1\end{array}$ & $\begin{array}{r}4.6 \\
2.6 \\
4.6 \\
6.7 \\
7.4 \\
4.6 \\
0.7 \\
11.7 \\
7.7\end{array}$ & $\begin{array}{l}\frac{3.3}{2.9} \\
3.0 \\
3.9 \\
3.9 \\
3.2 \\
3.1 \\
3.9 \\
3.9\end{array}$ & $\begin{array}{r}1.3 \\
-0.3 \\
1.6 \\
2.8 \\
3.5 \\
1.4 \\
-2.4 \\
7.8 \\
3.8\end{array}$ & $\begin{array}{l}\text { AM } \\
\text { AME } \\
\text { AME } \\
\text { AME } \\
\text { AE } \\
\text { AME } \\
\text { AME } \\
\text { AME }\end{array}$ & $\begin{array}{c}\mathrm{RW} \\
\mathbf{A B} \\
\mathbf{A E} \\
\mathbf{A E} \\
\mathbf{A E} \\
\mathrm{RE} \\
\mathbf{A M E} \\
\mathbf{A E}\end{array}$ \\
\hline$\frac{\text { Tlaxcala }}{105 . \text { Apizaco }}$ & $\frac{6768}{6768}$ & $\frac{12710}{12710}$ & $\frac{15705}{15705}$ & $\frac{6.1}{6.1}$ & $\frac{2.9}{2.9}$ & $\frac{3.2}{3.2}$ & $\frac{2.1}{2.1}$ & $\frac{2.9}{2.9}$ & $\frac{-0.8}{-0.8}$ & $\mathbf{A E}$ & $\mathrm{RM}$ \\
\hline $\begin{array}{l}\text { Veracruz } \\
\text { 106. Veracruy } \\
\text { 107. Orizaba } \\
\text { 108. Jalapa } \\
\text { 109. Cordoba } \\
\text { 110. Coatzacoalcos } \\
\text { 111. Minatitlán } \\
\text { 112. Tuxpan } \\
\text { 113. San André Tuxtla } \\
\text { 114. Poza Rica } \\
\text { 115. Papantla } \\
\text { 116. Coatepec } \\
\text { 117. Cosamaloapan } \\
\text { 118. Tierra Blanca }\end{array}$ & $\begin{array}{rr}294 & 971 \\
71 & 720 \\
76 & 825 \\
39 & 530 \\
17 & 865 \\
13 & 740 \\
18 & 539 \\
13 & 381 \\
10 & 154 \\
4 & 119 \\
6 & 644 \\
11 & 459 \\
3 & 740 \\
7 & 255\end{array}$ & $\begin{array}{rl}409 & 729 \\
101 & 246 \\
86 & 656 \\
51 & 169 \\
32 & 888 \\
20 & 850^{e /} \\
22 & 455 \\
18 & 415 \\
15 & 150 \\
14 & 901 \\
11 & 359 \\
13 & 747 \\
8 & 881 \\
12 & 012\end{array}$ & $\begin{array}{rl}585 & 278 \\
147 & 5019 \\
108 & 894 \\
68 & 524 \\
47 & 448 / \\
40 & 4069 \\
35 & 350 \\
26 & 948 \\
20 & 256 \\
19 & 564 \\
18 & 865 \\
18 & 022 \\
16 & 944 \\
16 & 556\end{array}$ & $\begin{array}{r}\frac{3.2}{3.4} \\
1.2 \\
2.7 \\
5.9 \\
3.7 \\
1.9 \\
1.7 \\
3.9 \\
11.3 \\
5.2 \\
1.8 \\
8.2 \\
4.9\end{array}$ & $\begin{array}{l}\frac{1.5}{1.2} \\
1.5 \\
1.2 \\
0.9 \\
1.4 \\
1.8 \\
2.7 \\
3.6 \\
2.0 \\
1.6 \\
1.2 \\
2.7 \\
2.7\end{array}$ & $\begin{array}{r}1.6 \\
2.2 \\
-0.3 \\
1.5 \\
5.0 \\
2.3 \\
0.1 \\
-1.0 \\
0.3 \\
9.3 \\
3.6 \\
0.6 \\
5.5 \\
2.2\end{array}$ & $\begin{array}{l}\frac{3.5}{3.7} \\
2.3 \\
2.5 \\
3.6 \\
6.4 \\
4.5 \\
3.8 \\
2.9 \\
2.7 \\
5.0 \\
2.7 \\
6.2 \\
3.2\end{array}$ & $\begin{array}{l}\frac{2.3}{1.6} \\
2.2 \\
2.2 \\
2.6 \\
2.8 \\
2.8 \\
2.6 \\
3.1 \\
3.6 \\
1.6 \\
2.7 \\
2.5 \\
3.8\end{array}$ & $\begin{array}{r}\frac{1.2}{2.1} \\
0.1 \\
0.3 \\
1.0 \\
3.6 \\
1.7 \\
1.2 \\
-0.2 \\
-0.9 \\
3.4 \\
0.0 \\
3.7 \\
-0.6\end{array}$ & $\begin{array}{c}\text { AE } \\
\text { RM } \\
\text { AE } \\
\text { AME } \\
\text { AE } \\
\text { AM } \\
\text { RM } \\
\text { AM } \\
\text { AME } \\
\text { AE } \\
\text { AM } \\
\text { AME } \\
A E\end{array}$ & $\begin{array}{l}A E \\
A M \\
A M \\
A E \\
A E \\
A E \\
A E \\
R M \\
R M \\
A E \\
A M \\
A E \\
P M\end{array}$ \\
\hline
\end{tabular}

(continúa) 
Cuadro 20 (conclusión)

\begin{tabular}{|c|c|c|c|c|c|c|c|c|c|c|c|}
\hline \multirow{3}{*}{$\begin{array}{l}\text { Entidades } \\
\text { y oiudadee }\end{array}$} & \multirow{2}{*}{\multicolumn{3}{|c|}{ Población a/ }} & \multicolumn{6}{|c|}{ Incremento medio anual b } & \multirow{2}{*}{\multicolumn{2}{|c|}{ Clase of }} \\
\hline & & & & \multicolumn{3}{|c|}{$1940-1950$} & \multicolumn{3}{|c|}{$1950-1960$} & & \\
\hline & 1940 & 1950 & 1960 & $\overline{\text { Total }}$ & $\begin{array}{c}\text { Natu } \\
\text { rai }\end{array}$ & $\begin{array}{c}\text { So- } \\
\text { cial }\end{array}$ & Total & Natu & $\begin{array}{l}\text { so- } \\
\text { cial }\end{array}$ & $\begin{array}{l}1940 \\
1950\end{array}$ & $\begin{array}{l}1950 \\
1960\end{array}$ \\
\hline $\begin{array}{l}\text { Tucatén } \\
\frac{119 \cdot \text { Morida }}{120 . \text { Tizimín }}\end{array}$ & $\begin{array}{r}103539 \\
96852 \\
6687\end{array}$ & $\begin{array}{r}153507 \\
142858 \\
10649\end{array}$ & $\begin{array}{l}\frac{187878}{172455}=/ \\
15723\end{array}$ & $\begin{array}{l}\frac{3.9}{3.8} \\
4.6\end{array}$ & $\begin{array}{l}\frac{2.0}{1.9} \\
2.5\end{array}$ & $\begin{array}{l}\frac{1.9}{1.9} \\
2.1\end{array}$ & $\begin{array}{l}\frac{1.9}{1.8} \\
3.9\end{array}$ & $\begin{array}{l}\frac{2.5}{2.5} \\
3.7\end{array}$ & $\begin{array}{r}-0.6 \\
-0.7 \\
0.2\end{array}$ & $\begin{array}{l}\mathbf{A E} \\
\mathbf{A S}\end{array}$ & $\begin{array}{l}\text { RM } \\
A M\end{array}$ \\
\hline $\begin{array}{l}\text { Zecatecas } \\
\text { 121. Freanillo } \\
\text { 122. Zaoatecas } \\
\text { 123. Jerez de Garola } \\
\text { Salinas }\end{array}$ & $\begin{array}{r}55235 \\
24614 \\
21 \quad 846 \\
8775\end{array}$ & $\begin{array}{ll}64 & 609 \\
29 & 936 \\
24 & 257 \\
10 & 416\end{array}$ & $\begin{array}{ll}82 & 299 \\
35 & 582 \\
31 & 701 \\
15 & 016\end{array}$ & $\begin{array}{l}\frac{1.6}{1.9} \\
1.0 \\
1.7\end{array}$ & $\begin{array}{l}\frac{2.8}{2.9} \\
2.4 \\
3.2\end{array}$ & $\begin{array}{l}\frac{-1.2}{-1.0} \\
-1.4 \\
-1.5\end{array}$ & $\begin{array}{l}\frac{2.4}{1.7} \\
2.7 \\
3.6\end{array}$ & $\begin{array}{l}\frac{3.7}{3.9} \\
3.4 \\
3.5\end{array}$ & $\begin{array}{l}\frac{-1.3}{-2.2} \\
-0.7 \\
0.1\end{array}$ & $\begin{array}{l}\mathrm{RM} \\
\mathrm{RE} \\
\mathrm{RE}\end{array}$ & $\begin{array}{l}\text { RME } \\
\text { RM } \\
\text { AN }\end{array}$ \\
\hline
\end{tabular}

Fuentes: 1) Información proporcionada por la Oficina de Estadísticas Demográficas, Dirección General de Estadística, Secretaría de Industria y Comercio.

2) Robert Stevens, Internal Migration in Mexico, 1950-1960, tesis de maestría, Universidad de Florida, 1966.

3) Información cartográfica y aerofotogramétrica, proporcionada por la Dirección de Planeación y Programación de la Secretaría de Obras Públicas.

4) Información cartográfica proporcionada por el Registro Nacional de Electores, Secretaría de Gobernación.

a La población en 1940 y 1950 corresponde a la de las localida des que eran urbanas en esos años (véase el cuadro 13), más la de aquellas localidades que se reclasificaron en urbanas duran te el período 1940-1960. En 1960, la población es la urbana en ese año (véase el cuadro 13). Esto explica claramente la diferencia entre las cifras de población urbana del país en los años estudiados, entre los cuadros 13 y 18.

b El incremento medio anual se obtuvo mediante las expresiones siguientes:

Total $=2\left(P_{1}-P_{0}\right) /\left(P_{1}+P_{0}\right) \cdot \frac{1}{n} \cdot 100 ; \quad$ Natural $=2(C N) /\left(P_{1}+P_{0}\right) \cdot \frac{1}{n} \cdot 100 ;$

Social $=2(C S) /\left(P_{1}+P_{0}\right) \cdot \frac{1}{n} \cdot 100 ;$ en las cuales $P_{0}$ y $P_{1}$ son las poblaciones al principio y al final del período; $C N$ es el crecimiento natural, $C S$ es el crecimiento social y $n$ es el número de años del período. El cálculo se realizó, para los períodos 1940-1950 y 1950-1960, con las áreas urbanas de 1950 y 1960, respectivamente, llevadas al comienzo del período. Por este 
motivo, en el caso de ciertas áreas urbanas existen pequeñas diferencias entre la población real y la utilizada para el cálculo de los incrementos medios anuales y por tanto en la de algunas entidades que tienen áreas urbanas (únicamente en el caso del estado de México la diferencia es importante por los cambios habidos en la parte que le corresponde del área urbana de la ciudad de México).

e La clasificación de localidades en ciudades de "atracción" y de "rechazo" - "muy elevado", "elevado" y "moderado"- se basa en el incremento medio anual social. Las siglas presen tadas tienen el siguiente significado:

AME = Atracción muy elevada

$\mathrm{AE} \equiv$ Atracción elevada

RME = Rechazo muy elevado

AM = Atracción moderada

RE = Rechazo elevado

Para más detalles sobre los límites numéricos de cada grupo, véase el cuadro 10.

d En el cálculo de los incrementos medios anuales del país, no está considerada la población urbana de Oaxaca (Oaxaca y Juchitán) por no contarse con la información necesaria.

e La población de estas áreas urbanas está formada por la registrada en el Censo -denominada ciudad central- más localidades periféricas que se consideraron integradas físicamente a la primera, con fundamento en su contiguiidad y la relativa accesibilidad a la ciudad central.

1 Estas seis ciudades manifestaron tener área urbana en todo el período.

\& Las áreas urbanas de las ciudades de Torreón y de México rebasan los límites de las entidades de Coahuila y Distrito Federal respectivamente, hacia las entidades de Durango y México. Por ello se ha considerado conveniente registrar la pobla. ción total de tales áreas urbanas, en la lista de ciudades de la entidad donde se ubica la ciudad central. Para los efectos del cómputo estatal, la población de las dos áreas urbanas se contabilizó de acuerdo con los límites político-administrativos co rrespondientes.

h La localidad de Tlalpan se registró en forma independiente en 1940 y 1950 . No se presentó en igual forma en 1960 por contabilizarse incorporada en el área urbana de la ciudad de México. Por este motivo no se numeró.

1 No se incluyen los incrementos medios anuales por no disponerse de información sobre estadísticas vitales necesaria. 


\section{Cuadro 21}

México: Distribución de la poblactón por entidad, CIASIFICAda EN RURAL, MIXTA Y URBANA, 1940

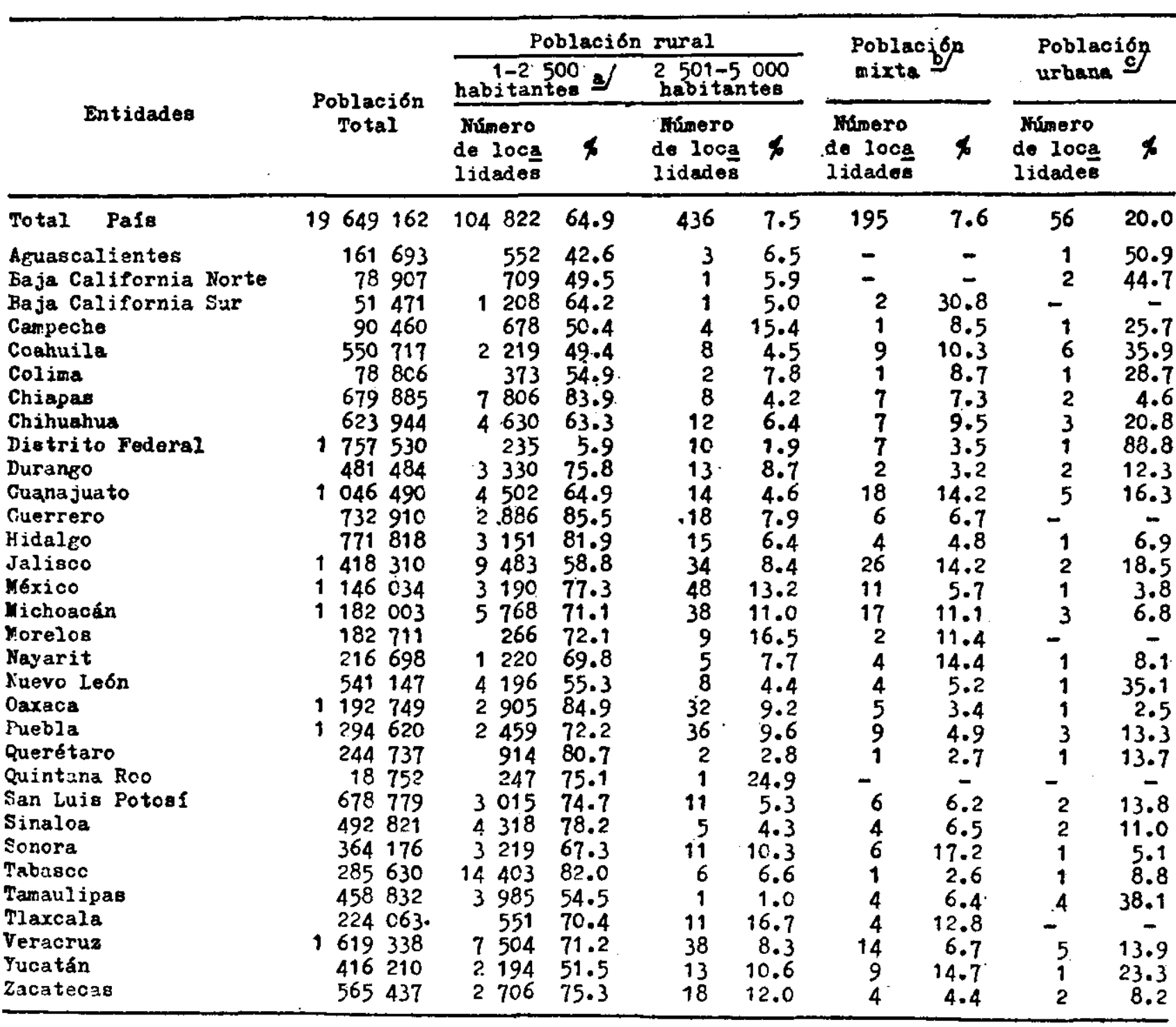

Fuente: Elaboraciones a partir del VI Censo General de Población.

a Se ha optado presentar este dato debido a la falta de subtotales estatales de la población en localidades de 1-1000 habitantes.

b Comprende las localidades mixtas rurales (5-10000 habitantes y las mixtas urbanas (10-15 000 habitantes).

c Comprende las localidades de 15000 y más habitantes. 
UNIKEL: URBANIZACION EN MEXXICO

Cuadro 22

México: Distribución de la población POR ENTIDad, Clasificada EN RURAL, MIXTA Y URBANA, 1950

\begin{tabular}{|c|c|c|c|c|c|c|c|c|c|}
\hline \multirow{2}{*}{ Entidades } & \multirow{2}{*}{$\begin{array}{c}\text { Población } \\
\text { Total }\end{array}$} & $\frac{P c}{\begin{array}{r}1-1 c \\
\text { habita }\end{array}}$ & $\begin{array}{l}\text { blacio } \\
00 \\
\text { ites }\end{array}$ & $\begin{array}{l}\text { rural } \\
1001-5 \\
\text { habitan }\end{array}$ & 8 & \multicolumn{2}{|c|}{$\begin{array}{l}\text { Población } \\
\text { mixta }\end{array}$} & \multicolumn{2}{|c|}{$\begin{array}{l}\text { Poblacion } \\
\text { uxbara by }\end{array}$} \\
\hline & & $\begin{array}{l}\text { Nimero } \\
\text { de loca } \\
\text { lidades }\end{array}$ & $\phi$ & $\begin{array}{l}\text { Múmero } \\
\text { de loca } \\
\text { lidades }\end{array}$ & $\%$ & $\begin{array}{l}\text { Mimero } \\
\text { de loca } \\
\text { lidades }\end{array}$ & $\%$ & $\begin{array}{l}\text { Mimero } \\
\text { de loce } \\
\text { lidades }\end{array}$ & $\%$ \\
\hline Total Pafs & 5779254 & 94890 & 42.3 & 3098 & 22.0 & 254 & 7.9 & 85 & 27.9 \\
\hline $\begin{array}{l}\text { Aguascalientes } \\
\text { Baja California Norte } \\
\text { Baja California Sur } \\
\text { Campeche } \\
\text { Coahuila } \\
\text { Colima } \\
\text { Chiapas } \\
\text { Chihuahua } \\
\text { Distrito Federal } \\
\text { Durargo } \\
\text { Guanajuato } \\
\text { Guerrero } \\
\text { Hidaleo } \\
\text { Jalisco } \\
\text { México } \\
\text { Michoacán } \\
\text { Morelcs } \\
\text { Nayarit } \\
\text { Nuevo Ieón } \\
\text { Oaxaca } \\
\text { Fuebla } \\
\text { Querétaro } \\
\text { Quintana Foo } \\
\text { San Luis Fotes1 } \\
\text { Siralca } \\
\text { Sonora } \\
\text { Tabasco } \\
\text { Tamalilipas } \\
\text { Tlaxcala } \\
\text { Veracruz } \\
\text { Yucatán } \\
\text { Zacatecas }\end{array}$ & 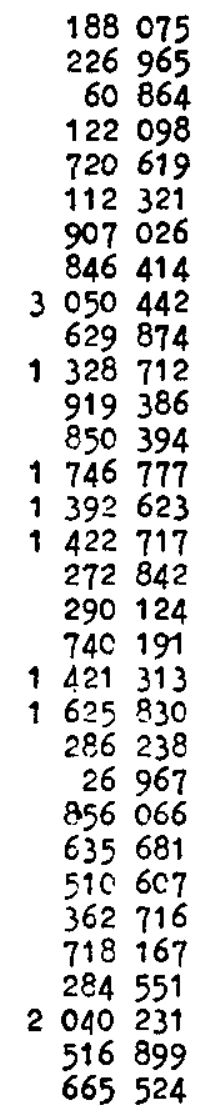 & $\begin{array}{ll} & 819 \\
& 534 \\
1 & 251 \\
& 883 \\
2 & 202 \\
& 541 \\
6 & 704 \\
5 & 268 \\
& 71 \\
3 & 427 \\
4 & 828 \\
2 & 988 \\
2 & 841 \\
9 & 149 \\
2 & 423 \\
5 & 867 \\
& 212 \\
1 & 055 \\
4 & 034 \\
2 & 761 \\
2 & 341 \\
& 934 \\
& 278 \\
2 & 969 \\
4 & 010 \\
3 & 316 \\
5 & 795 \\
4 & 189 \\
& 497 \\
7 & 595 \\
2 & 236 \\
2 & 872\end{array}$ & $\begin{array}{l}35.1 \\
27.3 \\
58.7 \\
32.2 \\
33.0 \\
34.9 \\
64.6 \\
46.4 \\
0.6 \\
55.9 \\
51.5 \\
58.9 \\
63.2 \\
40.0 \\
39.3 \\
50.3 \\
27.4 \\
46.3 \\
35.3 \\
52.5 \\
38.8 \\
61.5 \\
64.5 \\
57.9 \\
58.8 \\
41.9 \\
59.2 \\
40.3 \\
33.4 \\
52.4 \\
27.0 \\
61.5\end{array}$ & $\begin{array}{r}17 \\
14 \\
3 \\
16 \\
63 \\
10 \\
93 \\
65 \\
46 \\
79 \\
91 \\
151 \\
111 \\
185 \\
368 \\
199 \\
55 \\
44 \\
44 \\
295 \\
351 \\
32 \\
1 \\
82 \\
62 \\
57 \\
59 \\
39 \\
69 \\
240 \\
74 \\
83\end{array}$ & $\begin{array}{r}15.3 \\
9.3 \\
8.4 \\
32.7 \\
14.1 \\
18.8 \\
19.0 \\
13.5 \\
3.3 \\
23.4 \\
12.6 \\
30.0 \\
22.4 \\
20.2 \\
48.7 \\
26.6 \\
40.0 \\
26.6 \\
11.2 \\
36.4 \\
37.6 \\
18.6 \\
8.6 \\
17.4 \\
15.7 \\
21.3 \\
28.8 \\
11.0 \\
44.7 \\
21.9 \\
28.7 \\
22.2\end{array}$ & $\begin{array}{r}- \\
-2 \\
1 \\
8 \\
2 \\
9 \\
9 \\
4 \\
2 \\
18 \\
6 \\
6 \\
29 \\
17 \\
21 \\
3 \\
7 \\
5 \\
15 \\
15 \\
1 \\
1 \\
8 \\
7 \\
4 \\
1 \\
3 \\
8 \\
23 \\
11 \\
8\end{array}$ & $\begin{array}{r}- \\
- \\
32.9 \\
9.5 \\
9.5 \\
18.0 \\
8.0 \\
9.4 \\
1.1 \\
1.8 \\
11.4 \\
5.5 \\
5.3 \\
13.7 \\
8.2 \\
12.0 \\
8.4 \\
18.7 \\
5.7 \\
7.8 \\
7.2 \\
2.6 \\
26.9 \\
9.3 \\
7.8 \\
6.8 \\
2.3 \\
3.3 \\
21.9 \\
8.6 \\
16.7 \\
8.2\end{array}$ & $\begin{array}{r}1 \\
3 \\
- \\
1 \\
7 \\
1 \\
3 \\
4 \\
3 \\
2 \\
9 \\
2 \\
2 \\
4 \\
1 \\
5 \\
2 \\
1 \\
1 \\
1 \\
3 \\
1 \\
- \\
1 \\
3 \\
6 \\
1 \\
6 \\
- \\
8 \\
1 \\
2\end{array}$ & $\begin{array}{r}49.6 \\
63.4 \\
- \\
25.6 \\
43.4 \\
29.0 \\
8.4 \\
30.7 \\
95.1 \\
18.9 \\
24.5 \\
5.2 \\
9.1 \\
26.2 \\
3.8 \\
11.1 \\
24.2 \\
8.5 \\
47.8 \\
3.3 \\
16.3 \\
17.3 \\
-1 \\
15.4 \\
17.7 \\
30.6 \\
9.8 \\
45.4 \\
- \\
17.1 \\
27.6 \\
8.1\end{array}$ \\
\hline
\end{tabular}

Fuente: Elaboraciones a partir del VII Censo General de Población.

a Comprende las localidades mixtas rurales (5-10000 habitantes) y las mixtas urbanas (10-15000 habitantes).

b Comprende las localidades de 15000 y más habitantes. 
Cuadro 23

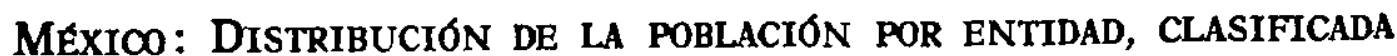
EN RURAL, MIXTA Y URBANA, 1960

\begin{tabular}{|c|c|c|c|c|c|c|c|c|c|}
\hline \multirow[b]{2}{*}{ Entidades } & \multirow{2}{*}{$\begin{array}{c}\text { Población } \\
\text { Total }\end{array}$} & $\begin{array}{r}\text { Po } \\
\begin{array}{r}1-10 \\
\text { habitar }\end{array}\end{array}$ & $\begin{array}{l}\text { blacio } \\
0 \\
\text { ntes }\end{array}$ & $\begin{array}{l}\text { rural } \\
1001-5 \\
\text { habitan }\end{array}$ & $\begin{array}{l}00 \\
\text { es }\end{array}$ & \multicolumn{2}{|c|}{$\begin{array}{l}\text { Población } \\
\text { nixta }\end{array}$} & \multicolumn{2}{|c|}{$\begin{array}{l}\text { Población } \\
\text { urbene }\end{array}$} \\
\hline & & $\begin{array}{l}\text { Núnero } \\
\text { de loca } \\
\text { lidedes }\end{array}$ & $\%$ & $\begin{array}{l}\text { Nómero } \\
\text { de. loca } \\
\text { lidades }\end{array}$ & $\%$ & $\begin{array}{l}\text { Nímero } \\
\text { de loca } \\
\text { lidades }\end{array}$ & $\%$ & $\begin{array}{l}\text { Numero } \\
\text { de loca } \\
\text { lidades }\end{array}$ & $\%$ \\
\hline PafB & $34923 \quad 129$ & 84590 & 39.7 & 3950 & 20.9 & 342 & 7.9 & 125 & 36.5 \\
\hline $\begin{array}{l}\text { Aguascalientes } \\
\text { Baja California Norte } \\
\text { Baja California Sur } \\
\text { Campeche } \\
\text { Coahuila } \\
\text { Colima } \\
\text { Chiapas } \\
\text { Chihuahua } \\
\text { Distrito Federal } \\
\text { Durango } \\
\text { Guanajuato } \\
\text { Guerroro } \\
\text { Hidalgo } \\
\text { Jalisco } \\
\text { Moxico } \\
\text { Michoacán } \\
\text { Morelos } \\
\text { Nayarit } \\
\text { Nuevo l.eon } \\
\text { Oaxaca } \\
\text { Puebla } \\
\text { querbtaro } \\
\text { Quintana Roo } \\
\text { San Iuia Potosi } \\
\text { Sinaloa } \\
\text { Sonora } \\
\text { Tabasco } \\
\text { Pamauljpas } \\
\text { Mlaxcala } \\
\text { Veracrua } \\
\text { Yucatán } \\
\text { Zacatecas }\end{array}$ & 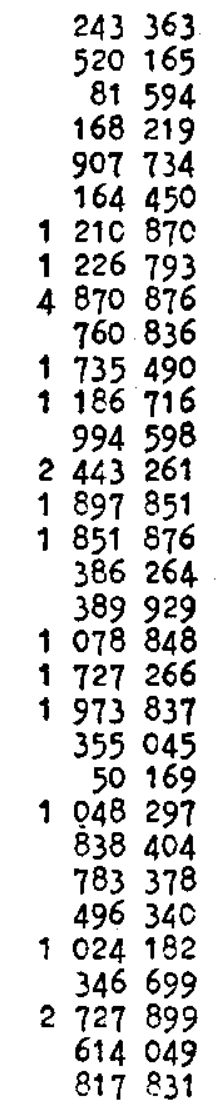 & $\begin{array}{ll} & 736 \\
& 399 \\
1 & 194 \\
& 463 \\
2 & 148 \\
& 440 \\
6 & 566 \\
4 & 152 \\
& 57 \\
2 & 359 \\
4 & 630 \\
3 & 020 \\
2 & 454 \\
8 & 375 \\
1 & 939 \\
5 & 242 \\
& 200 \\
1 & 333 \\
3 & 004 \\
2 & 860 \\
2 & 259 \\
1 & 022 \\
& 456 \\
3 & 284 \\
2 & 787 \\
4 & 245 \\
1 & 758 \\
4 & 415 \\
& 476 \\
7 & 281 \\
2 & 185 \\
2 & 851\end{array}$ & $\begin{array}{l}31.4 \\
14.3 \\
51.4 \\
26.6 \\
25.1 \\
27.3 \\
61.6 \\
33.8 \\
0.4 \\
48.3 \\
44.9 \\
53.7 \\
58.7 \\
30.2 \\
29.7 \\
43.2 \\
18.8 \\
41.0 \\
22.6 \\
48.3 \\
33.3 \\
59.0 \\
59.0 \\
54.2 \\
46.7 \\
32.9 \\
47.2 \\
33.8 \\
26.0 \\
46.7 \\
24.5 \\
54.8\end{array}$ & $\begin{array}{r}16 \\
32 \\
6 \\
22 \\
63 \\
15 \\
-138 \\
94 \\
39 \\
103 \\
133 \\
205 \\
147 \\
219 \\
438 \\
262 \\
71 \\
58 \\
41 \\
374 \\
417 \\
37 \\
5 \\
105 \\
97 \\
63 \\
103 \\
56 \\
88 \\
305 \\
83 \\
115\end{array}$ & $\begin{array}{l}11.7 \\
10.4 \\
12.3 \\
31.4 \\
11.9 \\
21.7 \\
21.4 \\
13.6 \\
2.0 \\
24.2 \\
13.8 \\
31.5 \\
24.5 \\
18.2 \\
44.4 \\
26.8 \\
38.3 \\
27.8 \\
7.3 \\
36.9 \\
38.5 \\
16.8 \\
15.4 \\
18.2 \\
19.0 \\
15.7 \\
34.8 \\
11.1 \\
47.9 \\
20.5 \\
29.0 \\
23.9\end{array}$ & $\begin{array}{r}2 \\
3 \\
1 \\
1 \\
9 \\
- \\
9 \\
12 \\
7 \\
5 \\
18 \\
11 \\
10 \\
33 \\
23 \\
30 \\
6 \\
7 \\
6 \\
20 \\
20 \\
2 \\
1 \\
8 \\
9 \\
7 \\
5 \\
3 \\
9 \\
40 \\
12 \\
13\end{array}$ & $\begin{array}{r}4.8 \\
3.4 \\
6.6 \\
3.3 \\
9.3 \\
-. \\
7.0 \\
8.9 \\
1.0 \\
4.0 \\
9.6 \\
6.9 \\
7.4 \\
11.6 \\
8.9 \\
12.8 \\
14.0 \\
17.9 \\
5.3 \\
9.2 \\
7.8 \\
4.8 \\
25.6 \\
7.0 \\
8.3 \\
6.8 \\
6.9 \\
2.1 \\
21.6 \\
11.3 \\
15.9 \\
11.3\end{array}$ & $\begin{array}{r}1 \\
3 \\
1 \\
2 \\
9 \\
3 \\
4 \\
6 \\
2 \\
2 \\
11 \\
3 \\
2 \\
9 \\
2 \\
9 \\
2 \\
1 \\
1 \\
2 \\
5 \\
1 \\
- \\
3 \\
4 \\
9 \\
1 \\
8 \\
1 \\
13 \\
2 \\
3\end{array}$ & $\begin{array}{r}52.0 \\
72.0 \\
29.7 \\
38.7 \\
53.6 \\
51.0 \\
10.0 \\
43.8 \\
96.6 \\
23.6 \\
31.6 \\
7.9 \\
9.4 \\
40.1 \\
17.0 \\
17.2 \\
29.0 \\
13.9 \\
64.8 \\
5.5 \\
20.4 \\
19.5 \\
- \\
20.6 \\
26.0 \\
44.6 \\
11.2 \\
52.9 \\
4.5 \\
21.5 \\
30.6 \\
10.1\end{array}$ \\
\hline
\end{tabular}

Fuente: Elaboraciones a partir del VIII Censo General de Población.

a Comprende las localidades mixtas rurales (5-10000 habitantes) y las mixtas urbanas (10-15000 habitantes).

b Comprende las localidades de 15000 y más habitantes. 


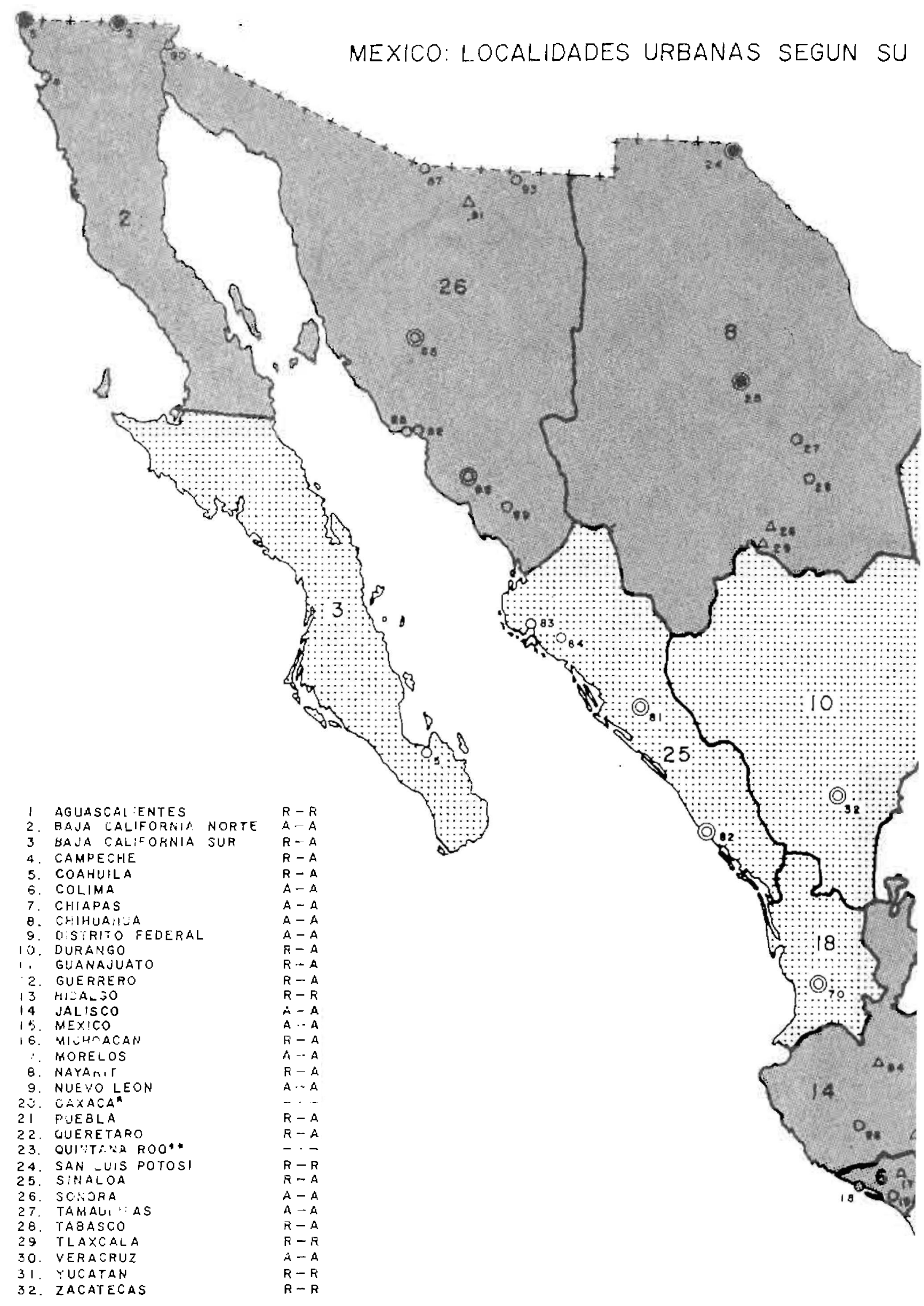

CLAVE:

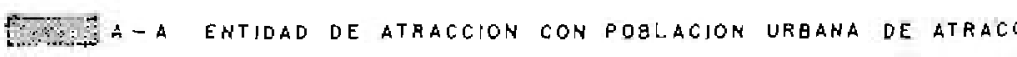
27.7. R-a evtidad de rechazo con pollacion urbaha de atrael T J R R entidao de rechazo con poblacion urbana de reot.

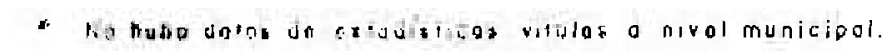

* No llatic robugriáll urbane.

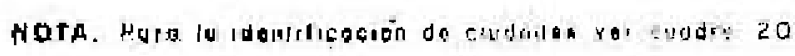




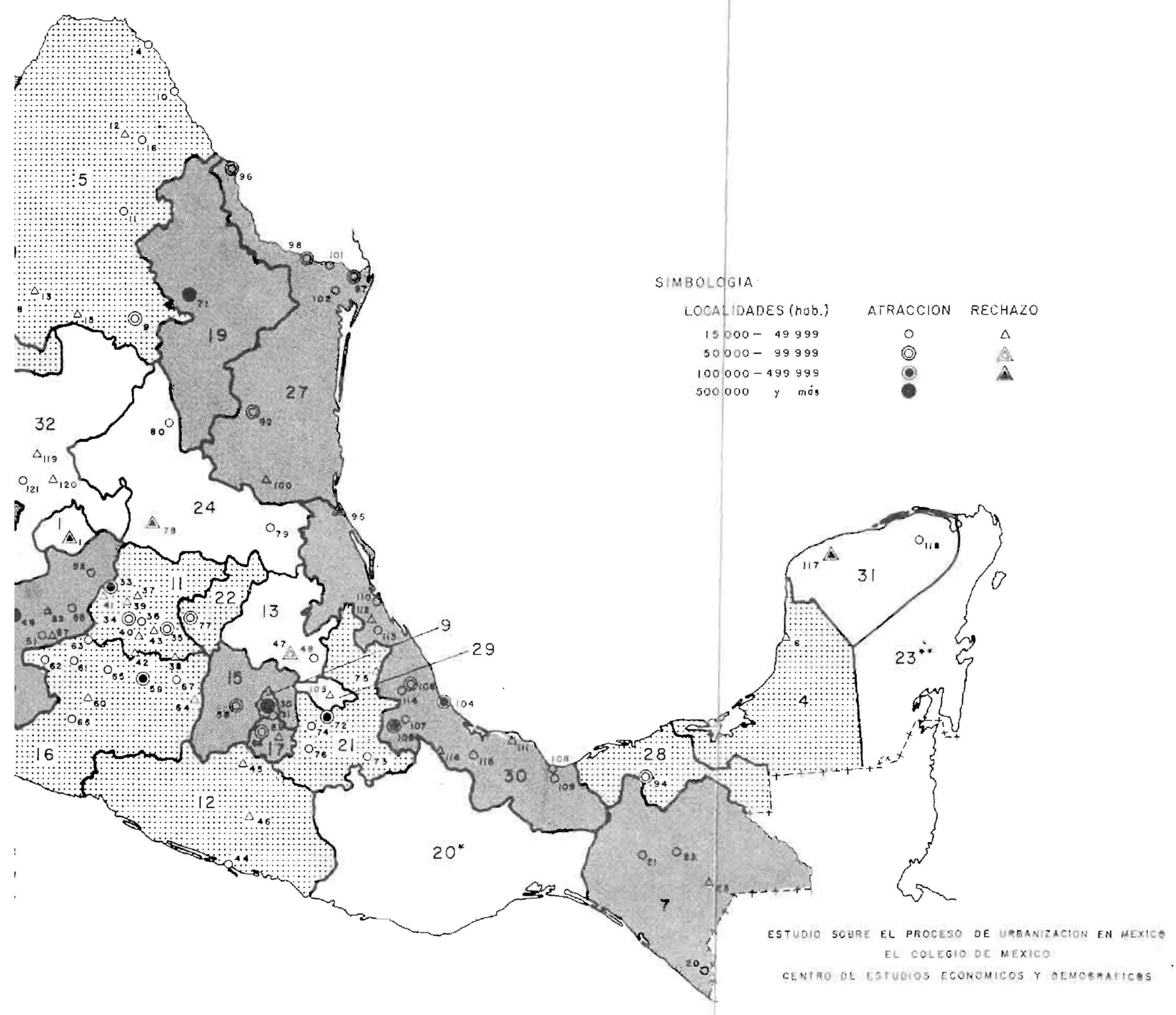

